Does befriending by trained lay workers improve psychological well-being and quality of life for carers of people with dementia, and at what cost? A randomised controlled trial

G Charlesworth, L Shepstone, E Wilson, $M$ Thalanany, M Mugford and F Poland

Health Technology Assessment NHS R\&D HTA Programme www.hta.ac.uk

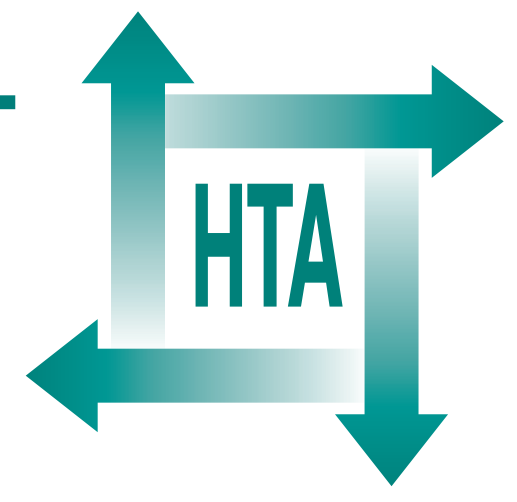




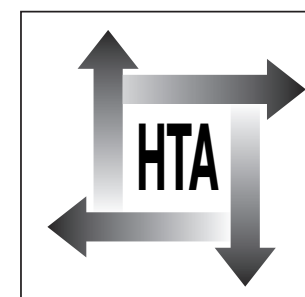

INAHTA

How to obtain copies of this and other HTA Programme reports.

An electronic version of this publication, in Adobe Acrobat format, is available for downloading free of charge for personal use from the HTA website (http://www.hta.ac.uk). A fully searchable CD-ROM is also available (see below).

Printed copies of HTA monographs cost $£ 20$ each (post and packing free in the UK) to both public and private sector purchasers from our Despatch Agents.

Non-UK purchasers will have to pay a small fee for post and packing. For European countries the cost is $£ 2$ per monograph and for the rest of the world $£ 3$ per monograph.

You can order HTA monographs from our Despatch Agents:

- fax (with credit card or official purchase order)

- post (with credit card or official purchase order or cheque)

- phone during office hours (credit card only).

Additionally the HTA website allows you either to pay securely by credit card or to print out your order and then post or fax it.

Contact details are as follows:

HTA Despatch

c/o Direct Mail Works Ltd

Email: orders@hta.ac.uk

4 Oakwood Business Centre

Tel: 02392492000

Downley, HAVANT PO9 2NP, UK

Fax: 02392478555

Fax from outside the UK: +442392478555

NHS libraries can subscribe free of charge. Public libraries can subscribe at a very reduced cost of $£ 100$ for each volume (normally comprising 30-40 titles). The commercial subscription rate is $£ 300$ per volume. Please see our website for details. Subscriptions can only be purchased for the current or forthcoming volume.

\section{Payment methods}

Paying by cheque

If you pay by cheque, the cheque must be in pounds sterling, made payable to Direct Mail Works Ltd and drawn on a bank with a UK address.

Paying by credit card

The following cards are accepted by phone, fax, post or via the website ordering pages: Delta, Eurocard, Mastercard, Solo, Switch and Visa. We advise against sending credit card details in a plain email.

Paying by official purchase order

You can post or fax these, but they must be from public bodies (i.e. NHS or universities) within the UK. We cannot at present accept purchase orders from commercial companies or from outside the UK.

\section{How do I get a copy of HTA on CD?}

Please use the form on the HTA website (www.hta.ac.uk/htacd.htm). Or contact Direct Mail Works (see contact details above) by email, post, fax or phone. HTA on CD is currently free of charge worldwide.

The website also provides information about the HTA Programme and lists the membership of the various committees. 


\section{Does befriending by trained lay workers improve psychological well-being and quality of life for carers of people with dementia, and at what cost? $A$ randomised controlled trial}

\section{G Charlesworth, ${ }^{\text {* }}$ L Shepstone, ${ }^{2}$ E Wilson, ${ }^{3}$ $M$ Thalanany, ${ }^{3}$ M Mugford $^{3}$ and $F$ Poland ${ }^{4}$}

${ }^{\prime}$ Centre for Behavioural and Social Sciences in Medicine, University College London, UK, and North East London Mental Health Trust, UK

${ }^{2}$ School of Medicine, Health Policy and Practice, University of East Anglia, UK

${ }^{3}$ Health Economics Group, School of Medicine, Health Policy and Practice, University of East Anglia, UK

${ }^{4}$ School of Allied Health Professions, University of East Anglia, UK

* Corresponding author

Declared competing interests of authors: none

Published March 2008

This report should be referenced as follows:

Charlesworth G, Shepstone L, Wilson E, Thalanany M, Mugford M, Poland F. Does befriending by trained lay workers improve psychological well-being and quality of life for carers of people with dementia, and at what cost? A randomised controlled trial. Health Technol Assess 2008; I 2(4).

Health Technology Assessment is indexed and abstracted in Index Medicus/MEDLINE, Excerpta Medica/EMBASE and Science Citation Index Expanded (SciSearch ${ }^{\circledR}$ ) and Current Contents ${ }^{\circledR} /$ Clinical Medicine. 


\section{NIHR Health Technology Assessment Programme}

$T$ The Health Technology Assessment (HTA) Programme, part of the National Institute for Health Research (NIHR), was set up in 1993. It produces high-quality research information on the effectiveness, costs and broader impact of health technologies for those who use, manage and provide care in the NHS. 'Health technologies' are broadly defined as all interventions used to promote health, prevent and treat disease, and improve rehabilitation and long-term care.

The research findings from the HTA Programme directly influence decision-making bodies such as the National Institute for Health and Clinical Excellence (NICE) and the National Screening Committee (NSC). HTA findings also help to improve the quality of clinical practice in the NHS indirectly in that they form a key component of the 'National Knowledge Service'.

The HTA Programme is needs-led in that it fills gaps in the evidence needed by the NHS. There are three routes to the start of projects.

First is the commissioned route. Suggestions for research are actively sought from people working in the NHS, the public and consumer groups and professional bodies such as royal colleges and NHS trusts. These suggestions are carefully prioritised by panels of independent experts (including NHS service users). The HTA Programme then commissions the research by competitive tender.

Secondly, the HTA Programme provides grants for clinical trials for researchers who identify research questions. These are assessed for importance to patients and the NHS, and scientific rigour.

Thirdly, through its Technology Assessment Report (TAR) call-off contract, the HTA Programme commissions bespoke reports, principally for NICE, but also for other policy-makers. TARs bring together evidence on the value of specific technologies.

Some HTA research projects, including TARs, may take only months, others need several years. They can cost from as little as $£ 40,000$ to over $£ 1$ million, and may involve synthesising existing evidence, undertaking a trial, or other research collecting new data to answer a research problem.

The final reports from HTA projects are peer-reviewed by a number of independent expert referees before publication in the widely read journal series Health Technology Assessment.

\section{Criteria for inclusion in the HTA journal series}

Reports are published in the HTA journal series if (1) they have resulted from work for the HTA

Programme, and (2) they are of a sufficiently high scientific quality as assessed by the referees and editors.

Reviews in Health Technology Assessment are termed 'systematic' when the account of the search, appraisal and synthesis methods (to minimise biases and random errors) would, in theory, permit the replication of the review by others.

The research reported in this issue of the journal was commissioned by the HTA Programme as project number 99/34/07. The contractual start date was in January 2002. The draft report began editorial review in October 2006 and was accepted for publication in August 2007. As the funder, by devising a commissioning brief, the HTA Programme specified the research question and study design. The authors have been wholly responsible for all data collection, analysis and interpretation, and for writing up their work. The HTA editors and publisher have tried to ensure the accuracy of the authors' report and would like to thank the referees for their constructive comments on the draft document. However, they do not accept liability for damages or losses arising from material published in this report.

The views expressed in this publication are those of the authors and not necessarily those of the HTA Programme or the Department of Health.

Editor-in-Chief:

Professor Tom Walley

Series Editors:

Dr Aileen Clarke, Dr Peter Davidson, Dr Chris Hyde,

Dr John Powell, Dr Rob Riemsma and Professor Ken Stein

Programme Managers:

Sarah Llewellyn Lloyd, Stephen Lemon, Kate Rodger,

Stephanie Russell and Pauline Swinburne

ISSN 1366-5278

(C) Queen's Printer and Controller of HMSO 2008

This monograph may be freely reproduced for the purposes of private research and study and may be included in professional journals provided that suitable acknowledgement is made and the reproduction is not associated with any form of advertising.

Applications for commercial reproduction should be addressed to: NCCHTA, Mailpoint 728, Boldrewood, University of Southampton, Southampton, SO16 7PX, UK.

Published by Gray Publishing, Tunbridge Wells, Kent, on behalf of NCCHTA.

Printed on acid-free paper in the UK by St Edmundsbury Press Ltd, Bury St Edmunds, Suffolk. 


\title{
Abstract
}

\section{Does befriending by trained lay workers improve psychological well-being and quality of life for carers of people with dementia, and at what cost? A randomised controlled trial}

\author{
G Charlesworth, ${ }^{\text {* }}$ L Shepstone, ${ }^{2}$ E Wilson, ${ }^{3}$ M Thalanany, ${ }^{3}$ M Mugford ${ }^{3}$ \\ and $\mathrm{F}$ Poland ${ }^{4}$ \\ ${ }^{\prime}$ Centre for Behavioural and Social Sciences in Medicine, University College London, UK, and \\ North East London Mental Health Trust, UK \\ ${ }^{2}$ School of Medicine, Health Policy and Practice, University of East Anglia, UK \\ ${ }^{3}$ Health Economics Group, School of Medicine, Health Policy and Practice, University of East Anglia, UK \\ ${ }^{4}$ School of Allied Health Professions, University of East Anglia, UK \\ * Corresponding author
}

\begin{abstract}
Objectives: To determine whether a social support intervention (access to an employed befriending facilitator in addition to usual care) is effective compared with usual care alone. Also to document direct and indirect costs, and establish incremental cost-effectiveness.
\end{abstract}

Design: The Befriending and Costs of Caring (BECCA) trial was a cost-effectiveness randomised controlled trial. Data on well-being and resource use were collected through interviews with participants at baseline and at 6, 15 and 24 months.

Setting: This research was carried out in the English counties of Norfolk and Suffolk, and the London Borough of Havering. It was a community-based study. Participants: Participants were family carers who were cohabiting with, or providing at least 20 hours' care per week for, a community-dwelling relative with a primary progressive dementia.

Interventions: The intervention was 'access to a befriender facilitator' (BF). BFs, based with charitable/ voluntary-sector organisations, were responsible for local befriending schemes, including recruitment, screening, training and ongoing support of befriending volunteers, and for matching carers with befrienders. The role of befrienders was to provide emotional support for carers. The target duration for befriending relationships was 6 months or more.

Main outcome measures: Depression was measured by the Hospital Anxiety and Depression Scale (HADS) at 15 months postrandomisation. The health-related quality of life scale EQ-5D (EuroQol 5 Dimensions) was used to derive utilities for the calculation of qualityadjusted life-years (QALYs).
Results: A total of 236 carers were randomised into the trial (I I6 intervention; 120 control). At final follow-up, 190 carers (93 intervention; 97 control) were still involved in the trial (19\% attrition). There was no evidence of effectiveness or cost-effectiveness from the primary analyses on the intention-to-treat population. The mean incremental cost per incremental QALY gained was in excess of $£ 100,000$, with only a $42.2 \%$ probability of being below $£ 30,000$ per QALY gained. Where care-recipient QALYs were included, mean incremental cost per incremental QALY gained was $£ 26,848$, with a $51.4 \%$ probability of being below $£ 30,000$ per QALY gained. Only 60 carers (52\%) took up the offer of being matched with a trained lay befriender, and of these only 37 (32\%) were befriended for 6 months or more. A subgroup analysis of controls versus those befriended for 6 months or more found a reduction in HADS-depression scores that approached statistical significance $(95 \% \mathrm{Cl}-0.09$ to 2.84$)$.

Conclusions: 'Access to a befriender facilitator' is neither an effective nor a cost-effective intervention in the support of carers of people with dementia, although there is a suggestion of cost-effectiveness for the care dyad (carer and care recipient). In common with many services for carers of people with dementia, uptake of befriending services was not high. However, the small number of carers who engaged with befrienders for 6 months or more reported a reduction in scores on HADS depression that approached statistical significance compared with controls ( $95 \% \mathrm{Cl}-0.09$ to 2.84 ). While providing only weak evidence of any beneficial effect, further research into befriending interventions for carers is warranted. 



\section{Contents}

Glossary and list of abbreviations

\section{Executive summary}

I Introduction

Background

Social consequences of caring

Support provision

Psychosocial interventions

Cost-effectiveness of support for

carers

Economic methods in carer intervention

evaluations

Summary

Aim and objectives

2 Methods

Design

Ethics approval

Intervention and control conditions

Study population

Randomisation

Measures

Data-collection procedures ..................... 10

Data checking ......................................... 11

Data analysis ........................................... 11

Economic analyses ................................... 11

Summary of changes to protocol ............. 12

3 Intervention

Development of the BECCA befriending

schemes

Befriending scheme procedures ............... 14

Befriender training programme ............... 16

Costing of befriending services ................ 18

Protocol changes relating to

intervention

4 Results: characteristics and outcomes Participant flow
Baseline characteristics of randomised

carers ............................................... 21

Main outcomes ........................................ 24

5 Results: overall costs and economic analysis ........................................... 31

Costs ..................................................... 31

Quality-adjusted life-years ...................... 31

Cost-utility analysis ............................... 31

Alternative scenarios ............................. 32

Summary of cost-effectiveness analyses .... 35

6 Discussion and conclusions ...................... 37

Main findings .................................... 37

Implications for healthcare .................... 37

Factors to consider in carer support

research ............................................. 39

Recommendations for future research ...... 41

Conclusions .......................................... 42

Acknowledgements ............................. 43

References .......................................... 45

Appendix I Organisations involved in the trial

Appendix 2 Unit costs and sources

Appendix 3 Resource-use quantities at 15 months (complete case analysis)

Appendix 4 Detailed breakdown of per-carer/person with dementia costs at 15 months

\section{Health Technology Assessment reports} published to date

Health Technology Assessment

Programme 



\section{Glossary and list of abbreviations}

Technical terms and abbreviations are used throughout this report. The meaning is usually clear from the context, but a glossary is provided for the non-specialist reader. In some cases, usage differs in the

literature, but the term has a constant meaning throughout this review.

\section{Glossary}

Befriender facilitator In the context of this study, a voluntary sector employee with the responsibility of recruiting, screening, training, matching and supporting volunteer befrienders.

Befriending In the context of this study, befriending refers to one-to-one emotional support by a trained lay volunteer.

Bootstrapping Statistical method for examining uncertainty. It is a non-parametric simulation method used in economic evaluation and is particularly useful when underlying data have a skewed distribution.

Carers Carers are defined in this report as family members providing care for a person with a primary progressive dementia.

Direct costs The costs of providing the intervention, primary and secondary care resource use, out-of-pocket expenses and travel costs incurred by patients or carers, and family care costs.

Discounting A method by which future costs and benefits are converted to present values.

Indirect costs In the context of this study, the value of time spent in the caring role.

Opportunity cost The benefit that could have been obtained from the next best use of resources. The opportunity cost of an action is the value of the forgone alternative action. Opportunity costs arise because the resources available to meet wants are finite, so that all wants cannot be satisfied.
Perspective A viewpoint for conducting a cost-effectiveness analysis. Four perspectives are used in this analysis. The societal perspective incorporates all costs and all health effects regardless of who incurs the costs and who obtains the effects. Thus, a societal perspective in healthcare means considering costs that fall upon health services, other public sector budgets such as provision of social support, cost of lost productivity as well as the costs that fall upon patients and caregivers. The statutory sector perspective incorporates costs incurred by the health service and other public sector budgets (e.g. social services) alone. The voluntary sector perspective incorporates costs incurred by the voluntary sector alone. The household sector perspective incorporates costs incurred by private households and individuals alone.

Quality adjusted life-years (QALYs) A metric that combines both the quality and quantity of life gained from an intervention. One QALY is defined as 1 year of perfect health, or 2 years at ' $50 \%$ of perfect health', etc.

Resources In economics, 'resources' refer to all the factors of production (usually simplified to labour and capital) that are used to produce goods and services. In health programmes, resources include medical and nursing staff time, hospitals, medical equipment and drugs, and patients' time.

Sensitivity analysis A technique used in economic analysis to test whether uncertainty in the values of the main variables is sufficient to affect the results of the analysis. 


\section{List of abbreviations}

\begin{tabular}{|c|c|c|c|}
\hline $\mathrm{ACH}$ & Age Concern Havering & ITT & intention-to-treat \\
\hline ACS & Age Concern Suffolk & MCBS & $\begin{array}{l}\text { Mutual Communal Behaviours } \\
\text { Scale }\end{array}$ \\
\hline BECCA & Befriending and Costs of Caring & & \\
\hline $\mathrm{BF}$ & befriender facilitator & MREC & multisite research ethics committee \\
\hline $\mathrm{BL}$ & baseline & MSPSS & $\begin{array}{l}\text { Multidimensional Scale of } \\
\text { Perceived Social Support }\end{array}$ \\
\hline CADI & $\begin{array}{l}\text { Carers Assessment of Difficulties } \\
\text { Index }\end{array}$ & $n$ & $\begin{array}{l}\text { number who selected a certain } \\
\text { response }\end{array}$ \\
\hline CAS & Caregiver Activity Schedule & $N$ & $\begin{array}{l}\text { total number who answered a given } \\
\text { question }\end{array}$ \\
\hline CBT & cognitive behavioural therapy & & \\
\hline CEAC & $\begin{array}{l}\text { cost-effectiveness acceptability } \\
\text { curve }\end{array}$ & NVS & $\begin{array}{l}\text { Norwich and Norfolk Voluntary } \\
\text { Services }\end{array}$ \\
\hline CI & confidence interval & ONS & Office for National Statistics \\
\hline СMHT & community mental health team & PANAS & $\begin{array}{l}\text { Positive and Negative Affect } \\
\text { Schedule }\end{array}$ \\
\hline COPE & $\begin{array}{l}\text { Coping Orientation for Problem } \\
\text { Experience }\end{array}$ & PANT & $\begin{array}{l}\text { Practitioner Assessment of Network } \\
\text { Type }\end{array}$ \\
\hline $\mathrm{CPN}$ & community psychiatric nurse & PSSRU & $\begin{array}{l}\text { Personal Social Services Research } \\
\text { Unit }\end{array}$ \\
\hline CRB & Criminal Records Bureau & & \\
\hline CSRI & Client Service Receipt Inventory & PwD & person (people) with dementia \\
\hline CUA & cost-utility analysis & QALY & quality-adjusted life-year \\
\hline EQ-5D & EuroQol 5 Dimensions & RCT & randomised controlled trial \\
\hline FU & follow-up & RUD & Resource Utilization in Dementia \\
\hline GLM & generalised linear model & SPSS & $\begin{array}{l}\text { Statistical Package for the Social } \\
\text { Sciences }\end{array}$ \\
\hline HADS & $\begin{array}{l}\text { Hospital Anxiety and Depression } \\
\text { Scale }\end{array}$ & VAS & visual analogue scale \\
\hline $\mathrm{CE}$ & incremental cost-effectiveness rati & & \\
\hline
\end{tabular}

All abbreviations that have been used in this report are listed here unless the abbreviation is well known (e.g. NHS), or it has been used only once, or it is a non-standard abbreviation used only in figures/tables/appendices in which case the abbreviation is defined in the figure legend or at the end of the table. 


\section{. \\ Executive summary}

\section{Objectives}

The aims of this trial were two-fold. First, to determine whether a social support intervention (access to an employed befriending facilitator in addition to usual care) is effective compared with usual care alone, through randomly allocating carers of people with dementia to one of two groups (intervention versus usual care control) and follow-up for 2 years postrandomisation. Secondly, to document direct and indirect costs in both the intervention and control group, and establish incremental cost-effectiveness, calculating the costs from the perspectives of the statutory and voluntary sectors and from a societal perspective.

\section{Methods}

\section{Design}

The Befriending and Costs of Caring (BECCA) trial was a cost-effectiveness randomised controlled trial that compared outcomes and associated costs for family carers offered 'access to befriending facilitator' with those of control carers receiving standard services only. Data on wellbeing and resource use were collected through interviews with participants at baseline and at three follow-up interviews (6, 15 and 24 months). The main end-point was at 15 months postrandomisation, and for the economic analyses the perspective in the base case is society.

\section{Setting}

This research was carried out in the English counties of Norfolk and Suffolk, and the London Borough of Havering. It was a community-based study.

\section{Participants}

Participants were family carers who were cohabiting with, or providing at least 20 hours' care per week for, a community-dwelling relative with a primary progressive dementia.

\section{Intervention}

The intervention was 'access to a befriender facilitator' (BF). BFs, based with charitable/ voluntary-sector organisations, were responsible for local befriending schemes, including recruitment, screening, training and ongoing support of befriending volunteers, and for matching carers with befrienders. The role of befrienders was to provide emotional support for carers. The target duration for befriending relationships was 6 months or more.

\section{Main outcome measures}

The main outcome was depression as measured by the Hospital Anxiety and Depression Scale (HADS) at 15 months postrandomisation. Secondary measures were anxiety, positive affect, loneliness and global health. The health-related quality of life scale EQ-5D (EuroQol 5

Dimensions) was used to derive utilities for the calculation of quality-adjusted life-years (QALYs). Resource use and other data related to costs were collected using a semi-structured interview based on the Resource Utilisation in Dementia questionnaire and Client Service Receipt Inventory. Measures of burden, social support and coping were also used.

\section{Results}

Of 316 people expressing interest in participating, $236(75 \%)$ were randomised into the trial (116 intervention; 120 control). At final follow-up (24 months postrandomisation) 190 carers (93 intervention; 97 control) were still involved in the trial ( $19 \%$ attrition). There was no evidence of effectiveness or cost-effectiveness from the primary analyses on the intention-to-treat population. The mean incremental cost per incremental QALY gained was in excess of $£ 100,000$, with only a $42.2 \%$ probability of being below $£ 30,000$ per QALY gained. Analyses on secondary outcomes were similarly negative, and there was no evidence of cost-effectiveness in the alternative scenarios considered except where care-recipient QALYs were included. In this case mean incremental cost per incremental QALY gained was $£ 26,848$, with a $51.4 \%$ probability of being below $£ 30,000$ per QALY gained. Only 60 carers (52\%) took up the offer of being matched with a trained lay befriender, and of these only 37 (32\%) were befriended for 6 months or more. A subgroup 
analysis of controls versus those befriended for 6 months or more found a reduction in HADSdepression scores that approached statistical significance (95\% CI -0.09 to 2.84 ).

\section{Conclusions}

'Access to a befriender facilitator' is neither an effective nor a cost-effective intervention in the support of carers of people with dementia, although there is a suggestion of cost-effectiveness for the care dyad (carer and care recipient). In common with many services for carers of people with dementia, uptake of befriending services was not high. However, the small number of carers who engaged with befrienders for 6 months or more reported a reduction in scores on HADS depression that approached statistical significance compared with controls (95\% CI -0.09 to 2.84). While providing only weak evidence of any beneficial effect, further research into befriending interventions for carers is warranted.

\section{Implications for healthcare}

Volunteers can be safely involved in the provision of emotional support for carers. When considering commissioning support services for carers of people with dementia, befriending schemes alone should not be commissioned, and short-term contracts should not be considered.

\section{Recommendations for further research}

- Additional research is required to establish: the characteristics of carers most likely to take up befriending; befriender-carer characteristics of successful matches; interplay between statutory and voluntary support services and support from families; carer well-being in the context of receipt of befriending; and placement of the care recipient in long-term residential or nursing care.

- Future cost-effectiveness evaluations of carer support should include outcomes for both the carer and care recipient.

- Further work is required on economic methods for carer intervention research. 


\section{Chapter I Introduction}

\section{Background}

This study was a response to a call for bids from the NHS Health Technology Assessment (HTA) Programme for research into 'support for carers of people with dementia'. The call was made in the context of increased recognition of the needs of carers and the associated UK government legislation and initiatives such as the Carers (Recognition and Services) Act $1995^{1}$ and the National Strategy for Carers, ${ }^{2}$ and in the National Service Frameworks for Mental Health ${ }^{3}$ and for Older People. ${ }^{4}$ The needs of carers of people with dementia were highlighted as a particular concern, with there being perceived deficiencies in the evidence base, especially in terms of evidence on cost-effectiveness.

It is estimated that there are around 6.8 million adult carers in the UK, with up to 1.5 million people involved in caring for a relative or friend with a mental illness or some form of dementia. ${ }^{5}$ Dementia is an umbrella term encompassing a broad range of cognitive losses, usually including multiple deficits in aspects of memory, expressive and/or receptive language, perception and executive function. Dementia is the consequence of a large number of progressive brain disorders, the most common being Alzheimer's disease and vascular dementias. The prevalence of dementia depends greatly on the age structure of the population and for UK the prevalence rates are $2 \%$ in the $65-70$ age group; $5 \%$ in the $70-80$ age group and $20 \%$ in the over-80 age group (Alzheimer's Society, UK). It is estimated that there are currently over 750,000 people in the UK with dementia, ${ }^{4}$ which may increase to 840,000 by 2026 and 1.2 million by $2050 .^{4}$

Dementias are long-term, pervasive illnesses, affecting all aspects of a person's life. The person with dementia (PwD) becomes increasingly dependent on those around them, most usually their spouse or other family members. It is widely accepted that providing care for a person with dementia is stressful and demanding, and research has provided evidence on the poorer physical and mental health of carers compared with noncarers. ${ }^{6,7}$ In addition, there is some evidence that carers who experience caring as stressful are at higher risk of mortality than non-carers. ${ }^{8}$

\section{Social consequences of caring}

The association between social support and wellbeing is well established for both physical and mental health, ${ }^{9,10}$ with low levels of support being associated with poorer health. Family carers can experience a reduction in their social network owing to a lack of opportunities to socialise and/or the stigma associated with illness. Carers report less social interaction and fewer friendships. ${ }^{11,12}$ The emotional and physical burden of caring can result in family role conflicts that may reduce the amount of emotional support available. A carer's family and friends may distance themselves physically and/or psychologically from the carer and care recipient, contributing to a reduction in social support for the carer. ${ }^{11-13}$

Given the commitment involved in caring for a relative with increasing levels of cognitive impairment and dependency, carers of people with dementia may be particularly at risk of social isolation. Carers who experience social isolation are more vulnerable to the negative impacts of caring. ${ }^{13}$

Social isolation is a risk factor for loneliness, and loneliness has been associated with increased mortality and morbidity, including psychiatric morbidity. Protective factors are thought to include companionship ${ }^{14}$ and long-standing friendships, especially for women, and where the friendship is based on choice and not obligation. ${ }^{15}$

\section{Support provision}

Support provision for family carers in the UK is part of a mixed economy of care in which statutory, private and voluntary sectors provide community services in addition to the support given by family and friends. Britain has a long tradition of voluntary action, and the emphasis on partnership in recent government policies has given voluntary, community and user organisations a more central role in the delivery of services. ${ }^{16,17}$ 
At the same time, social service departments have been encouraged to develop local markets in care by providing fewer direct care services themselves and commissioning independent service providers. ${ }^{18}$ Local authority welfare provision in England is organised to prioritise instrumental needs within a system of case management in which needs are assessed, care packages are set up and cases are discharged. Such procedure-based care management systems prevent the formation of sustained relationships. ${ }^{19}$ As Community Mental Health Teams integrate the working practice of the NHS and Social Services and move towards an 'assess and discharge' model, it can be voluntary and charitable sector workers who provide longterm support. For carers of $\mathrm{PwD}$, emotional support may have a greater influence on the course of stressors than instrumental support. ${ }^{20}$

\section{Psychosocial interventions}

A range of psychosocial interventions has been developed to support carers, including, but not limited to, the provision of accessible and relevant information on available services, education and training programmes, access to support groups, short-term breaks, and interventions targeted at the whole family, such as family therapy and family counselling.

Evaluations of carer interventions have been extensively reviewed. Schulz and colleagues ${ }^{21}$ identified nine systematic reviews prior to their own. The varying methodologies used for the systematic review have led to significant differences in conclusions about the quantity and quality of research, ${ }^{22}$ yet there is consensus that carer intervention research has historically been of questionable quality, and that poor study design has contributed to inconclusive findings.

Interventions showing greatest impact have generally been comprehensive and intensive. ${ }^{23}$ Cognitive behavioural interventions have been shown to be effective in reducing carer stress, ${ }^{24}$ but the provision of such interventions is expensive and often not available owing to a lack of appropriately trained therapists within dementia care or carer support services.

Only a fraction of psychological support is provided by psychological therapists, and there is much in common between informal and formal helping, such as empathy, positive regard and genuineness. ${ }^{25}$ Faust and Zlotnick ${ }^{26}$ found that, for mild to moderate mental health problems, the paraprofessionals, such as clergy and family doctors, are roughly the same as those of professional, formal helping, carried out by psychiatrists and psychologists.

A range of social support interventions has been devised and evaluated, but reviews of the evidence base of social support interventions generally highlight a lack of methodological rigour. ${ }^{27-29}$ Within the voluntary sector, a commonly used model of social support is 'befriending'. There are many befriending schemes in the UK, most particularly in the voluntary and charitable sector. The role of befrienders varies widely from project to project, and the characteristics of the befrienders also vary, including both volunteers and paid staff. Befriending has the potential to foster friendship, with the reciprocities entailed in this ${ }^{30,31}$ and concomitant gains experienced by peer-befrienders. ${ }^{32}$ For befriendees, a volunteer visit may be experienced as very different from that of a professional, perhaps without fear of institutional intervention in their family or care choices, which may be especially welcomed by older people trying to maintain their independence. In addition, empathic, nondirective befriending was as effective as structured cognitive behavioural therapy (CBT) in the short term for people with treatment-resistant schizophrenia, ${ }^{33}$ although CBT was superior at 9-month follow-up. An analysis of session content indicated that the befriending was distinct from $\mathrm{CBT}$, and a conclusion was drawn that social support is "no mere placebo". ${ }^{34}$

During protocol development for the Befriending and Costs of Caring (BECCA) project, a literature search was undertaken for befriending schemes for family carers of people with dementia. No quantitative research trials were found for the use of befriending volunteers to support carers. The closest trial was Harris and colleagues, ${ }^{35}$ evaluation of a volunteer befriending intervention for women with chronic depression in inner London. With additional searching using a broader range of search terms, two randomised controlled trials (RCTs) were identified which evaluate 'friendly visiting' for isolated elders. ${ }^{36,37}$ Macintyre and colleagues ${ }^{37}$ found improved life satisfaction, worth and social integration, and concluded that volunteer visitors made a difference for elderly people in the community. Most recently, a report has been published of a peer-support intervention for carers of people with Alzheimer's disease, ${ }^{38}$ but there was no evidence of a beneficial effect, possibly because of the short time-frame. 


\section{Cost-effectiveness of support for carers}

The Carers Special Grant was established to support the implementation of the National Carers Strategy, with ring-fenced funding of $£ 140$ million made available to local authorities to help them to develop a wider range of services to give carers a break from their caring responsibilities. However, there is evidence for managers wishing to commission cost-effective interventions.

In an RCT, Patel and colleagues ${ }^{39}$ evaluated the cost-effectiveness of a training programme for carers of stroke patients and found that costs were significantly lower in the training group, while improving overall quality of life of carers at 1 year. Similarly, the economic evaluation of a training programme for carers of people with dementia ${ }^{40}$ reported cost savings of Aus $\$ 7967$ (US $\$ 5975$ ) per patient, with improved patient survival at home and decreased carer morbidity. Drummond and colleagues $^{41}$ evaluated a support programme for carers (RCT) which showed improved quality of life with incremental cost per quality-adjusted lifeyear (QALY) gained of Can $\$ 20,000$. The evaluation of a daily living programme (RCT) by Knapp and colleagues ${ }^{42}$ found that it was more cost-effective than hospital-based care. Similarly, Donaldson and Gregson ${ }^{43}$ reported that a community support intervention resulted in prolonged life at home for the elderly and concluded that the intervention will be costeffective if the cost of long-term institutional care averted is included in the calculations. Payton and colleagues, ${ }^{44}$ in their cost analysis of a community health information network for carers of people with Alzheimer's disease, concluded that it provides social and economic benefit to their users.

\section{Economic methods in carer intervention evaluations}

The cost-effectiveness literature for carers has used a range of costing methodologies and there is presently no consensus. Considerations include: whether to cost for the carer, care recipient or both; whether to take cross-sectional snapshots of service receipt or try to build up a longitudinal picture of costs; and costing informal care.

Options for costing informal care include: the market price method, the contingent valuation method and the opportunity cost method. ${ }^{45}$ Theoretical and practical challenges of evaluating carer time have previously been acknowledged. ${ }^{46}$ Wimo and colleagues ${ }^{47}$ recommend that the valuation be based on the opportunity costs of time sacrificed on each type of time-use. This would necessitate data collection on the specific nature of time sacrificed; for example, time spent in caring, nursing and supervision; loss of time in work; and impact on leisure activities.

Distinguishing between 'care activities' and 'normal household duties' can be especially challenging for spouse carers where the carer is also the person who has had a long-term responsibility for the domestic household duties.

From a societal perspective, the value of informal care may be recognised by considering the cost of its replacement. Should individuals be unwilling or unable to undertake the role of carer, society would have little choice but to fund formal care. This would involve diverting resources away from other uses; the opportunity cost of those resources - the forgone benefit - determines the cost of informal care. The value of the resources diverted is a measure of the cost of informal care and is known as 'replacement cost'. From the perspective of the individual carer, the opportunity cost of caring may be understood in terms of the alternatives forgone as a result of taking on this role, which may include employment opportunities, other unpaid work, such as caring for other family members, and leisure activities, including holidays, social activities and relaxation. Whether employment opportunities should be valued is the subject of considerable debate and scepticism, ${ }^{48}$ as inclusion of economically active individuals' time will be valued more highly than the time of those who are economically inactive, and this may lead to an exacerbation of existing inequalities in the provision of care or support.

\section{Summary}

Family carers of people with dementia report high burden and stress. Demands of time and lack of understanding among family and friends can lead to reduced social contact and social supports. A wide range of psychosocial interventions has been devised, including one-to-one social support interventions such as befriending, but no rigorous studies of cost-effectiveness exist for befriending.

\section{Aim and objectives}

The aim of this report is to address this gap in the evidence base by evaluating the cost-effectiveness 
of befriending schemes for carers of people with dementia alongside an RCT. The objectives of the trial were as follows.

- To determine whether a social support intervention (access to an employed befriending facilitator in addition to usual care) is effective compared with usual care alone, through randomly allocating carers of people with dementia to one of two groups (intervention versus usual care control) and follow-up for 2 years postrandomisation.

- To document direct and indirect costs in both the intervention and control groups, and to establish incremental cost-effectiveness, calculating the costs from the perspectives of the statutory and voluntary sectors and from a societal perspective. 


\section{Chapter 2 Methods}

\section{Design}

An RCT design was used to compare usual care plus a social support intervention [access to a befriender facilitator (BF)] with control (usual care) for carers of people with dementia. Data collection points were at 6,15 and 24 months from the date of randomisation, with the main end-point being at 15 months. The primary perspective of the economic evaluation was societal.

\section{Ethics approval}

A protocol was submitted for ethical scrutiny by the multisite research ethics committee (MREC) in 2001. The submission described the methodology approved by peer reviewers for the HTA programme, and included a Zelen randomisation procedure. The protocol was rejected on the grounds of the Zelen design, and also concerns for the safety of carers put in contact with lay intervention providers. The proposed methodology was revised to use a standard RCT design, and with additional information on the recommended good practice for the involvement of volunteers in the provision of heath and social care. Ethical approval was received in November 2001 with the proviso that a pilot be carried out in not more than three local research ethics committee (LREC) districts before the implementation of the full trial. The aim of the pilot was to ensure that procedures for the research interviews and befriending scheme were feasible and appropriate. LREC approval was subsequently received from all five LRECs in Norfolk and Suffolk, plus the London Borough of Havering. Trust research and development (R\&D) approval was also sought where recruitment was planned within secondary care, and from primary care groupings that had $\mathrm{R} \& \mathrm{D}$ approval procedures during the recruitment phase of the trial.

There were consent procedures for both family carers and potential befriending volunteers. The PwD was not involved in interviews and was not the intended recipient of the befriending intervention, and was not therefore involved in the consent procedures.

\section{Intervention and control conditions}

The befriending schemes were organised and administered separately from the research interviews. The befriending intervention comprised access to an employed BF, and the offer of contact with a trained volunteer befriender for the duration of the befriending schemes. The expectation was that befriending visits by the trained volunteer befrienders would be weekly home visits (dose) for at least 6 months (duration), with variations in location, duration and frequency of contact negotiated as necessary by each carer-volunteer pairing, overseen by the BF.

The remit of the befriending volunteers was to provide companionship and conversation. Their role was to be a listening ear; that is, to provide emotional support to the carer. Some informational support or 'signposting' was also permissible in appropriate circumstances. The boundaries of the role specifically excluded giving advice and carrying out practical caring tasks that would otherwise be carried out by a paid worker such as a nurse or home care worker. Further details of the befriending intervention are given in Chapter 3.

The intervention was offered as an addition to usual care, and was not a replacement for any other service (health, social or voluntary). In the study areas, typical health services for the care recipient included diagnostic clinics for memory impairment and dementia (memory clinics) and community support for challenging behaviours through community psychiatric nurses (CPNs). Typical social services for carers included shortterm and longer term respite in the form of day centres and residential or nursing home stays, and assistance with washing, dressing and eating for more dependent care recipients. Typical voluntary sector provision included carer information and support groups, and luncheon clubs. All carers randomised into the trial were sent locally relevant information on services for caring for people with dementia by the research interviewer. 


\section{Study population}

The BECCA project was carried out in the UK, in the East Anglian counties of Norfolk and Suffolk, and in the London Borough of Havering, with recruitment between April 2002 and July 2004.

The HTA call for bids had specified that participants should be the carers of people with Alzheimer's type dementia. However, Alzheimer's disease can only be diagnosed with certainty postmortem, and the diagnosis of Alzheimer's disease in vivo is made by exclusion of evidence of other possible causes, and on a possible or probable basis only. Alzheimer's type pathology commonly co-occurs with other dementia-causing pathologies, and the symptom profiles are not generally distinguished within primary care. Therefore, carers in this study are of people with a primary progressive dementia in general, rather than specifically Alzheimer's disease.

\section{Eligibility criteria Inclusion}

The main inclusion criteria were that participants must be family carers aged 18 years or older, caring for a person with a primary progressive dementia. Carers should either be cohabiting with the $\mathrm{PwD}$, or spending an average of 20 hours or more per week on care-related tasks such as supervision and assistance in activities of daily living (ADL).

\section{Exclusion}

Carers with significant congenital or acquired cognitive impairment were excluded, as were those with terminal illness. Carers of people in permanent residential, nursing or long-stay hospital accommodation were also excluded.

\section{Sample size}

During the planning stages of the trial there were no published trials of befriending for carers of people with dementia. Therefore, sample size calculations were based on the effect size seen in befriending interventions with different client groups $;{ }^{35,49}$ that is, $0.42-0.45$. It was anticipated that retention of carers postrandomisation would be high, based on the experience of Aneshensel and colleagues; ${ }^{20}$ in a 3-year longitudinal study of caring (without an intervention), $82 \%$ of carers were followed up to 3 years.

Using nQuery ${ }^{50}$ and making an assumption of a normal distribution, to achieve $90 \%$ power at the $5 \%$ significance level (two-tailed), 150 carers were needed for each group, for postrandomisation dropout of $20 \%$ at 6 months. Making an assumption that between $30 \%$ and $60 \%$ of people invited to take part would not respond, ${ }^{35,51}$ a target of 750 was set for carer invitations. In the course of the trial, targets were recalculated on the grounds that fewer carers were being lost to follow-up than had been anticipated. For a postrandomisation dropout of $7 \%$, it was calculated that adequate precision and power should be gained from a sample size of between 225 and 235 carers.

\section{Recruitment procedures}

A significant proportion of the population in Norfolk and Suffolk lives in rural areas. Rural carers are considered "hard to reach" 52 and dissemination of information can be difficult owing to there being very few contact points. ${ }^{53}$ Therefore, a recruitment strategy was needed that would maximise equality of access to the trial, irrespective of urban or rural location. Given that most gerontological research work involves gatekeepers such as health and social service practitioners, ${ }^{54}$ it was hoped that there would be less sample bias from a primary care than from a secondary care population. Therefore, general practices were approached to identify surgeries that would be happy to send out invitations to participate. It was hoped that this would be acceptable to practices given that the Government's National Priorities Guidance for health and social services in England had asked primary care teams to take a lead and identify carers by April 2000.

Unfortunately, initial recruitment was slow and after 6 months, only 13 responses had been received from practices in the pilot area. In keeping with the picture in the rest of the UK, practices had neither carers' registers nor straightforward means for identifying informal carers in either computerised or paper records. Only around half of practices expressed willingness to send out invitations, even though funding was available from the project to reimburse administration time and postage costs. It was clear that additional recruitment strategies would be necessary if targets were to be met in the full trial, so strategies were developed for media and other publicity, and for wider dissemination of information through gatekeepers in social services, secondary care and the voluntary sector.

- Mailouts of publicity posters and leaflets: these went to all libraries in Suffolk and Norfolk, in addition to social services, mental health services for older people, pharmacies, day services, supermarkets and voluntary organisations. 
- Media publicity: radio interviews and various articles were arranged with local press.

- Voluntary-sector mailouts: some voluntary and charitable organisations were willing to circulate invitations akin to those used in primary care to all on their mailing lists. This was the only strategy used in the London Borough of Havering, and mailing by Suffolk Carers provided a significant response in Suffolk.

- Presentations to potential participants and to gatekeepers: presentations were devised for carers' groups, and for health-, social- and voluntary-sector personnel who may act as gatekeepers.

All recruiters were briefed on the inclusion and exclusion criteria for the trial, and the importance of avoiding inappropriate approaches (e.g. to family members who are unaware of their relative's suspected diagnosis) was emphasised. All used standard letters of invitation and approved participant information leaflets. Potential participants expressed their interest in participating in the research by completing and returning a response form in a prepaid envelope to the researchers. Recruitment strategies were kept under continuous review, including monitoring of productivity.

Following receipt of a response form (expression of interest), research associates made contact with carers by telephone (or e-mail if this was requested) to provide further information about the trial, and where appropriate to carry out initial screening. The purpose of the initial screening was to check eligibility (see the section 'Eligibility criteria', p. 6).

For eligible carers who expressed continued interest after this initial contact, arrangements were made for a face-to-face interview. Times and venues for face-to-face interviews were organised as flexibly as possible to accommodate interviewees' caring responsibilities. All contact with carers aimed to be sensitive to their needs, and appropriately responsive to disclosure of circumstances that present significant risk to the well-being of the carer or care recipient (e.g. abuse, suicidal or homicidal intent). Constraints such as pressures on carers' time and transport difficulties were acknowledged. The importance of considering transportation has also been highlighted in previous recruitment literature. For this project, it was anticipated that most carers would prefer home visits, or interviews based at a neutral location within their locality, rather than travel to a research base. Therefore, the study protocol and budget included transport costs for interviewers to travel throughout the counties on a regular basis. Interviewers endeavoured to meet all carers' preferences for days and times of day.

Once carers had contacted the research team expressing interest in participation, they were contacted by telephone, given the opportunity to ask questions, and sent a full information booklet. Written consent was taken at the first face-to-face interview, after researchers had given an oral overview of the trial and answered any questions on the content of the information booklet. Information about the trial clearly explained randomisation, and made it clear to participants that they were free to withdraw at any time without giving a reason and without this affecting the services available to the current or future carer, or the care recipient.

\section{Randomisation}

\section{Sequence generation}

Randomisation lists were drawn up by the trial statistician. Randomisation was stratified by kinship between carer and $\mathrm{PwD}$ (either vertical or horizontal) and also by region of residence (urban or rural). Blocked randomisation (block length of six) was used. For the stratification by kinship, spouses, long-term partners, cousins of the same generation and siblings were designated a 'horizontal bond', whereas adult offspring (sons and daughters) and sons- and daughters-in-law were classified as having a 'vertical bond'. It was anticipated that this stratification for kinship would increase the likelihood of the two groups matching in terms of gender balance and age, since adult children carers are more commonly women, whereas there is a more even gender balance among spouse carers. Urban and rural areas were classified on the basis of population density, with densities of 10,000 per $\mathrm{km}^{2}$ and above classified as urban.

\section{Allocation concealment}

Team members involved in carer consent and interviews were not involved in the randomisation process. The randomisation lists were drawn up before the start of recruitment by the trial statistician, and held by the research administrator.

\section{Implementation}

After obtaining informed consent and completing a baseline interview, the interviewer put forward the carer's ID number to the trial administrator. The administrator assigned the carer to 
intervention or control on the basis of the sequence laid out in the relevant randomisation list (urban/vertical; urban/horizontal; rural/vertical; rural/horizontal). The administrator was independent of interviews, had no direct contact with study participants and was entirely unaware of participants' personal circumstances.

\section{Blinding}

Over the course of the trial, six researchers were involved in the informed consent and recruitment process. To reduce experimenter bias all outcome measurement was completed with interviewers who were independent from the provision of befriending services. Carer well-being was assessed using self-report inventories, which are less susceptible to experimenter bias than observational measures.

Owing to the nature of the intervention it was not possible to blind trial participants to group allocation. Therefore, it was decided to keep participants fully informed of the outcome of the randomisation process by sending one of two standard letters outlining their allocation to either control or befriending intervention. Letters were sent by the trial administrator responsible for allocation from the randomisation lists. All participants had previously received brief details about the befriending intervention in their information booklet. However, given the quantity of information about using the scheme, full details were only supplied to those carers who were randomised to the befriending intervention.

\section{Measures}

All data were collected through interviews with the carer. The care recipient was not interviewed. The main outcomes were carer well-being as measured by the Hospital Anxiety and Depression Scale (HADS) depression and health-related quality of life measured using Euro-Qol 5 Dimensions (EQ5D). Secondary measures of well-being were HADS anxiety, loneliness, positive affectivity and global health. Measures of structural and perceived social support were used to characterise the sample, as were measures of relationship quality and carer burden. Demographic data and characteristics of the context of caring (e.g. multiple roles, sleep disturbance) were also collected through carer selfreport.

Demographic data included age, gender, ethnicity of the carer and $\mathrm{PwD}$, and kin relationship of characteristics of caring included hours spent caring, sleep disturbance, other caring roles and employment.

\section{Anxiety and depression}

The negative aspects of carers' well-being were assessed by the HADS. ${ }^{55}$ On this 14-item scale, seven items assess anxiety (e.g. 'I feel tense' or 'wound up', 'Worrying thoughts go through my mind') and seven items assess depression (e.g. 'I feel as if I am slowed down', 'I have lost interest in my appearance'). Items are scored on a fourpoint scale ranging from 0 to 3 , where the higher scores indicate higher levels of anxiety or depression. Both scales have good internal consistency, with Cronbach's $\alpha$ of 0.84 for the anxiety subscale at baseline and 0.74 for the depression subscale. Cut-offs have been used to indicate caseness, where a score of 7 or below indicates a non-case for both subscales, a score of 8-10 indicates a doubtful case, and a score of 11 or above indicates a definite case.

\section{Loneliness}

A two-item measure of emotional loneliness was used, after Stroebe and colleagues. ${ }^{56}$ The questions used were 'Over the past 7 days, how much have you felt distressed by feeling lonely/feeling lonely even when you are with people?' Both items were rated on a five-point scale from $0=$ not at all to $4=$ extremely. Cronbach's $\alpha$ was 0.86 .

\section{Positive and negative affectivity}

Positive and negative affectivity were measured using the 20-item Positive and Negative Affect Schedule (PANAS) scale. ${ }^{57}$ The measure consists of 20 adjectives, ten of which describe negative moods (e.g. distressed, upset, guilty) and ten describe positive moods (e.g. excited, proud, determined). Respondents indicated on a fivepoint scale (where $1=$ very slightly or not at all and $5=$ extremely) the extent to which they have experienced the feelings and emotions stated 'over the past seven days'. The internal consistency was $\alpha=0.88$ for the negative items and 0.84 for the positive items. The instrument was included so that the possibility of an increase in positive affect could be explored should floor effects be found on the HADS (carers scoring within asymptomatic range at baseline, with no room for further improvement).

\section{Burden}

The Carers Assessment of Difficulties Index $(\mathrm{CADI})^{58,59}$ frequency scale was used as a measure of objective burden. It is a 30 -item instrument 
including statements that describe experiences related to caring (e.g. 'It is physically tiring', 'The person I care for can demand too much of me'). Frequencies of experiences were indicated on a three-point scale from $1=$ never applies to me to $3=$ always applies to me. Cronbach's $\alpha$ was 0.89 .

\section{Relationship quality}

The quality of premorbid relationship was assessed using a single five-point scale $(0=$ very poor, $2=$ neither good nor bad, $4=$ very good), and also with the ten-item Mutual Communal Behaviours Scale (MCBS) ${ }^{60}$ which measures the responsiveness between the carer and care recipient before the onset of illness. The frequency of each behaviour was rated using a four-point scale from $1=$ never to $4=$ always. A principal components analysis for this study identified two five-item factors (oblimin rotation) with eigenvalues of 5.34 and 1.53, explaining $69 \%$ of the variance. All items loaded highly, with factor loadings of 0.7 and above. The first factor contained the five items evaluating the care recipient's communal behaviour towards the carer (e.g. 'They seemed to enjoy responding to my needs', 'They did things just to please me') and the second factor containing all items concerning the carer's communal behaviour towards the care recipient (e.g. 'If they were feeling bad, I tried to cheer him/her up', 'When they had a need, he/she turned to me for help'). Cronbach's $\alpha$ for the two subscales was 0.91 and 0.84 , respectively.

Perceived loss of companionship was assessed using a three-item scale by Aneshensel and colleagues. ${ }^{20}$ Each item ('How much have you lost being able to confide?' 'How much have you lost the person that you used to know?' 'How much have you lost having someone who knew you well?') was rated on a four-point scale from $1=$ completely to $4=$ not at all, giving a range of $3-12$, with lower scores indicating the greater perceived loss. However, for ease of interpretation of results, items were recoded such that higher scores indicate greater perceived loss. A principal components analysis on data from carers in this study indicated that all three items loaded heavily on one factor (loadings ranged from 0.82 to 0.89 ) and accounted for $73.5 \%$ of the variance.

Reliability of the scale, as indicated by Cronbach's $\alpha$ was 0.81 .

\section{Social support}

The Practitioner Assessment of Network Type (PANT) scale, ${ }^{61}$ which consists of eight items/questions (e.g. 'If you have any children where does your nearest child live?' 'How often do you see any of your neighbours to have a chat or do something with?'), was developed to identify social support network type. The instrument has been found to correlate highly with a range of demographic variables, level of service use and response to interventions. Items from the Network Typology questionnaire were also used to construct a social isolation index akin to that of Scharf and Smith ${ }^{62}$ summarising contact with family, friends and neighbours. The index provided a measure of social isolation ranging from $0=$ not isolated to $3=$ extremely isolated (no contact with family, friends or neighbours).

The Multidimensional Scale of Perceived Social Support (MSPSS) ${ }^{63}$ is a 12 -item measure assessing perceived social support. Each item is rated on a five-point Likert-type scale ranging from $1=$ strongly disagree to $5=$ strongly agree. The scale was developed to assess perceived social support in relation to the family (e.g. 'My family really tries to help me', 'I can talk about my problems with my family'), friends (e.g. 'I can count on my friends when things go wrong', 'I have friends with whom I can share my joys and sorrows') and significant other (e.g. 'There is a special person who is around when I am in need', 'I have a special person who is a real source of comfort to me') source of support, which form the three subscales of the measure. Strong psychometric properties of the measure have been documented previously, including test-retest reliability, with correlation coefficients of $r=0.73$ for the full scale, $r=0.73$ for the friends subscale, $r=0.74$ for the family subscale and $r=0.54$ for the significant other subscale. ${ }^{64}$ Cronbach's $\alpha$ in this study was $0.92,0.89$ and 0.87 for the family, friends and significant other subscales, respectively.

\section{Coping}

The Brief Coping Orientation for Problem Experience (COPE) ${ }^{65}$ is a 28 -item measure for multidimensional assessment of coping. Active coping includes the subscales acceptance, emotional support, religion, active coping, planning and positive reframing. Avoidance coping includes the subscales self-distraction, venting, humour, denial, behavioural disengagement and substance use. Items (e.g. 'I've been turning to work or other activities to take my mind off things', 'I've been saying to myself "this isn't real"') assess responses of individuals when confronted with difficult or stressful situations and are scored on a four-point Likert-type scale ranging from $1=$ don't do this at all to $4=$ do this a lot. 


\section{Life events}

The List of Threatening Experiences ${ }^{66}$ is a 12-item measure, which states life events (e.g. 'serious injury or illness to yourself', 'Death of a first degree relative including a child or a spouse'). The scale accounts for two-thirds of life events that may have a marked or moderate long-term threat. The occurrence or absence of a life event was scored as Yes or No.

\section{Health-related quality of life}

Health-related quality of life was measured in QALYs for both the carer and PwD using the EQ-5D instrument, ${ }^{67}$ with the carer providing a proxy measure on behalf of the PwD. The EQ-5D is a standardised instrument designed to measure health outcomes and was recommended for adults by Dixon and co-authors ${ }^{68}$ in an HTA review of health status measures for economic evaluation. It is a six-item self-assessment, health state measure of health-related quality of life. The scale includes five items accounting for five dimensions of quality of life (mobility, self-care, usual activities, pain/discomfort and anxiety/depression) and a visual analogue 'thermometer', ranging from 0 to 100 points, where 100 represents the best possible health state and 0 the worst. The five

items/dimensions of quality of life are scored on a three-level scale ranging from $1=$ no problem to $3=$ extreme problem. Carers were not asked to proxy for the PwD on the visual analogue scale (VAS).

\section{Resource use}

Data on resource use were collected through a semi-structured interview devised for this trial influenced by pre-existing interview schedules, namely the Client Service Receipt Inventory (CSRI), ${ }^{69}$ the Caregiver Time Questionnaire, ${ }^{70}$ the Caregiver Activity Schedule (CAS) $)^{71,72}$ and the Resource Utilization in Dementia (RUD) questionnaire. ${ }^{47}$ Information was collected on statutory and voluntary sector usage by both carer and PwD. Areas covered included home care (personal care, e.g. bathing and dressing), day care, inpatient admission, use of GP services, use of medication, respite care, aids and adaptations, loss of income, time taken off work and benefits received. The data-collection instrument varied at follow-up depending on whether the PwD remained in the community, had moved permanently into residential or nursing care, or had died.

\section{Support from family and friends}

made with family or friends which occurred on a regular daily or weekly basis were deemed 'regular support'. Regular support was subdivided into 'respite support', where the family member or friend replaced the carer, and 'assistance', where the carer remained with the PwD.

\section{Data-collection procedures}

Baseline questionnaire data were collected after the carer had consented to take part in the study, with follow-up at 6,15 and 24 months postrandomisation. A longitudinal picture of resource use was constructed for each carer. Carers interviewed at 6 months were asked about all resource use that occurred between the first (baseline) interview and the ongoing interview. This method was repeated at the 15- and 24month interviews, so a complete picture of resource use for each carer and carer recipient was available at the end of the final interview. It was anticipated that all data would be collected through face-to-face interviews in carers' own homes, with the resource-use semi-structured interview being used to gather information from carers' recall, with the use of their own recording systems such as calendars, diaries and copies of repeat prescriptions. The recommended best practice for drug-use information is to go through the prescription sheets and repeat prescriptions of study participants and take down names of drugs, including the correct dosage and frequency. ${ }^{47}$ Where possible this practice was followed. However, where repeat prescription forms were not available, interviewers relied on carer recall. Similarly, where diaries and calendars were available, interviewers encouraged carers to use them to ensure accuracy of frequency of visits and duration of stays; however, in the absence of such prompts, data were again subject to carer recall.

Psychometric questionnaires were completed either as part of a semi-structured interview or as self-completion, depending on the carer's preference.

To maximise data collection, some variations were made in data-collection methods. For example, in cases where carers were fatigued by the interview process, or their caring responsibilities precluded completion of the interview, either a second appointment was made or, for the psychometric component only, carers were provided with a stamped addressed envelope for return of questionnaires. Where carers did not wish to be interviewed in their own homes, alternative venues 
were organised, for example GP surgeries, health centres, or voluntary-sector or university meeting rooms. Where the carer moved away from the catchment area after randomisation, a telephone interview was developed for the resource-use data collection, and psychometric measures were either completed over the telephone, or posted to carers with a return envelope. Over the course of the trial, it became standard procedure for follow-up psychometric questionnaires to be posted out to participants with letters confirming the arrangements for follow-up interview, thus giving carers the option of precompleting all or part of the questionnaire, or waiting to complete with the researcher.

\section{Data checking}

Data were entered into the Statistical Package for the Social Sciences (SPSS, version 12.0.2; SPSS, Chicago, IL, USA, 2003) and accuracy checks were carried out. Subscale scores for psychometric measures were both handscored and calculated by SPSS as part of error checking. Other data checks for the psychometric data included checks for outof-range values. A proportion of the resource-use interview scripts was checked by the lead economics researcher and a second researcher, with any queries resolved with the main project researchers.

\section{Data analysis}

\section{Missing data}

The proportion of missing psychometric data was generally low (less than 5\%), with greater missing data for earlier rather than later interviews. No psychometric scale or subscale was missing for more than $10 \%$ of data from interviewer participants. Where individual items were missing within scales or subscales, data were imputed before calculation of the scale or subscale score. For the resource-use data, where five or fewer of the 136 cost data items were missing, or two or fewer of the utility items were missing, data were imputed using Rubin's multiple imputation method. ${ }^{73}$

\section{Baseline characteristics}

As is now recommended, ${ }^{74}$ no formal tests were carried out for significant differences in baseline characteristics between the study groups. Data were tabulated for intervention, control and whole sample for both demographic and clinical variables.

\section{Primary effectiveness analysis}

The psychometric data were transferred to SAS software for outcome analysis. The intervention group carers were compared with control on the HADS depression scale at 6,15 and 24 months, using the intention-to-treat (ITT) population. Unadjusted analysis was based on a pooled $t$-test, and the adjusted analysis based on a generalised linear model (GLM) with baseline HADS depression score and stratification categories (urban/rural location; horizontal/vertical kinship) as covariates.

\section{Secondary effectiveness analyses}

The method used for the primary analysis was repeated for the secondary measures of HADS anxiety, loneliness, positive affectivity and the global VAS of the EQ-5D. In addition, the proportion of $\mathrm{PwD}$ still in home care compared with those institutionalised was compared between groups.

\section{Subgroup analyses}

The primary analysis was repeated on a perprotocol basis (i.e. removing those carers from the intervention group who were not matched with a befriender for at least 6 months and those carers in the control group who ended up matched with a befriender) and also looking at spouse carers only (carers in a horizontal kinship relationship).

\section{Economic analyses}

\section{Valuing resource use}

The chosen price year was 2005. Resource-use data were multiplied by national unit costs obtained from routine NHS and other data sources such as the national schedule of reference costs. Drug prices were obtained from the British National Formulary. Where unit cost data were not readily available, costs were obtained directly from the relevant agency or estimated separately. Time spent by carers, friends and family in caring for their relative was valued at average UK gross income rates for 2005, derived from Office for National Statistics (ONS). Unit cost data are listed in Appendix 2.

\section{Discounting costs}

It is conventional to discount costs (and outcomes) incurred more than 1 year in the future to their 'present value'. However, it was not possible to identify which costs in the 15-month follow-up data set had been incurred after the 12-month cut-off point. Not discounting costs incurred between 12 and 15 months is unlikely to have a great impact on the results of this analysis, and therefore no attempt was made to do so. Costs 
incurred and QALYs accrued between 15 and 24 months were discounted at $3.5 \%$.

\section{Primary economic analysis}

An economic evaluation was performed from the perspective of society comparing costs with the QALYs gained by carers in intervention versus control after 15 months' follow-up. The EQ-5D health profiles were converted to utilities using UK general population valuations, ${ }^{75}$ and thence to QALYs over the period measured. ${ }^{76}$

To compare costs and effects, an incremental cost-effectiveness ratio (ICER) was calculated, comparing the difference (increment) in costs with the difference in QALYs gained in each arm of the study. The ratio states the cost of buying one extra QALY by enacting the befriending strategy compared with no befriending. Typically, the NHS is willing to pay up to $£ 20,000-30,000$ for a QALY. ${ }^{77}$ Thus, if the ICER is below this threshold, befriending may be considered good value for money. If it is above this, it may be considered poor value for money.

$$
\operatorname{ICER}=\frac{C_{2}-C_{1}}{E_{2}-E_{1}}
$$

where $C_{2}$ is cost per carer-PwD in the befriending arm, $C_{1}$ is cost per carer-PwD in the control arm, $E_{2}=$ QALYs gained by carer in the befriending arm, and $E_{2}=$ QALYs gained by carer in the control arm.

Mean costs and QALYs gained in the intervention and control arms were calculated from trial observations. A non-parametric bootstrap approach of 1000 replications was used to construct distributions around the mean costs and QALYs gained in each arm. The simulations are used to construct 95\% confidence intervals (CIs) resulting around mean difference in cost and QALYs between the arms, and the ICERs used to construct a cost-effectiveness acceptability curve (CEAC) ${ }^{76}$

\section{Alternative economic scenarios}

Further analyses were performed to consider the cost-effectiveness of the intervention within different scenarios.

\section{Varying the perspective}

The base case was societal, but within that there are different sectors:

- the statutory sector (NHS, social services and other government-funded services)

- the voluntary sector

- the household sector.
Each calculation includes only those costs relevant to each sector. For example, the statutory sector analysis includes only costs borne by the NHS and social services, and thus excludes voluntarysector costs, patients' and their carers' out-ofpocket costs, the value of carers' time, and so on.

\section{Varying the time-point}

Although 15 months postrandomisation was the main end-point, data were available at 6 months and also at 24 months. The cost-utility analysis is repeated for these time-points.

\section{Complete case analysis}

This comprised only observations for whom complete cost and outcome data were available at 15 months (30 intervention; 31 control).

\section{Taking account of both carer and PwD quality of life}

The resource-use data included costs for both the carer and the person with dementia, but in the main utility analysis the health-related quality of life relates to the carer only. This alternative scenario includes the QALYs calculated for the care recipient from the EQ-5D, completed by the carer.

\section{Summary of changes to protocol}

As already described above, recruitment strategies were amended to include recruitment through the voluntary sector, self-referral and secondary services. The changes to the carer recruitment process also included the addition of Havering as a trial site. To maintain the original project end date, follow-up periodicities were amended such that follow-up occurred at 6,15 and 24 months rather than at 9, 18 and 36 months. That is, the time-horizon (follow-up period) was reduced from 36 to 24 months owing to the extension of the recruitment period. Low attrition rates in the project facilitated the reduction of recruitment targets as the assumed attrition was not experienced. To maintain maximum follow-up, data-collection methods were also broadened through the course of the trial to include selfcompletion of the psychometric follow-up and the use of telephone follow-ups for carers who had moved out of the area. Other protocol changes were revisions to the management committees in the light of new governance guidelines and the inclusion of a pilot study as requested by the ethical committee. The latter is described further in Chapter 3. 


\section{Chapter 3 Intervention}

$\mathbf{n}$ this chapter the development and

implementation of the befriending intervention are described in detail.

\section{Definition of befriending}

Befriending is a form of social support where a supportive other is introduced to, or matched with an individual who would otherwise be socially isolated. The term 'befriending' has been used to describe a range of interventions from emotional support to tangible assistance. In the initial protocol for this trial, befriending was conceptualised as offering emotional, informational and practical support. However, through consultation with the potential local providers, the definition of befriending and the planned content of the intervention were amended to focus on the provision of emotional support and also, where appropriate, some 'signposting' to information and services. The role did not encompass instrumental support (handson caring, DIY, shopping, etc.) or advice. That is, befriending comprised companionship and conversation rather than instrumental support or activities that aimed to increase community participation.

\section{Development of the BECCA befriending schemes}

The BECCA project was devised at the University of East Anglia (UEA) in the city of Norwich (population 120,000) in the county of Norfolk (population 800,000), to take place in Norfolk and the adjoining county of Suffolk (population $700,000)$. The physical size of the two counties made it unfeasible to have a single scheme, and there were no voluntary organisations spanning both Norfolk and Suffolk that could support a suitable befriending scheme. Discussions were held between representatives of the research team (GC and FP) and the Alzheimer's Society's national office to determine ways in which the befriending intervention could be set up and managed. Various options were considered, and it was decided that the only feasible option was for a number of small befriending schemes to be set up on a locality basis, with multiple BFs employed by separate organisations, each of which had experience of providing befriending services. As Norwich and its surrounding areas had been identified as the pilot area, further discussions were held with community organisations within the voluntary organisations in Norwich. It was agreed that the first scheme would be hosted by Norwich and Norfolk Voluntary Services (NVS), and a contract was drawn up between UEA and NVS. Following this agreement, and during the process of recruiting to the post of $\mathrm{BF}$, several consultation meetings were held with key stakeholders, with the remit of deciding the appropriate policies and procedures for ensuring the safe involvement of both carers and volunteers in the befriending scheme. Once procedures for recruitment, training and matching of volunteers were in place in Norwich, the scheme was extended to other areas of Norfolk overseen by the same BF. In addition, two further schemes were set up, one with Age Concern Suffolk (ACS) and the smallest with Age Concern Havering $(\mathrm{ACH})$. Consistent with arrangements for the initial Norwich scheme, the BFs were jointly managed by the operations manager from the 'host' organisation and the BECCA grantholder with responsibility for managing the befriending intervention (designated 'intervention manager').

The contracted host voluntary organisations (NVS, ACS, ACH) agreed to employ a part-time BF, and jointly manage the post with the UEA-based trial intervention manager; register all potential volunteer befrienders in their area, taking informed consent for the volunteers' involvement in the BECCA research trial; take up references; facilitate Criminal Records Bureau (CRB) disclosures; provide public liability and personal accident insurance; provide BECCA training for volunteers including details of the Code of Conduct and Statement of Confidentiality; and provide ongoing support for the $\mathrm{BF}$ and all registered BECCA volunteers. They also had policies in place for volunteer support, complaints, disciplinary action, grievance and the storage of information about volunteers under the Data Protection Act. 


\section{Consultation and advisory groups}

The initial Norfolk-focused consultation group was made up of representatives of organisations with an interest in carer support, volunteer support and/or people with dementia. This included committee members from branches of the Alzheimer's Society, Alzheimer's Society outreach workers, representatives from Age Concern Norwich and Age Concern Norfolk, Pabulum (a Norwich-based project for reminiscence with people with dementia), the Mental Health Service dementia nurse specialist, Norfolk Social Services planning and community development officer and Suffolk Social Services carers grant officer. Discussions within this initial consultation forum included consideration of the boundaries of the intervention, insurance, screening and training, and exit strategies for the end of the project. Members of this group also contributed to the piloting of the befriender training. This initial consultation group was extended to form a broader group which met approximately every 6 months for the duration of the trial, to comment on trial progress and contribute to decisionmaking on evolving procedures. Similar groups were convened in Suffolk and Havering.

In addition to issues policies, procedures and training, the consultation groups proved particularly helpful in anticipating some problems and in suggesting solutions during the ongoing trial. These included publicity phrasing, placement and timing to fit with local-voluntary sector programmes, and issues to consider in befrienders' introductory visits to carers' homes, particularly in considering the carer's relationship with the PwD.

\section{Befriending scheme procedures}

\section{Befriender facilitator recruitment and induction}

BF posts were all part-time. They were advertised internally within the host organisation, and where necessary in the local press. The person specification for BFs included the following criteria: prior experience of working in the voluntary sector, working with people with dementia and their carers, and proficiency in training volunteers. The job description was to recruit and screen volunteers, organise training, maintain contact with and support referred carers, match befrienders and carers, monitor ongoing befriending relationships, support endings, and accurately compile records for the research team.

The initial BF played a key part in the development of policies and procedures for the scheme, in close collaboration with the intervention manager and principal investigator for the BECCA trial. Subsequently employed BFs took part in a full-day training course, which covered the role of the BFs, befriender recruitment and training procedures, volunteer registration and screening, befriender training, initial contact with carers, support across the befriending relationship, reporting procedures, expenses and volunteer time recording and management, risk assessment, and befriender and carer reviews.

\section{Recruitment and screening of potential befriending volunteers}

Pilot procedures for volunteer recruitment included dissemination of recruitment posters and leaflets through the network of volunteer bureaux in the Norwich and District area, and through partner organisations represented in the consultation group. Open meetings were organised and advertised so that potentially interested volunteers could, without commitment, hear a short talk about the project and about the role of befrienders. There were attendees at two pilot open meetings held in the City of Norwich (one in a suburb at a venue with parking facilities, and one in the centre of town convenient for public transport). However, a similar meeting arranged in one small market town did not attract any new interest. Early indications were that befrienders would be harder to identify outside the largest centre of population. For the full trial, therefore, opportunities were sought for contact with a greater number of local social-care organisations, in addition to dissemination of recruitment leaflets and posters, and media advertising. Recruitment literature emphasised the importance of a 'listening ear' and the ability to provide 'companionship and conversation'.

\section{Inclusion criteria}

Potential befriending volunteers were asked to meet the following criteria before being considered eligible for matching with a family carer.

\footnotetext{
Attend an open meeting, or individual meeting with the $B F$

The aim of open meetings was to welcome potential volunteers, to orientate them to the stages to becoming a befriender and to outline the
} 
expectations of befrienders. The meetings also provided volunteers with an opportunity to meet those involved in the befriending scheme and to ask questions before formally registering their interest.

\section{Read the information for potential befriending volunteers and complete a befriender registration form}

As the BECCA befriending schemes were part of a research trial, the befriending volunteers were considered a form of research participant. Therefore, the information booklet included MREC-approved information relevant to research trial participants, and the registration form also included MREC-approved statements akin to those found on research consent forms. The volunteer registration form was also used to record information on existing skills (e.g. experience as a family carer and/or caring experience, or from training within the helping professions or as a paid carer), and volunteers' availability (weekdays or weekends; daytime or evening) and preferences for placements (e.g. no pets or smoking; local or away from own community).

The information booklet and registration form had been revised and amended in the light of pilot work which identified the risk of dual roles for befrienders and carers. It had been assumed that all current carers would be too busy to be considering voluntary activity; however, some carers expressed an interest in being befrienders themselves. Indeed, some misinterpreted the carer information sheet used for recruitment of family carers to the project to mean that they were being asked to be befrienders, and they engaged in the research interviews with this express intent. To clarify literature, the information sheets were amended, and some of the terminology was changed to remove any possible ambiguities. A procedure was devised for ensuring that active carers were not taken on as potential befrienders during their time as a research participant, but to value their offer and contribution during later phases of the trial, once their research participation was complete. It was noted that some carers saw themselves as better equipped for the befriending role, and not just in need of care. Feedback from pilot work also showed that befrienders needed to be aware of some aspects of the research design, for example making it clear that carers had contact with research interviewers before entry into the trial, and that referrals could not be taken for the befriending scheme except from within the trial.

\section{Provide names of referees and complete a CRB standard disclosure form}

Contact details were requested for two character referees (not relatives), and references were taken up by the BF. Potential volunteers were also asked to disclose criminal convictions, including any that were spent, as people over the age of 65 (which many carers were) are considered vulnerable people under the terms of the Rehabilitation of Offenders Act 1974. During the start-up of the project, procedures for police checks were being transferred to the new CRB, and participants were asked to complete the CRB disclosure form.

Assistance was provided by the $\mathrm{BF}$ where necessary.

\section{Attend the befriender training course}

The befriender training course consisted of six 2-hour modules, totalling 12 hours of learning (further details on p. 16). The course was compulsory and volunteers were able attend sessions from more than one course as long as all modules were covered. A record of attendance was kept.

\section{Agree to abide by the Code of Conduct, including the statement of confidentiality}

The Code of Conduct outlined the expectations of the work that befrienders would do on the scheme's behalf. It included a statement of confidentiality, as organisers had to be able to trust volunteers with personal information about the carers who used its services, and personal information about the caredfor PwD. Volunteers signed to say that they would not pass on confidential information to anyone other than their BF, or supporters nominated by the BF. Volunteers could pass on confidential information if they had been given the permission of the person concerned. The statement of confidentiality also emphasised situations where safety took a higher priority than confidentiality, for example in situations of suspected abuse.

\section{Availability}

Volunteers were asked to make a minimum commitment to be involved with the scheme for 6 months, at an intensity of an hour per week plus travel.

\section{Exclusion criteria}

The following exclusion criteria were applied:

- volunteers under the age of 18 years

- volunteers regarded as unsuitable in the light of references or information from standard disclosures from the CRB

- volunteers with special needs that could not be catered for within the scheme, or which 
might add to the caring burden of a befriender

- volunteers who failed to declare convictions which later came to light.

The above criteria were in line with the key principles for the safe involvement of volunteers with vulnerable clients. ${ }^{78}$ In the event, no volunteers were excluded on the grounds of any of these criteria.

\section{Befriender training programme}

The training programme was developed specifically for the trial, and delivered by the BFs in conjunction with invited others. The aims of the training were to equip volunteers for their befriending role, and ensure that they were aware of scheme boundaries and guidelines for safe and ethical involvement with carers. Certificates of attendance were provided on completion.

An early version of the training programme was written by a clinical psychologist with experience of working with carers and people with dementia, and of training in the voluntary sector. Some information was drawn from existing training programmes, plus information from organisations such as the Alzheimer's Society. The training included skills-based work, including listening skills and maintaining boundaries. It also covered key aspects of policies and procedures, including non-discriminatory practice, health and safety when working in other people's homes, and the balance of confidentiality versus communication of risk. The initial programme was piloted with members of the consultation group, and others nominated by consultation group members. The programme was amended to focus specifically on the befriending role rather than dementia knowledge, and the use of case vignettes was increased. The final 12-hour training programme was organised into six 2-hour units which could be organised into six, three or two sessions. The course curriculum is outlined below.

- Unit 1: Befriending: what is it, and what it isn't: covered the role and responsibilities of befrienders in the BECCA scheme, including confidentiality and safety. Short 'carer scenarios' provided a focus for discussion and learning.

- Unit 2: Listening skills: theory and practice of good listening, and establishing a good relationship with carers.

- Unit 3: Carers' needs; the befriending relationship: 'carer scenarios' from session 1 were developed to highlight the impact of caring for a person with dementia, to raise befrienders' awareness of needs that befriending can meet. The four stages of the befriending relationship were introduced, and skills developed in stages 1 and 2 ('breaking the ice' and 'getting to know one another').

- Unit 4: Working in other people's homes: guidelines for health and safety when visiting carers at home, including risk assessment, and what to do in the face of incidents, accidents or untoward situations.

- Unit 5: Dementia and services: this session gave information about dementia and signposted volunteers to a variety of information resources to assist in signposting.

- Unit 6: Later stages of befriending, and looking after yourself: skills were developed for maintaining companionship (stage 3), including avoiding miscommunication and troubleshooting. Procedures for ending befriending relationship (stage 4) were covered, and the importance of ongoing self-care was emphasised.

\section{Carer registration}

In parallel with the recruitment, screening and training of befriending volunteers, the BFs also registered carers expressing an interest in receiving visits from a befriending volunteer. All carers in contact with the BFs were put in contact through the BECCA research trial. The BECCA befriending schemes did not accept referrals from outside the research project. In the pilot, carers randomised to intervention were asked to opt in to the befriending scheme by sending an expression of interest form to the BF. However, carers randomised to intervention during the pilot phase did not opt in. The project consultation group suggested that opting in could be perceived by carers as 'another hurdle to jump', rather than as protection of their right to choose whether or not to be involved. Therefore, a protocol amendment was sought and approved such that all carers were asked for permission for their contact details to be passed on to the local BF should they be allocated to intervention as a result of the randomisation process. Following the protocol amendment, those carers allocated to the befriending intervention through the randomisation procedure received a letter from the trial administrator informing them of their allocation and enclosing a brief information leaflet about the befriending scheme. Their contact details were forwarded to the relevant BF. The introductory leaflet gave a clear statement that making use of the befriending scheme was optional. On receipt of a carer's details, the BF would make telephone contact to 
introduce themselves, to answer questions on the introductory leaflet and, where appropriate, to arrange to visit the carer. At the initial face-to-face meeting, the $\mathrm{BF}$ provided carers with a full information booklet about using the befriending scheme. Carers interested in participating at that stage completed a registration form and those who declined involvement were given an open invitation to change their mind at any time during the life of the project. In accordance with the suggestions of the consultation group, the $\mathrm{BF}$ maintained occasional contact with those carers who were not initially interested in having a befriender. The information booklet and registration form for carers using the befriending scheme corresponded to those used with the befriending volunteers.

\section{Befriender-carer matches}

Matches were made by the BFs on the basis of locality and knowledge of both the carer and befriender. Information was used from the registration forms, most particularly befrienders' and carers' preferences for time and location of meetings. There were no requirements or restrictions for matches relating to gender, current circumstances or prior experience. The BF organised an initial meeting to introduce the befriender to the carer, to remind both parties of the ground rules for the befriending partnerships, and to set up an informal contract for meeting location, duration and frequency.

\section{Monitoring of matches}

Both befriender and carer were reminded that the BF would be contacting each of them individually to review the partnership after 1 month, 6 months and every subsequent 6 months, but that they could contact the BF at any time in between.

\section{Befriender support}

Local peer-support group meetings were organised for befrienders at a minimum of 6 -monthly intervals. These provided opportunities for volunteers to support each other on issues that could be raised without breaching confidentiality, and to have further training and topical information about aspects of volunteering or carer support, such as telephone support. Newsletters were circulated, also at 6-monthly intervals, giving information about the BECCA project, volunteer recruitment and signposting issues. The $\mathrm{BF}$ maintained individual contact with each volunteer and carer between meetings, usually by telephone, and 6-monthly reviews of the activity and the quality of befriender relationship were routinely carried out. However, both befriender and carer were actively encouraged to contact the BF if they had any concerns about issues within or relating to the befriending activity.

Previous work has recommended that one fulltime befriending coordinator could only successfully support 15-20 matched befrienders. ${ }^{79}$ Therefore, it was initially intended that the BF would liaise with counterparts in relevant organisations to identify potential befriender contacts, and also work to develop a pyramid of volunteer support in which more experienced volunteers within a community take on the role of local befriending contact, supporting and training new recruits, matching befrienders with care dyads and publicising the befriending scheme. For the Suffolk and Havering schemes, the number of matched did not rise above the recommended ceiling. In Norfolk, the BF worked closely with Alzheimer's Society outreach workers, with some aspects of the BF role delegated.

\section{Ending of partnerships}

At the start of their involvement with the scheme, participating carers were told that they could use the befriending scheme as long as there was an appropriate BF. If the carer's active caring situation changed because the $\mathrm{PwD}$ had either moved into long-term care or died, the carer was then given the choice as to whether to continue or terminate a befriending relationship. From the start of the trial, the intervention manager and the BFs worked towards an exit strategy to ensure that ongoing matches could be supported beyond the end of the trial-specific schemes.

\section{Audit and data collection}

Volunteer screening and training procedures were audited by the BFs, in conjunction with the intervention manager. Audit data and demographic information on matched befriending volunteers were collated by the BFs and sent to the university-based research team in anonymised format. Data included age and gender of befriending volunteers, and whether or not they had previous experience as a carer. Dates of matches and partnership end dates were also collated for use by the research team.

\section{Volunteer flow}

A total of 124 volunteers approached BFs across the three schemes expressing interest in the volunteer befriender role. Of these, 81 (65\%) completed a volunteer registration form, $75(60 \%)$ were screened using references and $64(52 \%)$ completed CRB disclosures. In total, 63 (51\%) completed the training programme, and $60(48 \%)$ 
met all four screening criteria of registration, references, CRB disclosures and completion of befriender training. In other words, two potential volunteers had to be recruited to result in one eligible befriender or, alternatively, one in two potential volunteers was lost through the screening and training process.

Previous descriptions of befriending schemes, for example 'City Support' Case Study $6,{ }^{80}$ have found that around $15 \%$ of befriending applicants may be considered unsuitable for befriending within healthcare. The BECCA scheme screening procedures did not include any assessment of 'befriender suitability'. Individual applicants were encouraged to consider this for themselves during the recruitment, screening and training process, and it was indeed the case that some potential volunteers withdrew as they decided for themselves that the befriending role was not right for them. In some cases, BFs were able to direct volunteers to other volunteering opportunities.

Of the 60 volunteers who completed the screening and training process, only 49 became befrienders. As demographic data for volunteers were only passed on to the research team for those who became befrienders (i.e. matched with carers), no information is available on potential differences between those volunteers who become befrienders and those who withdrew earlier in the recruitment, screening and training process, or on those who were eligible to befriend, but not matched. Anecdotally, non-matching of eligible volunteers was often due to mismatches in geographical location between befriender and carer recruitment.

\section{Costing of befriending services}

Each BECCA befriending scheme was set up specifically for the trial in addition to existing services, and therefore each service was uniquely costed. Cost data were collected from the beginning of the pretrial consultation to the end of the financial year 2005/06. Costs collected included set-up costs, training costs (for staff and volunteers), staff salaries and travel, volunteer time and travel, overhead expenses (administration, stationery, telephone, postage, insurance, CRB disclosures) and running costs (ongoing and recruitment and publicity costs, room hire for support groups).

Half-yearly budget statements were obtained from the host organisations to collect details on staff salaries, travel claims and all expenses related to overheads and running expenses.

\section{Record of activities}

BFs kept accounts of their own work and budget, and basic records of befrienders' contact with carers. They also collected the records kept by befrienders and trainers of their time spent and expenses. The precise quantities of befriender time and expenses were recorded on monthly returns. Time, out-of-pocket expenses, use of volunteers' cars and organisational costs of running the befriending service were all collected routinely.

\section{Total cost of intervention}

Intervention costs were calculated as a fixed and variable component, specific to each of the three centres (Norfolk, Suffolk and Havering). The fixed cost was divided equally by centre among all those in the intervention arm, and variable costs were divided equally among those who actually received befriending.

\section{Protocol changes relating to intervention}

As a consequence of ethical review, a limited-area pilot phase was introduced to the project with the aim of piloting procedures for the recruitment and training of befriending volunteers. This had implications for the wider trial timetable, leading in part to the changes to the recruitment process described in the section 'Summary of changes to protocol' (p. 12). As a consequence of the pilot, there were changes to the consent procedures for carers, and associated changes to the information and consent forms. At this time the opportunity was taken to amend the terminology used in these forms to conform to best practice, in a changing field. 


\section{Chapter 4}

\section{Results: characteristics and outcomes}

\section{Participant flow}

A summary of participant flow is provided in the CONSORT diagram (Figure 1). Details at each stage are described below.

\section{Expressions of interest and assessment for eligibility}

In total, the research team received 316 expressions of interest. Of these, 107 (34\%) were received as a result of invitations from GP practices. The greatest proportion of responses $(136 ; 43 \%)$ came about as a consequence of carers' contact with voluntary-sector personnel or invitations received through voluntary-sector mailing lists. Eleven per cent were self-referrals following media publicity. Over the course of recruitment an increasing number of enquiries came by word of mouth.

Of the 316 people initially expressing interest in the trial, $31(10 \%)$ declined involvement. It is not known whether those who declined involvement would have been eligible for the trial. A further 49 people were excluded at the screening stage as they did not meet eligibility criteria for the trial. The most common reasons for exclusion were the PwD living in permanent care or having already passed away. Other reasons included carer illhealth and the care recipient having an illness other than a primary progressive dementia. Reasons for exclusion are shown in Table 1.

No demographic or psychosocial information was collected about potential participants prior to their

TABLE I Reasons for exclusion at screening

\begin{tabular}{|lr|}
\hline Reason for exclusion & $\mathbf{n}$ \\
\hline $\begin{array}{l}\text { Declined involvement }(\mathrm{n}=3 I) \\
\quad \text { Refused }\end{array}$ & 22 \\
No reason given & \\
Did not meet study eligibility criteria $(\mathrm{n}=49)$ & 19 \\
PwD in care, or deceased & 15 \\
Carer ill-health (physical or emotional) & 8 \\
Care recipient not having dementia & 4 \\
Carer spending <20 hours per week caring & 2 \\
Out of catchment area & 1 \\
Paid carer & \\
\hline
\end{tabular}

giving written informed consent to involvement in the trial. Therefore, it is not known whether nonresponders systematically differ from responders, nor is it known whether eligible carers had demographic or psychosocial differences compared with those who declined or were excluded.

\section{Randomised allocation}

All 236 carers screened as eligible for the trial gave informed consent and were randomised after baseline assessment between April 2000 and August 2004. A total of 116 carers were randomly allocated to intervention and 120 to control.

Of the 116 randomised to intervention, all 116 were offered contact with their local BF. During the initial pilot stage of the trial carers were asked to initiate this contact through the return of a response form. However, following discussion with the consultation group, this was seen as an unnecessary barrier to accessing the service, and a change to protocol was applied for and approved by the MREC such that all carers consented to having their details passed to the BF should they be allocated to intervention. There were 42 carers consented into the trial under the original procedure, with 20 in the intervention arm and 22 in the control. Of the 20 invited to make contact with the BF, 13 did so. For the 96 carers allocated to intervention under the revised consent procedures, all had contact with the BF. In addition, administrative error meant that the names of three carers allocated to control were forwarded to a BF, and therefore were treated by the $\mathrm{BF}$ as carers in the intervention.

\section{Follow-up}

Follow-up interviews were carried out as soon as could be arranged after the interview due date; that is, 6, 15 and 24 months postrandomisation. Overall retention in the trial over the 2-year followup was good at $81 \%$ overall $(80 \%$ intervention and $81 \%$ control). Loss to follow-up was proportionately greater in the intervention arm than in the control arm for the first two follow-up interviews (at 6 and 15 months), but was very similar by 24 months. The main reason for loss to follow-up was carer health. Six carers died over the course of the 2-year follow-up. Three carers withdrew from the 


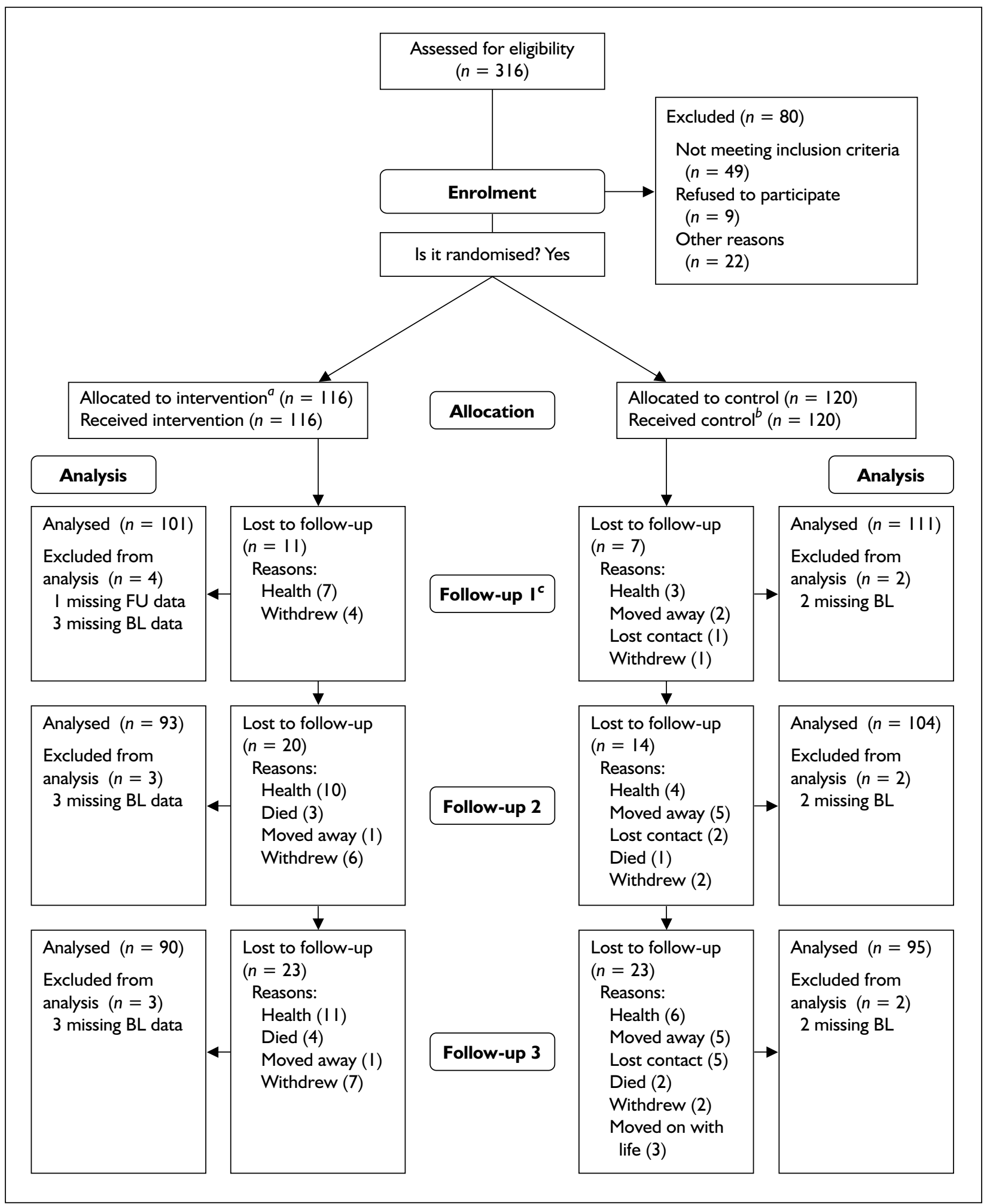

FIGURE I CONSORT summary of participant flow. ${ }^{a}$ Intervention was 'access to a befriender facilitator'. ${ }^{b}$ Three control carers also received intervention. For purposes of analysis they were treated as control carers. ${ }^{c}$ Figures for effectiveness analyses. The data set for 6-, 15- and 24-month economic evaluations comprised data from carers followed up at 6 months, i.e. 218 participants (I05 intervention; II 3 control). BL, baseline; FU, follow-up. 
trial on the grounds that they felt they had 'moved on with life' such that they no longer felt they had a carer identity following the death of the $\mathrm{PwD}$ or their move into permanent care.

\section{Analysis}

All carers who were followed up were included in the analyses, with the following exceptions:

- three intervention and two control carers had missing data on the HADS at baseline

- one further intervention carer had missing HADS data at 6-month follow-up, so was excluded from 6-month analyses

- 11 intervention and seven control carers had no resource-use data at 6 months, so were excluded from economic analyses.

\section{Baseline characteristics of randomised carers}

Baseline data are presented for the complete sample and by group (intervention versus control).
The denominators in the tables reflect the number of carers who answered a given question.

\section{Demographic information}

Over the whole sample, two-thirds of carers were female (Table 2). The kin relations of the carer to the person with dementia in the sample were: 97 wives, 62 husbands, 39 daughters, 15 sons, 12 daughters or sons-in-law, four siblings, two nieces, one parent, one cousin and two friends of long standing, 'as if related'. Three in five participants lived in 'urban' locations (population density 10,000 or greater). A majority ( $86 \%$ ) of the sample were cohabiting with the PwD. All participants except for two identified themselves as white. Two-thirds of the sample were retired. The mean age of carers was 68 years (range 36-91 years) and the mean age of PwD was older, at 78 years. The mean duration of caring was just under 4 years.

Almost the complete sample (97\%) was providing some form of assistance to the PwD on a daily basis (Table 3). Two-thirds considered themselves to be 'on duty' for 24 hours per day, and over half

TABLE 2 Baseline demographic information

\begin{tabular}{|c|c|c|c|c|c|c|c|c|c|}
\hline & & \multicolumn{2}{|c|}{ Total } & & \multicolumn{2}{|c|}{ Intervention } & & \multicolumn{2}{|c|}{ Control } \\
\hline & & $n / N$ & $\%$ & & $n / N$ & $\%$ & & $n / N$ & $\%$ \\
\hline Female carer & & $152 / 236$ & 64 & & $76 / 116$ & 66 & & $76 / 120$ & 63 \\
\hline Carer ethnicity: white & & $232 / 234$ & 99 & & $116 / 116$ & 100 & & $116 / 118$ & 98 \\
\hline Kinship: spouse & & $159 / 236$ & 67 & & $76 / 116$ & 66 & & $83 / 120$ & 69 \\
\hline Urban location & & $146 / 236$ & 62 & & $71 / 116$ & 61 & & $75 / 120$ & 63 \\
\hline Cohabiting & & $204 / 236$ & 86 & & $99 / 116$ & 85 & & $105 / 120$ & 88 \\
\hline \multirow[t]{2}{*}{ Retired } & & $158 / 235$ & 67 & & $78 / 115$ & 67 & & $80 / 120$ & 66 \\
\hline & $\mathbf{N}$ & Mean & SD & $n$ & Mean & SD & $n$ & Mean & SD \\
\hline Carer's age (years) & 236 & 68.0 & 11.4 & 116 & 68.4 & 11.3 & 120 & 67.6 & 11.6 \\
\hline PwD age (years) & 236 & 78.2 & 8.7 & 116 & 78.6 & 8.9 & 120 & 77.8 & 8.5 \\
\hline Duration of caring (years) & 232 & 3.8 & 5.9 & 114 & 3.9 & 7.7 & 118 & 3.7 & 3.5 \\
\hline
\end{tabular}

TABLE 3 Burden of caring

\begin{tabular}{|c|c|c|c|c|c|c|c|c|c|}
\hline & & \multicolumn{2}{|c|}{ Total } & & \multicolumn{2}{|c|}{ Intervention } & & \multicolumn{2}{|c|}{ Control } \\
\hline & & $\mathbf{N}$ & $\%$ & & $\mathbf{N}$ & $\%$ & & $\mathbf{N}$ & $\%$ \\
\hline Daily assistance & & $226 / 234$ & 97 & & $110 / 114$ & 97 & & $116 / 120$ & 97 \\
\hline 24 hours/day 'on duty' & & $139 / 216$ & 64 & & $67 / 105$ & 64 & & $72 / 111$ & 65 \\
\hline Relative can be left unsupervised & & $142 / 233$ & 61 & & $68 / 114$ & 60 & & $74 / 119$ & 62 \\
\hline \multirow[t]{2}{*}{ Sleep disturbance } & & $|25 / 22|$ & 57 & & $60 / 109$ & 55 & & $65 / 112$ & 58 \\
\hline & $\mathbf{N}$ & Mean & SD & $n$ & Mean & SD & $n$ & Mean & SD \\
\hline Objective burden (CADI-F) & 232 & 54.1 & 10.4 & 114 & 53.7 & 11.0 & 118 & 54.4 & 9.9 \\
\hline
\end{tabular}


experienced sleep disturbance on account of the PwD.

Sixteen per cent of carers were caring for another person in addition to a person with dementia and $16 \%$ were working, in full- or part-time paid employment, or were self-employed (Table 4). Eighteen carers (89\%) identified themselves as being full-time carers. The intervention and control groups were notably similar in terms of demographics, burden of caring and multiple roles.

\section{Psychological well-being}

The level of psychological morbidity for the participating carers is shown in Table 5. In total, 40 carers (17\%) self-reported case levels of depressive symptomology (HADS depression score $\geqslant 11$ ), either with or without case levels of anxiety. This proportion is in keeping with the expected prevalence of clinical depression in family carers of PwD (expected range $0.15-0.32^{81}$ ). The proportion of carers expressing case levels of anxiety (with or without depression) was higher, with $63(27 \%)$ scoring 11 or above on the HADS anxiety scale. The mean scores on the HADS depression and anxiety subscales are comparable with those found in carers of $\mathrm{PwD}$ in day-hospital settings or in contact with community mental health teams (CMHTs). ${ }^{82}$
Baseline scores on other psychometric measures are shown in Table 6. As for the baseline demographics, the intervention and control groups were similar on all measures.

\section{Support in caring role}

It was anticipated that the availability of support for carers would depend in part on their social network. There were participating carers in each of the social network categories (Table 7), with the largest category being 'private restricted'. The private restricted network type includes individuals who have no local relative and have very little local contact or informal support.

The network typology questionnaire was also used to generate an index of social isolation based on whether or not the carer has family, friends and contact with neighbours, and whether they see any of them (family, friends and neighbours) less often than once a week. The index does not incorporate information on proximity to family (nearest family/child/sibling), frequency of interaction with family, friends and neighbours, or information on local social ties (participation in social clubs, groups or religious meetings), but has the advantage of creating an ordered scale. On the Social Isolation Index, the carer population was evenly spread across the no-isolation, low- and

TABLE 4 Multiple roles: concurrent caring and paid employment

\begin{tabular}{|c|c|c|c|c|c|c|}
\hline & \multicolumn{2}{|c|}{ Total } & \multicolumn{2}{|c|}{ Intervention } & \multicolumn{2}{|c|}{ Control } \\
\hline & $n / N$ & $\%$ & $n / N$ & $\%$ & $n / N$ & $\%$ \\
\hline Concurrent caring & $38 / 233$ & 16 & $18 / 114$ & 16 & $20 / 119$ & 17 \\
\hline $\begin{array}{l}\text { Caring for dependant under } 18 \\
\text { Employment: }\end{array}$ & $12 / 36$ & 33 & $6 / 17$ & 35 & $6 / 19$ & 32 \\
\hline Paid work & $38 / 235$ & 16 & $20 / 115$ & 17 & $18 / 120$ & 15 \\
\hline Full-time carer & $18 / 235$ & 8 & $10 / 115$ & 9 & $8 / 120$ & 7 \\
\hline
\end{tabular}

TABLE 5 HADS depression and anxiety: caseness (score $\geqslant I I$ ) and continuous data

\begin{tabular}{|c|c|c|c|c|c|c|c|c|c|}
\hline & & \multicolumn{2}{|c|}{ Total } & & \multicolumn{2}{|c|}{ Intervention } & & \multicolumn{2}{|c|}{ Control } \\
\hline & & $n / N$ & $\%$ & & $n / N$ & $\%$ & & $n / N$ & $\%$ \\
\hline Depression and anxiety & & $22 / 231$ & 9 & & $9 / 113$ & 8 & & $13 / 118$ & 11 \\
\hline Depression only & & $|8 / 23|$ & 8 & & $10 / 113$ & 8 & & $8 / 118$ & 7 \\
\hline Anxiety only & & $4 I / 23 I$ & 18 & & $20 / 113$ & 18 & & $21 / 118$ & 18 \\
\hline \multirow[t]{2}{*}{ Non-case } & & $|50 / 23|$ & 65 & & $74 / 113$ & 66 & & $76 / 118$ & 64 \\
\hline & $\mathbf{N}$ & Mean & SD & $n$ & Mean & SD & $n$ & Mean & SD \\
\hline Depression & 231 & 6.8 & 3.7 & 113 & 6.7 & 3.6 & 118 & 6.9 & 3.9 \\
\hline Anxiety & 231 & 7.7 & 4.6 & 113 & 7.5 & 4.5 & 118 & 7.9 & 4.6 \\
\hline
\end{tabular}


TABLE 6 Affectivity, loneliness, social support, coping, quality of relationship and life events: mean and SD by group

\begin{tabular}{|c|c|c|c|c|c|c|c|c|c|}
\hline & \multicolumn{3}{|c|}{ Total $(N=236)$} & \multicolumn{3}{|c|}{ Intervention $(N=116)$} & \multicolumn{3}{|c|}{ Control $(N=120)$} \\
\hline & $n$ & Mean & SD & $n$ & Mean & SD & $n$ & Mean & SD \\
\hline Negative affectivity (PANAS) & 218 & 20.63 & 8.21 & 107 & 20.13 & 8.17 & III & 21.11 & 8.25 \\
\hline Positive affectivity (PANAS) & 219 & 31.35 & 7.58 & 108 & 31.03 & 7.50 & III & 31.67 & 7.68 \\
\hline Loneliness & 227 & 2.10 & 2.20 & 112 & 2.00 & 2.20 & 115 & 2.20 & 2.20 \\
\hline Perceived social support (MSPSS) & 229 & 44.21 & 9.51 & 113 & 44.03 & 9.98 & 116 & 44.39 & 9.08 \\
\hline Active coping (COPE) & 230 & 16.62 & 6.01 & 113 & 16.59 & 5.73 & 117 & 16.64 & 6.29 \\
\hline Avoidance coping (COPE) & 230 & 7.46 & 4.40 & 113 & 7.30 & 4.21 & 117 & 7.61 & 4.59 \\
\hline Loss of companionship & 228 & 8.37 & 2.45 & 113 & 8.38 & 2.59 & 115 & 8.35 & 2.32 \\
\hline MCBS (carer towards PwD) & 228 & 16.89 & 3.19 & 111 & 16.81 & 3.08 & 117 & 16.97 & 3.29 \\
\hline MCBS (PwD towards carer) & 228 & 14.87 & 3.93 & 111 & 14.77 & 3.95 & 117 & 14.96 & 3.92 \\
\hline Quality of premorbid relationship & 229 & 3.63 & 0.65 & 112 & 3.63 & 0.65 & 117 & 3.64 & 0.64 \\
\hline Life events & 229 & 2.28 & 1.89 & 112 & 2.25 & 2.02 & 117 & 2.31 & 1.77 \\
\hline
\end{tabular}

TABLE 7 Social network (PANT) categories

\begin{tabular}{|c|c|c|c|c|c|c|}
\hline & \multicolumn{2}{|c|}{ Total $(N=230)$} & \multicolumn{2}{|c|}{ Intervention $(N=1 \mid 3)$} & \multicolumn{2}{|c|}{ Control $(N=117)$} \\
\hline & $n$ & $\%$ & $n$ & $\%$ & $n$ & $\%$ \\
\hline Family dependent & 41 & 18 & 21 & 19 & 20 & 17 \\
\hline Locally integrated & 48 & 21 & 21 & 19 & 27 & 23 \\
\hline Locally self-contained & 46 & 20 & 19 & 17 & 27 & 23 \\
\hline Wider community focused & 28 & 12 & 14 & 12 & 14 & 12 \\
\hline Private restricted & 54 & 24 & 31 & 27 & 23 & 20 \\
\hline Inconclusive & 13 & 6 & 7 & 6 & 6 & 5 \\
\hline
\end{tabular}

moderate-isolation categories, with only $22(10 \%)$ falling into the high-isolation category (Table 8 ).

Support from family and friends is summarised in Table 9. Almost one-third of participants had no support from family or friends. One-quarter had occasional support only. Just over one in five had regular support only, and a similar proportion had both regular and occasional support. Of those carers reporting details of the regular support received, the mean number of hours respite received was only 2.2 hours per week (range 0-23 hours), and the mean number of hours assistance was 8.2 hours per week (range 0-42 hours, excluding an outlier of 168 hours).
In addition to support from family and friends, carers received support and assistance from statutory, private- and voluntary-sector services. A selection of these is shown in Table 10. Carers' support services were predominantly provided by the voluntary sector, and included sitting services, informational and support groups, lunch clubs and outings. Sixty per cent of participating carers had used some form of carers' support service. In addition, $50 \%$ of care recipients had attended some form of day care (including both day centres and day hospitals). Only $26 \%$ were in receipt of assistance with home care and $24 \%$ had undertaken residential or nursing respite stays.

TABLE 8 Social isolation categories

\begin{tabular}{|c|c|c|c|c|c|c|}
\hline & \multicolumn{2}{|c|}{ Total $(N=23 \mathrm{I})$} & \multicolumn{2}{|c|}{ Intervention $(N=1 \mid 3)$} & \multicolumn{2}{|c|}{ Control $(N=118)$} \\
\hline & $n$ & $\%$ & $n$ & $\%$ & $n$ & $\%$ \\
\hline Not isolated & 74 & 32 & 36 & 32 & 38 & 32 \\
\hline Low isolation & 70 & 30 & 35 & 31 & 35 & 30 \\
\hline Moderate isolation & 65 & 28 & 32 & 28 & 33 & 28 \\
\hline High isolation & 22 & 10 & 10 & 9 & 12 & 10 \\
\hline
\end{tabular}


TABLE 9 Support from family and friends

\begin{tabular}{|c|c|c|c|c|c|c|c|c|c|}
\hline & & \multicolumn{2}{|c|}{ Total } & & \multicolumn{2}{|c|}{ Intervention } & & \multicolumn{2}{|c|}{ Control } \\
\hline & & $n / N$ & $\%$ & & $n / N$ & $\%$ & & $n / N$ & $\%$ \\
\hline Regular support only & & $49 / 226$ & 22 & & $28 / 109$ & 26 & & $21 / 117$ & 18 \\
\hline Occasional support only & & $59 / 226$ & 26 & & $26 / 109$ & 24 & & $33 / 117$ & 28 \\
\hline Both regular and occasional & & $49 / 226$ & 22 & & $16 / 109$ & 15 & & $33 / 117$ & 28 \\
\hline \multirow[t]{2}{*}{ No support } & & $69 / 226$ & 31 & & $39 / 109$ & 36 & & $30 / 117$ & 26 \\
\hline & $n$ & Mean & SD & $n$ & Mean & SD & $n$ & Mean & SD \\
\hline Respite (hours/week) & 92 & 2.2 & 4.3 & 43 & 2.2 & 4.6 & 49 & 2.2 & 4.0 \\
\hline Assistance (hours/week) & 87 & 8.2 & 19.0 & 40 & 6.5 & 7.7 & 47 & $9.6^{a}$ & $25.0^{a}$ \\
\hline
\end{tabular}

TABLE 10 Receipt of support from services

\begin{tabular}{|c|c|c|c|c|c|c|}
\hline & \multicolumn{2}{|c|}{ Total } & \multicolumn{2}{|c|}{ Intervention } & \multicolumn{2}{|c|}{ Control } \\
\hline & $n / N$ & $\%$ & $n / N$ & $\%$ & $n / N$ & $\%$ \\
\hline Carer services & $|38 / 23|$ & 60 & $71 / 113$ & 63 & $67 / 118$ & 57 \\
\hline Day care & $117 / 234$ & 50 & $58 / 114$ & 51 & $59 / 120$ & 49 \\
\hline Home care & $61 / 236$ & 26 & $29 / 116$ & 25 & $32 / 120$ & 27 \\
\hline Respite stays & $56 / 232$ & 24 & $27 / 115$ & 23 & $29 / 117$ & 25 \\
\hline
\end{tabular}

\section{Summary}

The demographic, psychometric and support variables at baseline demonstrate that the population under study is typical of carers of $\mathrm{PwD}$. Comparison of the data for the two groups (intervention and control) demonstrates the success of the use of the urban/rural and horizontal/vertical kinship stratifications.

\section{Main outcomes}

\section{Primary analysis}

The primary analysis on the ITT population did not demonstrate any evidence of an advantage of intervention over control on the HADS depression subscale (Table 11) at any time-point.

\section{Subgroup analyses}

The primary analysis was repeated for two subgroups: first, an analysis of the subgroup of spouse carers $(N=158 ; 83$ control and 75 intervention) and, secondly, a per-protocol analysis comparing those intervention carers who are known to have been matched with a befriender for at least 6 months before the 15 -month interview $(N=37)$ and control carers known not to have had a befriender $(N=177)$.
There is no evidence to suggest a benefit of intervention compared with control for spouse carers (Table 12). However, results of the perprotocol analysis (Table 13) show a marginally significant difference in favour of intervention at 15 months.

\section{Secondary analyses}

There is no evidence of any benefit of the intervention with respect to any of the secondary outcomes (HADS anxiety subscale, loneliness, positive affectivity and the global VAS score of the EQ-5D) at any time-point (Tables 14-17).

\section{Admission to long-term care}

As disabilities increase for the $\mathrm{PwD}$, the level of dependency on family carers can become unsustainable, and a common outcome is for the person with dementia to move into residential or nursing accommodation, or into NHS continuing care, where such facilities still exist. Whereas all care recipients were living at home at baseline, 32 care recipients had been admitted to permanent care (institutionalised) at 15-month follow-up (Figure 2). The proportion of PwD still in home care was compared with those institutionalised by each time-point (Table 18). Those carers for whom the PwD had died were removed from the analysis. As for other secondary analyses, there is no evidence of any advantage of the intervention over control. 
TABLE II HADS depression subscale: primary analysis

\begin{tabular}{|c|c|c|c|c|}
\hline & $\begin{array}{c}\text { Control } \\
(N=120)\end{array}$ & $\begin{array}{c}\text { Intervention } \\
(N=116)\end{array}$ & Unadjusted analysis $^{b}$ & Adjusted analysis $^{c}$ \\
\hline $\begin{array}{l}\text { Baseline } \\
n \\
\text { Mean (SD) }\end{array}$ & $\begin{array}{c}118^{a} \\
6.96(3.94)\end{array}$ & $\begin{array}{c}113^{a} \\
6.73(3.62)\end{array}$ & & \\
\hline $\begin{array}{l}6 \text { months } \\
n \\
\text { Mean (SD) }\end{array}$ & $\begin{array}{c}113 \\
5.84(3.96)\end{array}$ & $\begin{array}{c}104 \\
6.03(3.63)\end{array}$ & $\begin{array}{c}-0.193 \\
(-1.21 \text { to } 0.83) \\
p=0.709\end{array}$ & $\begin{array}{c}-0.485 \\
(-1.23 \text { to } 0.26) \\
p=0.201\end{array}$ \\
\hline $\begin{array}{l}15 \text { months } \\
n \\
\text { Mean (SD) }\end{array}$ & $\begin{array}{c}106 \\
6.71(4.18)\end{array}$ & $\begin{array}{c}96 \\
6.03(4.00)\end{array}$ & $\begin{array}{c}0.676 \\
(-0.46 \text { to } I .8 I) \\
p=0.24 I\end{array}$ & $\begin{array}{c}0.468 \\
(-0.50 \text { to } 1.44) \\
p=0.342\end{array}$ \\
\hline $\begin{array}{l}24 \text { months } \\
n \\
\text { Mean (SD) }\end{array}$ & $\begin{array}{c}97 \\
6.35(4.59)\end{array}$ & $\begin{array}{c}93 \\
6.25(4.12)\end{array}$ & $\begin{array}{c}0.103 \\
(-1.15 \text { to } 1.35) \\
p=0.87 \mid\end{array}$ & $\begin{array}{c}-0.207 \\
(-1.32 \text { to } 0.90) \\
p=0.713\end{array}$ \\
\hline
\end{tabular}

TABLE 12 HADS depression subscale: spouse carers

\begin{tabular}{|c|c|c|c|c|}
\hline & $\begin{array}{l}\text { Control } \\
(N=83)\end{array}$ & $\begin{array}{l}\text { Intervention } \\
\quad(N=75)\end{array}$ & Unadjusted analysis $^{b}$ & Adjusted analysis $^{c}$ \\
\hline $\begin{array}{l}\text { Baseline } \\
n \\
\text { Mean (SD) }\end{array}$ & $\begin{array}{c}82^{a} \\
6.90(3.94)\end{array}$ & $\begin{array}{c}75 \\
7.07(3.48)\end{array}$ & & \\
\hline $\begin{array}{l}6 \text { months } \\
n \\
\text { Mean (SD) }\end{array}$ & $\begin{array}{c}78 \\
5.88(3.81)\end{array}$ & $\begin{array}{c}68 \\
6.30(3.7 I)\end{array}$ & $\begin{array}{c}-0.427 \\
(-1.66 \text { to } 0.8 I) \\
p=0.495\end{array}$ & $\begin{array}{c}-0.309 \\
(-1.20 \text { to } 0.58) \\
p=0.492\end{array}$ \\
\hline $\begin{array}{l}\text { I5 months } \\
n \\
\text { Mean (SD) }\end{array}$ & $\begin{array}{c}73 \\
6.48(4.09)\end{array}$ & $\begin{array}{c}60 \\
6.43(4.24)\end{array}$ & $\begin{array}{c}0.043 \\
(-1.39 \text { to } 1.48) \\
p=0.952\end{array}$ & $\begin{array}{c}0.269 \\
(-0.93 \text { to } 1.47) \\
p=0.659\end{array}$ \\
\hline $\begin{array}{l}24 \text { months } \\
n \\
\text { Mean (SD) }\end{array}$ & $\begin{array}{c}69 \\
6.91(4.80)\end{array}$ & $\begin{array}{c}57 \\
6.46(4.05)\end{array}$ & $\begin{array}{c}0.457 \\
(-1.13 \text { to } 2.04) \\
p=0.570\end{array}$ & $\begin{array}{c}0.493 \\
(-0.87 \text { to } 1.85) \\
p=0.474\end{array}$ \\
\hline
\end{tabular}


TABLE 13 HADS depression subscale: per protocol

\begin{tabular}{|c|c|c|c|c|}
\hline & $\begin{array}{l}\text { Control } \\
(N=117)\end{array}$ & $\begin{array}{c}\text { Intervention } \\
(N=37)\end{array}$ & Unadjusted analysis $^{b}$ & Adjusted analysis $^{c}$ \\
\hline $\begin{array}{l}\text { Baseline } \\
n \\
\text { Mean (SD) }\end{array}$ & $\begin{array}{c}115^{a} \\
6.98(3.95)\end{array}$ & $\begin{array}{c}36^{a} \\
6.86(3.54)\end{array}$ & & \\
\hline $\begin{array}{l}6 \text { months } \\
n \\
\text { Mean (SD) }\end{array}$ & $\begin{array}{c}111 \\
5.86(3.97)\end{array}$ & $\begin{array}{c}34 \\
5.47(3.37)\end{array}$ & $\begin{array}{c}0.383 \\
(-I . I I \text { to } I .87) \\
p=0.6 \mid 2\end{array}$ & $\begin{array}{c}0.107 \\
(-1.00 \text { to } 1.2 \mid) \\
p=0.848\end{array}$ \\
\hline $\begin{array}{l}15 \text { months } \\
n \\
\text { Mean (SD) }\end{array}$ & $\begin{array}{c}104 \\
6.75(4.21)\end{array}$ & $\begin{array}{c}31 \\
5.06(3.45)\end{array}$ & $\begin{array}{c}1.684 \\
(0.04 \text { to } 3.32) \\
p=0.044\end{array}$ & $\begin{array}{c}\mathrm{I} .377 \\
(-0.09 \text { to } 2.84) \\
p=0.066\end{array}$ \\
\hline $\begin{array}{l}24 \text { months } \\
n \\
\text { Mean (SD) }\end{array}$ & $\begin{array}{c}95 \\
6.37(4.63)\end{array}$ & $\begin{array}{c}30 \\
4.97(4.11)\end{array}$ & $\begin{array}{c}1.402 \\
(-0.47 \text { to } 3.27) \\
p=0.140\end{array}$ & $\begin{array}{c}\mathrm{I} .038 \\
(-0.63 \text { to } 2.7 \mathrm{I}) \\
p=0.220\end{array}$ \\
\hline
\end{tabular}

TABLE I4 HADS anxiety subscale

\begin{tabular}{|c|c|c|c|c|}
\hline & $\begin{array}{c}\text { Control } \\
(N=120)\end{array}$ & $\begin{array}{l}\text { Intervention } \\
(N=116)\end{array}$ & Unadjusted analysis $^{b}$ & Adjusted analysis $^{c}$ \\
\hline $\begin{array}{l}\text { Baseline } \\
n \\
\text { Mean (SD) }\end{array}$ & $\begin{array}{c}118^{a} \\
7.97(4.68)\end{array}$ & $\begin{array}{c}113^{a} \\
7.55(4.58)\end{array}$ & & \\
\hline $\begin{array}{l}6 \text { months } \\
n \\
\text { Mean (SD) }\end{array}$ & $\begin{array}{c}113 \\
6.96(4.37)\end{array}$ & $\begin{array}{c}104 \\
6.35(4.46)\end{array}$ & $\begin{array}{c}0.610 \\
(-0.57 \text { to } 1.79) \\
p=0.311\end{array}$ & $\begin{array}{c}0.218 \\
(-0.43 \text { to } 0.97) \\
p=0.568\end{array}$ \\
\hline $\begin{array}{l}15 \text { months } \\
n \\
\text { Mean (SD) }\end{array}$ & $\begin{array}{c}106 \\
7.55(4.47)\end{array}$ & $\begin{array}{c}96 \\
6.55(4.54)\end{array}$ & $\begin{array}{c}1.005 \\
(-0.25 \text { to } 2.26) \\
p=0.115\end{array}$ & $\begin{array}{c}0.610 \\
(-0.33 \text { to } 1.55) \\
p=0.200\end{array}$ \\
\hline $\begin{array}{l}24 \text { months } \\
n \\
\text { Mean (SD) }\end{array}$ & $\begin{array}{c}97 \\
6.97(4.50)\end{array}$ & $\begin{array}{c}93 \\
6.55(4.49)\end{array}$ & $\begin{array}{c}0.4 I 9 \\
(-0.87 \text { to } I .7 I) \\
p=0.52 I\end{array}$ & $\begin{array}{c}-0.037 \\
(-1.10 \text { to } 1.03) \\
p=0.946\end{array}$ \\
\hline $\begin{array}{l}{ }^{a} \text { Baseline d } \\
b^{b} \text { Based on } \\
{ }^{c} \text { Based on }\end{array}$ & $\begin{array}{l}\text { rol and thre } \\
\text {, kinship an }\end{array}$ & $\begin{array}{l}\text { vention subject } \\
\text { ine HADS scor }\end{array}$ & & \\
\hline
\end{tabular}


TABLE I5 PANAS: positive affect

\begin{tabular}{|c|c|c|c|c|}
\hline & $\begin{array}{c}\text { Control } \\
(N=120)\end{array}$ & $\begin{array}{l}\text { Intervention } \\
(N=116)\end{array}$ & Unadjusted analysis $^{b}$ & Adjusted analysis $^{c}$ \\
\hline $\begin{array}{l}\text { Baseline } \\
n \\
\text { Mean (SD) }\end{array}$ & $\begin{array}{c}111^{a} \\
31.7(4.68)\end{array}$ & $\begin{array}{c}108^{a} \\
31.0(7.50)\end{array}$ & & \\
\hline $\begin{array}{l}6 \text { months } \\
n \\
\text { Mean (SD) }\end{array}$ & $\begin{array}{c}111 \\
31.5(8.31)\end{array}$ & $\begin{array}{c}103 \\
30.1(8.13)\end{array}$ & $\begin{array}{c}\mathrm{I} .40 \\
(-0.82 \text { to } 3.62) \\
p=0.2 \mid 4\end{array}$ & $\begin{array}{c}0.922 \\
(-0.98 \text { to } 2.83) \\
p=0.34 I\end{array}$ \\
\hline $\begin{array}{l}15 \text { months } \\
n \\
\text { Mean (SD) }\end{array}$ & $\begin{array}{c}106 \\
30.5(8.02)\end{array}$ & $\begin{array}{c}96 \\
30.5(8.22)\end{array}$ & $\begin{array}{c}0.03 \\
(-2.22 \text { to } 2.29) \\
p=0.976\end{array}$ & $\begin{array}{c}-0.079 \\
(-2.13 \text { to } 1.97) \\
p=0.940\end{array}$ \\
\hline $\begin{array}{l}24 \text { months } \\
n \\
\text { Mean (SD) }\end{array}$ & $\begin{array}{c}95 \\
31.2(8.34)\end{array}$ & 30.12 & $\begin{array}{c}1.10 \\
(-1.36 \text { to } 3.57) \\
p=0.378\end{array}$ & $\begin{array}{c}1.17 \\
(-1.26 \text { to } 3.59) \\
p=0.344\end{array}$ \\
\hline
\end{tabular}

TABLE I6 Loneliness scale

\begin{tabular}{|c|c|c|c|c|}
\hline & $\begin{array}{l}\text { Control } \\
(N=120)\end{array}$ & $\begin{array}{l}\text { Intervention } \\
(N=116)\end{array}$ & Unadjusted analysis $^{b}$ & Adjusted analysis $^{c}$ \\
\hline $\begin{array}{l}\text { Baseline } \\
n \\
\text { Mean (SD) }\end{array}$ & $\begin{array}{c}115^{a} \\
2.29(2.21)\end{array}$ & $\begin{array}{c}112^{a} \\
2.07(2.28)\end{array}$ & & \\
\hline $\begin{array}{l}6 \text { months } \\
n \\
\text { Mean (SD) }\end{array}$ & $\begin{array}{c}\mathrm{II} 2 \\
2.21(2.2 \mathrm{I})\end{array}$ & $\begin{array}{c}104 \\
2.06(2.04)\end{array}$ & $\begin{array}{c}0.148 \\
(-0.42 \text { to } 0.72) \\
p=0.611\end{array}$ & $\begin{array}{c}0.016 \\
(-0.41 \text { to } 0.45) \\
p=0.945\end{array}$ \\
\hline $\begin{array}{l}15 \text { months } \\
n \\
\text { Mean (SD) }\end{array}$ & $\begin{array}{c}106 \\
2.57(2.23)\end{array}$ & $\begin{array}{c}96 \\
2.21 \\
(2.27)\end{array}$ & $\begin{array}{c}0.358 \\
(-0.27 \text { to } 0.98) \\
p=0.260\end{array}$ & $\begin{array}{c}0.320 \\
(-0.20 \text { to } 0.84) \\
p=0.230\end{array}$ \\
\hline $\begin{array}{l}24 \text { months } \\
n \\
\text { Mean (SD) }\end{array}$ & $\begin{array}{c}97 \\
2.63(2.30)\end{array}$ & $\begin{array}{c}93 \\
2.24(2.39)\end{array}$ & $\begin{array}{c}0.392 \\
(-0.28 \text { to } 1.06) \\
p=0.251\end{array}$ & $\begin{array}{c}0.173 \\
(-0.37 \text { to } 0.72) \\
p=0.529\end{array}$ \\
\hline
\end{tabular}


TABLE I7 EQ-5D global VAS

\begin{tabular}{|c|c|c|c|c|}
\hline & $\begin{array}{c}\text { Control } \\
(N=120)\end{array}$ & $\begin{array}{l}\text { Intervention } \\
(N=116)\end{array}$ & Unadjusted analysis $^{b}$ & Adjusted analysis $^{c}$ \\
\hline $\begin{array}{l}\text { Baseline } \\
n \\
\text { Mean (SD) }\end{array}$ & $\begin{array}{c}114^{a} \\
73.1(18.1)\end{array}$ & $\begin{array}{c}112^{a} \\
74.0(16.8)\end{array}$ & & \\
\hline $\begin{array}{l}6 \text { months } \\
n \\
\text { Mean (SD) }\end{array}$ & $\begin{array}{c}112 \\
72.9(17.7)\end{array}$ & $\begin{array}{c}I 0 \mid \\
75.7(17.0)\end{array}$ & $\begin{array}{c}-2.8 \mathrm{I} \\
(-7.5 \mathrm{I} \text { to } 1.89) \\
p=0.240\end{array}$ & $\begin{array}{c}-2.06 \\
(-5.5 \mid \text { to } I .38) \\
p=0.239\end{array}$ \\
\hline $\begin{array}{l}15 \text { months } \\
n \\
\text { Mean (SD) }\end{array}$ & $\begin{array}{c}106 \\
69.9(18.1)\end{array}$ & $\begin{array}{c}95 \\
73.8(18.3)\end{array}$ & $\begin{array}{c}-3.87 \\
(-8.94 \text { to } 1.19) \\
p=0.133\end{array}$ & $\begin{array}{c}-2.33 \\
(-6.88 \text { to } 2.23) \\
p=0.315\end{array}$ \\
\hline $\begin{array}{l}24 \text { months } \\
n \\
\text { Mean (SD) }\end{array}$ & $\begin{array}{c}96 \\
68.1(18.2)\end{array}$ & $\begin{array}{c}92 \\
72.5(19.7)\end{array}$ & $\begin{array}{c}-4.35 \\
(-9.82 \text { to } 1.11) \\
p=0.119\end{array}$ & $\begin{array}{c}-3.03 \\
(-8.42 \text { to } 2.35) \\
p=0.268\end{array}$ \\
\hline
\end{tabular}

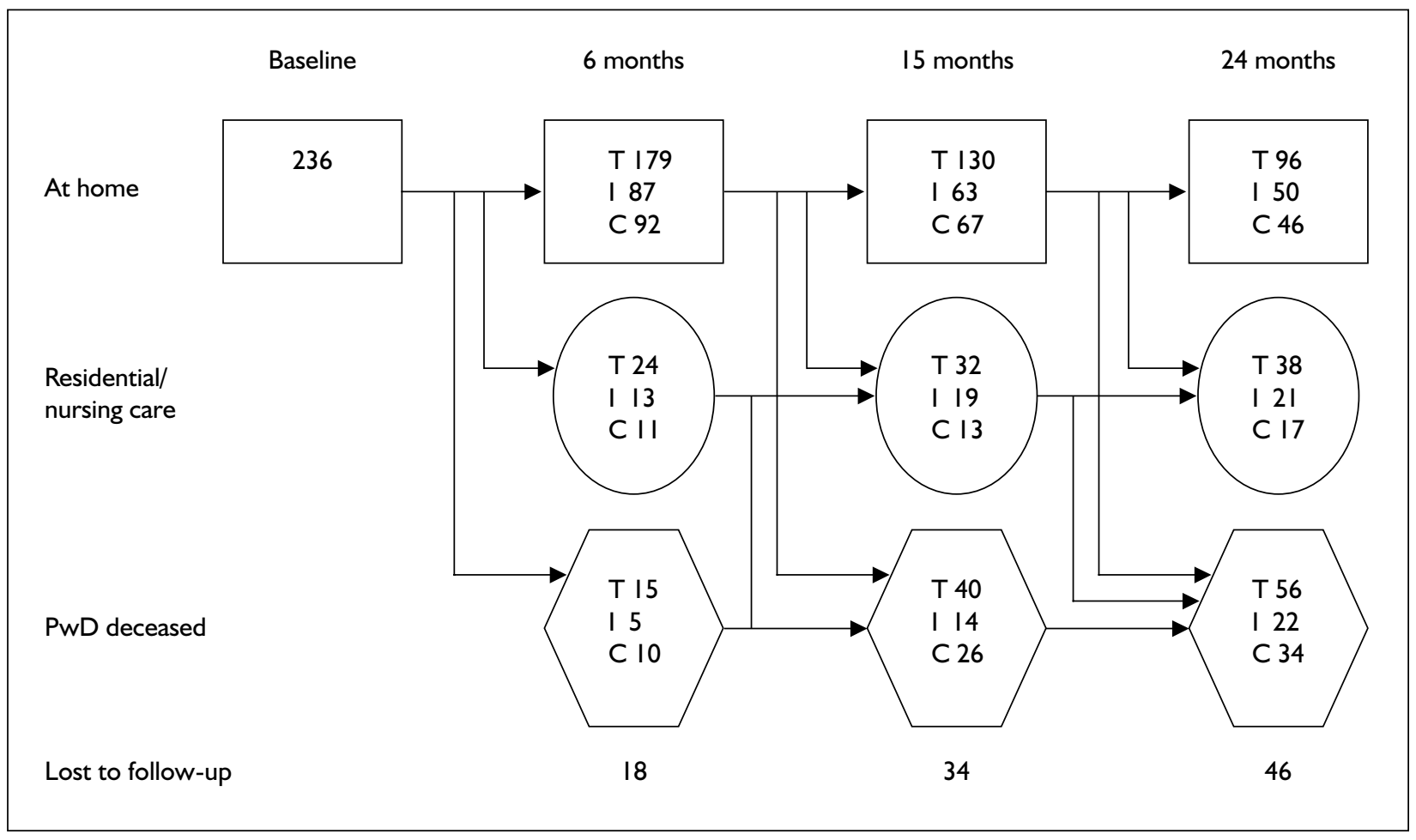

FIGURE 2 Status of PwD at each follow-up. C, control group; I, intervention group; T, total. 
TABLE 18 Location of PwD by 6, 15 or 24 months

\begin{tabular}{|c|c|c|c|c|}
\hline & $\begin{array}{l}\text { Control } \\
(N=116)\end{array}$ & $\begin{array}{l}\text { Intervention } \\
(N=120)\end{array}$ & Unadjusted analysis ${ }^{b}$ & Adjusted analysis $^{c}$ \\
\hline $\begin{array}{l}6 \text { months } \\
N^{a} \\
\text { PwD at home }\end{array}$ & $\begin{array}{c}103 \\
92(89 \%)\end{array}$ & $\begin{array}{c}100 \\
87(87 \%)\end{array}$ & $\begin{array}{c}O R=1.25 \\
(0.53 \text { to } 2.94) \\
p=0.609\end{array}$ & $\begin{array}{c}O R=1.18 \\
(0.49 \text { to } 2.86) \\
p=0.717\end{array}$ \\
\hline $\begin{array}{l}15 \text { months } \\
N^{a} \\
\text { PwD at home }\end{array}$ & $\begin{array}{c}80 \\
67(83 \%)\end{array}$ & $\begin{array}{c}82 \\
63(77 \%)\end{array}$ & $\begin{array}{c}O R=1.42 \\
(0.66 \text { to } 3.08) \\
p=0.372\end{array}$ & $\begin{array}{c}O R=I .4 I \\
(0.65 \text { to } 3.08) \\
p=0.388\end{array}$ \\
\hline $\begin{array}{l}24 \text { months } \\
N^{a} \\
\text { PwD at home }\end{array}$ & $\begin{array}{c}63 \\
46(73 \%)\end{array}$ & $\begin{array}{c}71 \\
50(70 \%)\end{array}$ & $\begin{array}{c}O R=1.14 \\
(0.53 \text { to } 2.42) \\
p=0.740\end{array}$ & $\begin{array}{c}O R=1.05 \\
(0.48 \text { to } 2.26) \\
p=0.911\end{array}$ \\
\hline
\end{tabular}





\section{Chapter 5}

\section{Results: overall costs and economic analysis}

\section{Costs}

Total costs are summarised in Table 19. Full cost tables and quantities are in Appendices 3 and 4.

\section{Quality-adjusted life-years}

Total QALYs gained for the intervention and control for carers, PwD and the sum of each are presented in Table 20.

\section{Cost-utility analysis}

The total cost from a societal point of view was $£ 1813$ greater in the intervention arm, although this was not statistically significant. The quality of life of the carer was slightly higher at +0.017 QALYs, although this was not statistically significant either (Table 21). Based on these point estimates, the extra cost per extra QALY gained is $£ 105,954$.

TABLE 19 Total cost summary at 15 months per participating carer ( $E$ sterling 2005 prices; 105 intervention; I / 3 control)

\begin{tabular}{|c|c|c|c|c|c|}
\hline & Mean & Median & Max. & Min. & SD \\
\hline \multicolumn{6}{|c|}{ Intervention cost } \\
\hline Intervention & $€ \mathrm{EI}, 138$ & $£ 907$ & $€ 1,722$ & $£ 589$ & $£ 395$ \\
\hline Control $^{a}$ & $E I I$ & E0 & 6318 & E0 & 665 \\
\hline \multicolumn{6}{|c|}{ PwD and carer resource use } \\
\hline Intervention & $£ 13,580$ & $£ 8,839$ & $£ 48,47 \mid$ & $E 1,113$ & $E 13,426$ \\
\hline Control & f13,583 & $£ 10,427$ & $£ 43,758$ & $£ 2,482$ & f12,037 \\
\hline \multicolumn{6}{|c|}{ PwD care following admission to care/nursing home } \\
\hline Intervention & $£ 4,176$ & E0 & $€ 44,205$ & Ło & $£ 12,306$ \\
\hline Control & $€ 2,174$ & E0 & $£ 34,826$ & E0 & $€ 7,894$ \\
\hline \multicolumn{6}{|c|}{ Miscellaneous other costs } \\
\hline Intervention & $€ 374$ & E0 & $€ 2,283$ & EO & $€ 2,080$ \\
\hline Control & f166 & E0 & $\notin 1,299$ & E0 & $£ 714$ \\
\hline \multicolumn{6}{|c|}{ Time spent caring for PwD by carer and family and friends, and time spent befriending } \\
\hline Intervention & $\neq 103,398$ & $f \mid 19,322$ & $€ 153,288$ & $€ 10,118$ & $£ 46,625$ \\
\hline Control & $f 104,918$ & $f \mid 22,176$ & $£ 151,230$ & $£ 9,455$ & $£ 46,708$ \\
\hline \multicolumn{6}{|l|}{ Grand total } \\
\hline $\begin{array}{l}\text { Intervention } \\
\text { Control }\end{array}$ & $\epsilon \mid 20,852$ & t 134,852 & $£ 203,977$ & $£ 22,014$ & $£ 45,778$ \\
\hline
\end{tabular}

TABLE 20 QALYs (based on EQ-5D) at 15 months

\begin{tabular}{lccrrr} 
& Mean & Median & Max. & Min. & SD \\
\hline $\begin{array}{l}\text { Carer QALYs } \\
\text { Intervention }\end{array}$ & 0.946 & 0.980 & 1.270 & -0.020 & 0.245 \\
Control & 0.929 & 0.980 & 1.250 & 0.010 & 0.260 \\
PwD QALYs & & & & \\
Intervention & 0.365 & 0.330 & 1.070 & -0.330 & 0.292 \\
Control & 0.314 & 0.290 & 1.040 & -0.450 & 0.317 \\
Carer + PwD QALYs & & & & & \\
Intervention & 1.311 & 1.330 & 2.150 & 0.088 & 0.416 \\
Control & 1.243 & 1.270 & 2.283 & -0.320 & 0.449 \\
\hline
\end{tabular}


TABLE 2 I Cost-utility analysis (societal perspective, 15-month time-horizon, carer quality of life only)

\begin{tabular}{|lccc|}
\hline & f/carer-PwD & QALYs/carer & ICER \\
\hline Intervention & $£ \mid 22,665$ & 0.946 & \\
Control & $£ \mid 20,852$ & 0.929 & \\
Increment & $£|, 8| 3$ & 0.017 & $£ \mid 05,954$ \\
(95\% Cl of increment, from bootstrap) & $(-£||, 3 \mid 2$ to $£ \mid 4,984)$ & $(-0.05 \mid$ to 0.083$)$ & NA \\
\hline
\end{tabular}

The scatterplot of bootstrapped increments in cost and QALYs (Figure 3) shows points in all four quadrants of the cost-effectiveness plane, although the majority are to the east of the $y$-axis, and somewhat to the north of the $x$-axis, suggesting a trend towards befriending being both more effective and more expensive than control. The resulting CEAC (Figure 4) suggests only a $42.2 \%$ probability that the ICER is below a typical willingness to pay of $£ 30,000$ per QALY gained.

An alternative means of presenting these results is as a net monetary benefit chart (Figure 5). This suggests that there is unlikely to be a net benefit from the intervention, even when the willingness to pay for a QALY is above $£ 100,000$. However, there is a wide confidence interval around the point estimates.

\section{Alternative scenarios}

\section{Varying perspectives}

A comparison of the results from the perspectives of the statutory sector, voluntary sector and household sectors is shown in Table 22.

The societal perspective costs are much higher than the statutory, voluntary or household costs, as societal costs include the indirect costs valuing carers', family and friends' time, which are the biggest single component of resource input, when valued as described earlier (see Table 19).

It should be noted that none of the cost or QALY differences reached statistical significance at a level of $95 \%$. Nevertheless, the intervention appears to show a trend towards being slightly

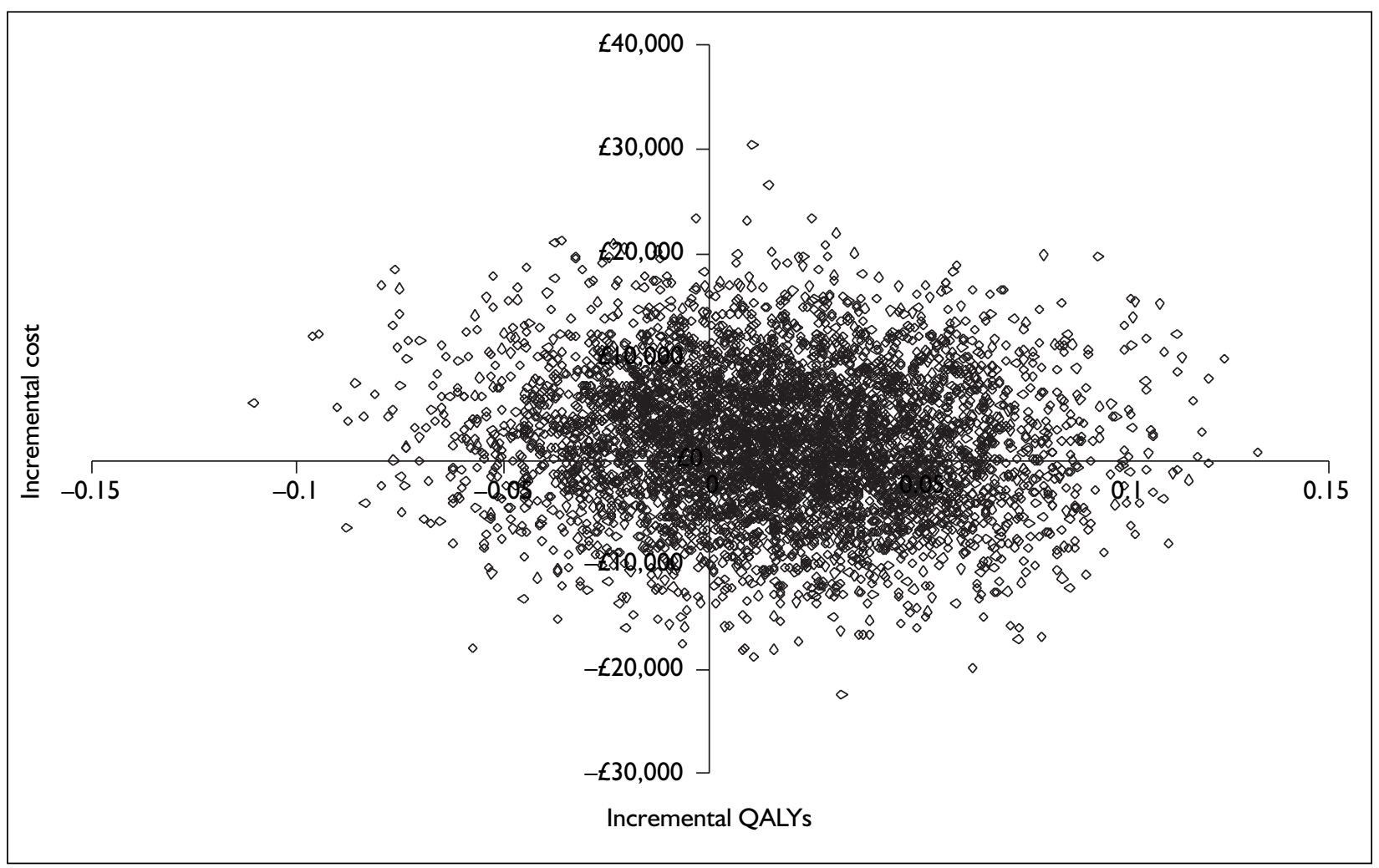

FIGURE 3 Scatterplot of increments (societal perspective, 15-month time-horizon, carer quality of life only) 


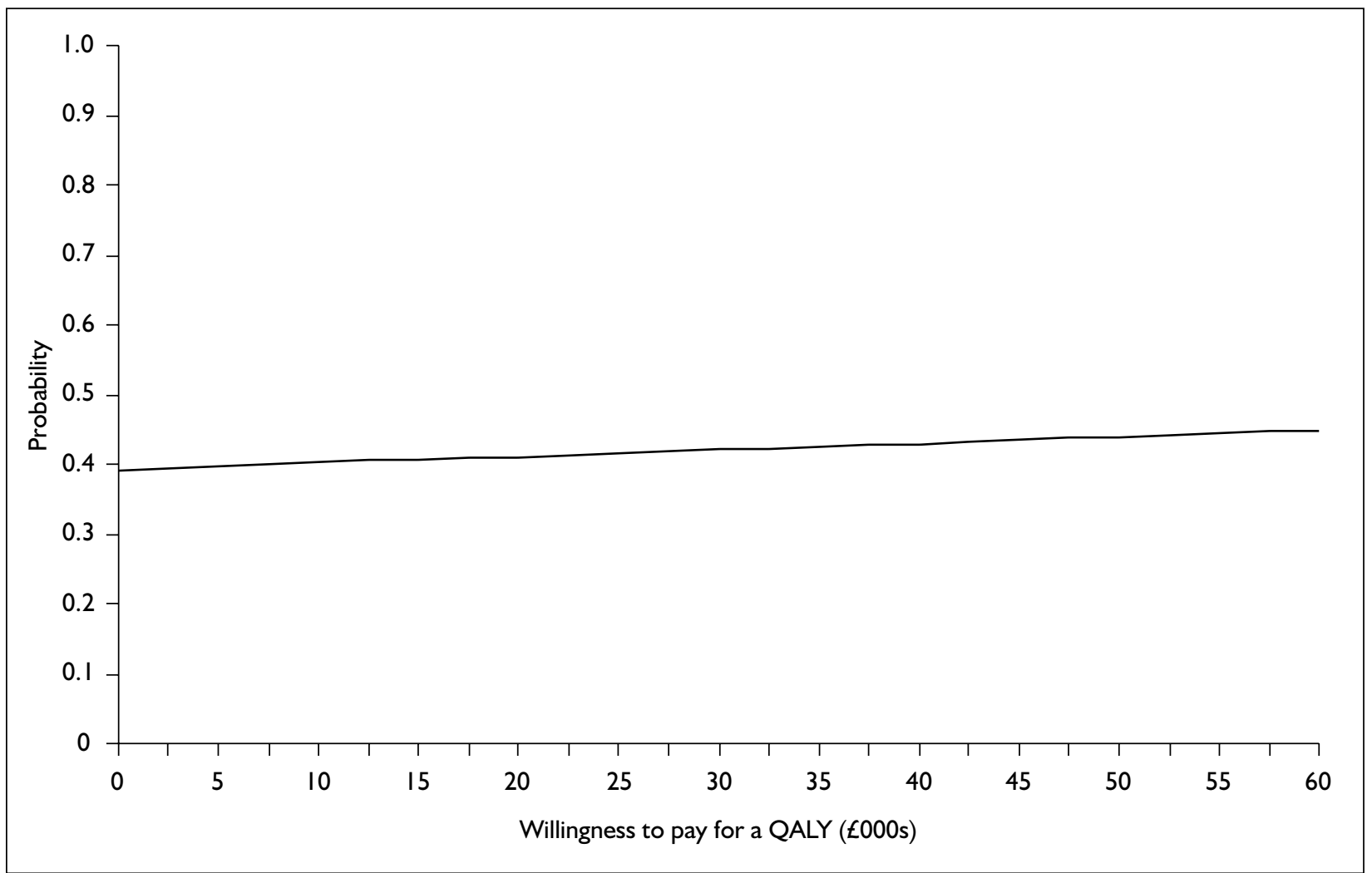

FIGURE 4 CEAC (societal perspective, 15-month time-horizon, carer quality of life only)

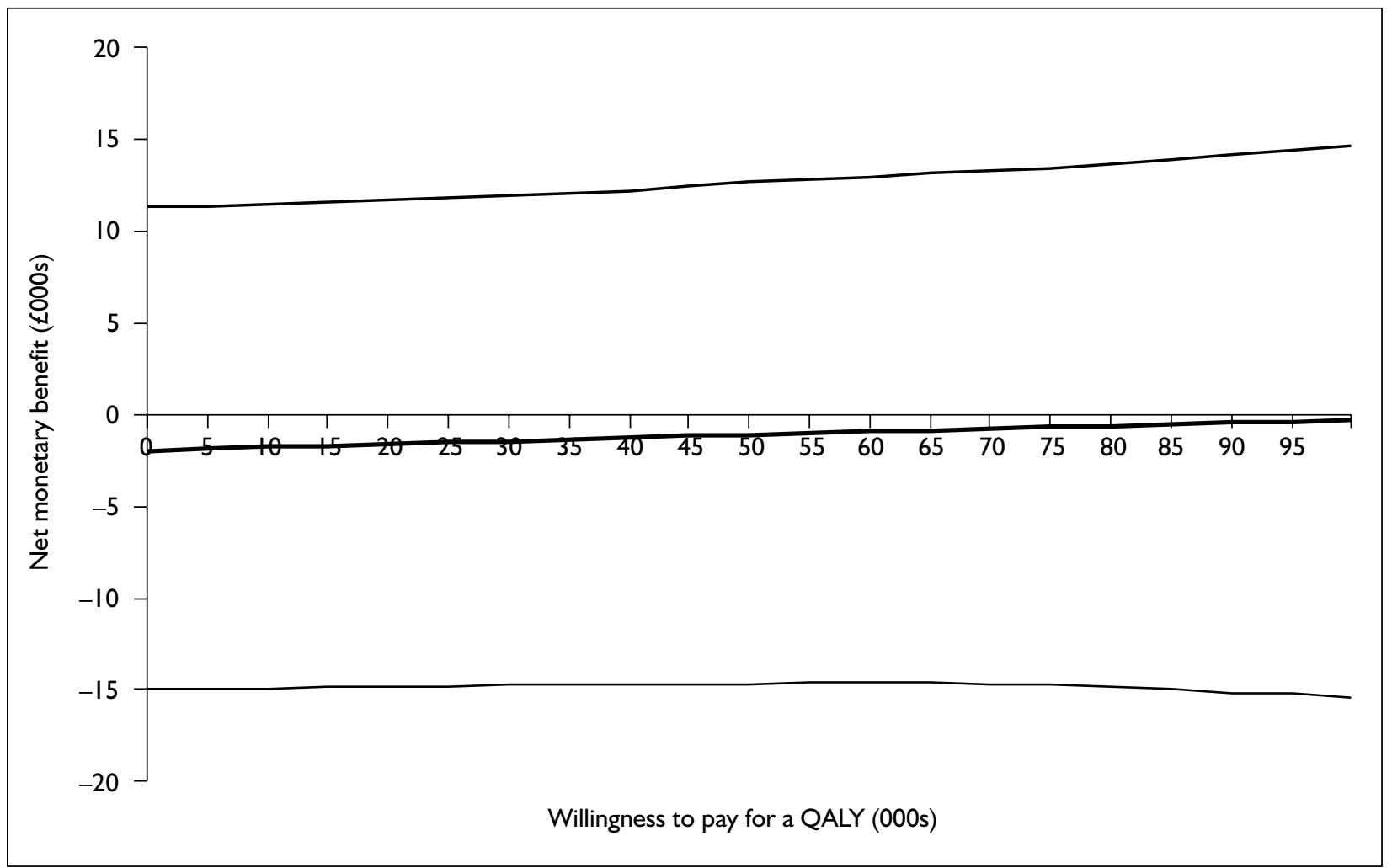

FIGURE 5 Net monetary benefit per carer-PwD (mean and 95\% Cl, societal perspective, 15-month time-horizon, carer quality of life only)

(c) Queen's Printer and Controller of HMSO 2008. All rights reserved. 
TABLE 22 Cost-utility analysis from societal, statutory, voluntary and household perspectives (15-month time-horizon, carer quality of life only)

\begin{tabular}{|c|c|c|c|c|c|c|c|c|}
\hline \multirow[b]{2}{*}{ Perspective } & \multicolumn{2}{|c|}{ Cost } & \multicolumn{2}{|c|}{ Carer QALYs } & \multicolumn{2}{|c|}{ Increments $(95 \% \mathrm{Cl})$} & \multirow[t]{2}{*}{ ICER } & \multirow{2}{*}{$\begin{array}{l}p \text { (cost- } \\
\text { effective) }\end{array}$} \\
\hline & Intervention & Control & Intervention & Control & Cost & QALYs $^{b}$ & & \\
\hline $\begin{array}{l}\text { Societal } \\
\text { (basecase) }\end{array}$ & $f \mid 22,665$ & $E \mid 20,852$ & 0.946 & 0.929 & $\begin{array}{c}\qquad|, 8| 3 \\
(-£|I, 3| 2 \text { to } \\
\qquad \mid 4,984)\end{array}$ & $\begin{array}{c}0.017 \\
(-0.051 \text { to } \\
0.083)\end{array}$ & $E 105,954$ & $42.2 \%$ \\
\hline Statutory & $E \mid 3,740$ & $E \mid I, 737$ & 0.946 & 0.929 & $\begin{array}{c}£ 2,003 \\
(-£ 1,981 \text { to } \\
£ 6,884)\end{array}$ & $\begin{array}{c}0.017 \\
(-0.049 \text { to } \\
0.084)\end{array}$ & $f 117,039$ & $29.4 \%$ \\
\hline Voluntary & $€ 716$ & $€ 707$ & 0.946 & 0.929 & $\begin{array}{c}£ 9 \\
(-£ 418 \text { to } \\
£ 44 I)\end{array}$ & $\begin{array}{c}0.017 \\
(-0.052 \text { to } \\
0.087)\end{array}$ & $€ 521$ & $69.9 \%$ \\
\hline Household & $£ 4,811$ & $£ 3,489$ & 0.946 & 0.929 & $\begin{array}{c}£ 1,322 \\
(-£ 655 \text { to } \\
£ 3,147)\end{array}$ & $\begin{array}{c}0.017 \\
(-0.048 \text { to } \\
0.086)\end{array}$ & $£ 77,236$ & $29.8 \%$ \\
\hline
\end{tabular}

more costly than the control from all perspectives. Given a typical willingness to pay of $£ 30,000$ per QALY gained, there is a less than $50 \%$ probability that befriending is 'cost-effective' from every perspective except for the voluntary sector. This is because the voluntary sector bears only a small proportion of the total costs. Note that this analysis only includes direct costs borne by the voluntary sector. The value of volunteers' time in caring and befriending (indirect cost) is incorporated in the societal perspective.

\section{Varying time-horizon}

As the time-horizon extends, the cost-effectiveness of the befriending intervention deteriorates
(Table 23). This is because while the QALY increment increases over time, the cost increment increases at a faster rate, and thus the costeffectiveness deteriorates. In general, a longer time-horizon is preferable to a shorter one as it allows for longer term costs and benefits to be accrued. These results suggest that over the longer term, befriending is not cost-effective at conventional thresholds.

\section{Complete case analysis}

The results from the complete case analysis are in marked contrast to the imputed analysis results, suggesting a positive cost-effectiveness ratio (the intervention is both less costly and

TABLE 23 Cost-utility analysis from a societal perspective at 6, 15 and 24 months

\begin{tabular}{|c|c|c|c|c|c|c|c|c|}
\hline \multirow{2}{*}{$\begin{array}{l}\text { Time- } \\
\text { horizon }\end{array}$} & \multicolumn{2}{|c|}{ Cost } & \multicolumn{2}{|c|}{ Carer QALYs } & \multicolumn{2}{|c|}{ Increments $(95 \% \mathrm{Cl})$} & \multirow[t]{2}{*}{ ICER } & \multirow{2}{*}{$\begin{array}{c}p \text { (cost- } \\
\text { effective) }\end{array}$} \\
\hline & Intervention & Control & Intervention & Control & Cost & QALYs & & \\
\hline 6 months & $£ 54,509$ & $£ 54,854$ & 0.388 & 0.379 & $\begin{array}{c}-£ 344 \\
(-£ 5,155 \text { to } \\
£ 4,465)\end{array}$ & $\begin{array}{c}0.008 \\
(-0.017 \text { to } \\
0.034)\end{array}$ & $-£ 40,996$ & $59.6 \%$ \\
\hline $\begin{array}{l}\text { I5 months } \\
\text { (basecase) }\end{array}$ & $E \mid 22,665$ & $f \mid 20,852$ & 0.946 & 0.929 & $\begin{array}{c}£|, 8| 3 \\
(-£|I, 3| 2 \text { to } \\
£ \mid 4,984)\end{array}$ & $\begin{array}{c}0.017 \\
(-0.051 \text { to } \\
0.083)\end{array}$ & $f 105,954$ & $42.2 \%$ \\
\hline 24 months & $\epsilon \mid 88,683$ & $E \mid 79,492$ & 1.474 & 1.450 & $\begin{array}{c}£ 9,191 \\
(-£ 7,864 \text { to } \\
£ 26,377)\end{array}$ & $\begin{array}{c}0.024 \\
(-0.083 \text { to } \\
0.136)\end{array}$ & $£ 380,939$ & $17.2 \%$ \\
\hline
\end{tabular}


more effective than control, with $87.7 \%$ probability that the ICER is below $£ 30,000$ per QALY gained) (Table 24). However, these results are based on only 61 observations (versus 218 in the imputed data set), and are likely biased owing to potential correlations between health status (and hence resource use) and probability of providing complete responses to all questions.

\section{Incorporating PwD quality of life}

When the quality of life of the PwD is taken into account as well as that of the carer, the point estimate ICER is $£ 26,848$, which is within the conventionally accepted threshold of costeffectiveness (Table 25). Taking into account uncertainty, the authors estimate a $51.4 \%$ probability that the ICER is below $£ 30,000$ per QALY gained. Therefore, when including PwD quality of life too, befriending may be a cost-effective intervention.

\section{Summary of cost-effectiveness analyses}

There are trends towards both increased quality of life and higher costs to society among carers randomised to intervention, although neither trend is statistically significant. The point estimate of the ICER is $£ 106,000$ per QALY gained. This is above conventionally accepted thresholds of costeffectiveness (approximately $£ 20,000-30,000$ per QALY gained). Indeed, there is only an estimated $42.2 \%$ probability that the ICER is below $£ 30,000$ per QALY gained.

From the point of view of the statutory sector, 'access to a BF' has an even lower probability of being the cost-effective choice. This is due to the statutory sector bearing a greater proportion of the incremental cost.

TABLE 24 Cost-utility analysis: comparison of imputed data versus complete case analysis (societal perspective, 15-month time-horizon, carer quality of life only)

\begin{tabular}{|c|c|c|c|c|c|c|c|c|}
\hline \multirow[b]{2}{*}{ Scenario } & \multicolumn{2}{|c|}{ Cost } & \multicolumn{2}{|c|}{ Carer QALYs } & \multicolumn{2}{|c|}{ Increments $(95 \% \mathrm{Cl})$} & \multirow[t]{2}{*}{ ICER } & \multirow{2}{*}{$\begin{array}{c}p \text { (cost- } \\
\text { effective) }\end{array}$} \\
\hline & Intervention & Control & Intervention & Control & Cost & QALYs & & \\
\hline $\begin{array}{l}\text { Imputed data } \\
\text { (basecase) }\end{array}$ & $f \mid 22,665$ & $E \mid 20,852$ & 0.946 & 0.929 & $\begin{array}{c}\qquad|, 8| 3 \\
(-£||, 3 \mid 2 \text { to } \\
\qquad \mid 4,984)\end{array}$ & $\begin{array}{c}0.017 \\
(-0.051 \text { to } \\
0.083)\end{array}$ & $£ 105,954$ & $42.2 \%$ \\
\hline $\begin{array}{l}\text { Complete } \\
\text { case analysis }^{b}\end{array}$ & $E|2|, 6 \mid 5$ & $€|32,7| 7$ & 0.900 & 0.872 & $\begin{array}{c}-£ \mid 1,103 \\
(-£ 31,469 \text { to } \\
£ 8,755)\end{array}$ & $\begin{array}{c}0.028 \\
(-0.091 \text { to } \\
0.150)\end{array}$ & $-£ 393,866$ & $87.7 \%$ \\
\hline
\end{tabular}

TABLE 25 Cost-utility analysis: comparison of base case versus inclusion of PwD quality of life (societal perspective, 15-month time-horizon)

\begin{tabular}{|c|c|c|c|c|c|c|c|c|}
\hline \multirow[b]{2}{*}{ Scenario } & \multicolumn{2}{|c|}{ Cost } & \multicolumn{2}{|c|}{ Carer QALYs } & \multicolumn{2}{|c|}{ Increments $(95 \% \mathrm{Cl})$} & \multirow[t]{2}{*}{ ICER } & \multirow{2}{*}{$\begin{array}{c}p \text { (cost- } \\
\text { effective) }\end{array}$} \\
\hline & Intervention & Control & Intervention & Control & Cost & QALYS & & \\
\hline $\begin{array}{l}\text { Carer QALYs } \\
\text { only (basecase) }\end{array}$ & $£ 122,665$ & $E \mid 20,852$ & 0.946 & 0.929 & $\begin{array}{c}f|, 8| 3 \\
(-£||, 3 \mid 2 \text { to } \\
\qquad \mid 4,984)\end{array}$ & $\begin{array}{c}0.017 \\
(-0.051 \text { to } \\
0.083)\end{array}$ & $f 105,954$ & $42.2 \%$ \\
\hline $\begin{array}{l}\text { Carer and } \\
\text { PwD QALYs }\end{array}$ & $f \mid 22,665$ & $E \mid 20,852$ & 1.311 & 1.243 & $\begin{array}{c}\qquad 1,813 \\
(-£|I,| 63 \text { to } \\
£ \mid 5,024)\end{array}$ & $\begin{array}{c}0.068 \\
(-0.045 \text { to } \\
0.185)\end{array}$ & $£ 26,848$ & $51.4 \%$ \\
\hline
\end{tabular}


The results from the voluntary sector perspective are in contrast to other sectors, for which there is an estimated $69.9 \%$ probability that the ICER will be below $£ 30,000$. However, this is because the voluntary sector bears only a small proportion of the overall costs of caring for carers or PwD. [Note that this analysis only includes direct costs borne by the voluntary sector. The value of volunteers' time in caring and befriending (indirect cost) is incorporated in the societal perspective.] This result underlines the importance of considering cost-effectiveness from the societal perspective, as an intervention can appear cost-effective to one individual or sector, when in fact this is simply an artefact of arbitrary budgetary boundaries.

From the household perspective, there is an estimated $29.8 \%$ probability that access to a $\mathrm{BF}$ is a cost-effective intervention (at a threshold of $£ 30,000$ per QALY gained). It is questionable, however, whether this is an appropriate analysis for evaluating cost-effectiveness from a household perspective. Cost-utility analysis is a useful tool to assist population-level rationing decisions, and the threshold is a general rule of thumb as to whether the benefits (generating a statistical QALY) are worth the cost, thus leading to more equitable distribution of finite societal resources. An individual's willingness to pay for a QALY for a named relative or friend is likely to be very different. Furthermore, the relevant budget constraint is the household's, not a 'community chest'. The household may therefore value health gains to a specific person much more highly than those to society as a whole. Again, this emphasises the need to consider the societal perspective when making societal resource allocation decisions.

As the time-horizon extended, the costeffectiveness deteriorated. Whereas the intervention was in a dominant situation at 6 months (intervention appeared to result in health-related quality of life gains and be less costly), at 24 months the point estimate ICER was $£ 381,000$ per QALY gained. The apparent deterioration in cost-effectiveness is because the costs were increasing at a faster rate than the corresponding health gain; therefore, the costeffectiveness deteriorates.

Complete data were available for only 61 out of 218 care dyads included in the economic evaluation. The results from this limited analysis were strongly in favour of befriending; however, the authors believe this to be a biased analysis as, first, only a small proportion of the valid data was used in this analysis and, secondly, the probability of a respondent providing a complete data set is likely to be related to the health status of the carer and/or PwD. Therefore, the imputed data set is likely to provide a more appropriate representation of costs and outcomes.

When taking into account quality of life of the $\mathrm{PwD}$ as well as the carers, the analysis found slightly in favour of befriending: the point estimate ICER was approximately £27,000 per QALY gained, with a $51 \%$ probability of being under $£ 30,000$. 


\section{Chapter 6}

\section{Discussion and conclusions}

$T^{\prime}$ he BECCA trial evaluated the impact of access to a befriender facilitator for family carers of people with dementia. The trial represents the largest RCT of befriending for carers of PwD, and involved an ambitious framework for costing care for carers of PwD.

\section{Main findings}

The primary cost and cost-effectiveness analyses did not show any benefit of intervention over control in terms of psychological well-being or cost. That is, at 15 months postrandomisation, access to a BF in the context of usual care did not significantly improve carer well-being as measured by HADS depression, and was associated with a trend towards higher costs to society. There was a trend towards increased health-related quality of life for those randomised to intervention, but this was not statistically significant. In terms of the main outcomes for the ITT analyses, therefore, this is a strongly negative study.

Secondary analyses on measures of carer anxiety, loneliness, positive affect and perceived global health showed no significant benefits for intervention over control, and similarly there were no differences between intervention and control on either a subgroup analysis with spouse carers or a comparison of proportions of people with dementia entering residential or nursing care. Looking from alternative perspectives (statutory, household and voluntary sector) did not offer any convincing evidence for the value of the intervention, and extending the time-frame strengthened the evidence against the intervention.

However, two further analyses that suggest the negative findings may be due to methodological limitations. First, a cost-utility analysis using the QALYs for the PwD in addition to the carer indicated that access to a BF may be a costeffective intervention. Given the importance of care recipient well-being to family carers, it could be argued that health economic analyses of interventions for family carers should include care recipient quality of life as part of the primary analysis. Secondly, a per-protocol subgroup analysis comparing control carers with the small number of intervention carers who engaged with befrienders for at least 6 months before 15-month follow-up reported a difference in HADS depression scores that approached statistical significance in favour of the intervention. While providing only weak evidence of any beneficial effect, this finding indicates that if uptake can be improved, positive findings in the ITT population are more likely.

\section{Implications for healthcare}

\section{Should befriending interventions be withdrawn?}

Given the largely negative findings, should befriending still be provided as a support intervention for carers? It should be emphasised that the negative results reported here are for the intervention 'access to a befriender facilitator' and not 'receipt of befriending'. Given that only around half of the carers offered befriending chose to take up the offer, should it be concluded that befriending is not a service that carers want? Lack of service uptake by carers is well known for both standard services and research interventions. Although awareness is a vital precursor to service use, ${ }^{83}$ awareness alone does not account for whether or not carers uptake services. Other factors include work status, socio-economic status and level of burden. ${ }^{84,85}$ Lack of time is associated with non-uptake, ${ }^{86}$ although increased burden, depression or distress may increase uptake. ${ }^{86-88}$ It is apparent that no one service is appropriate for all carers, and that each carer may have differing needs over the years spent supporting the care recipient. In their work on the "caregiving career', Aneshensel and colleagues ${ }^{20}$ suggested that different interventions are appropriate at difference stages of the care recipient's illness, for example, before and after diagnosis, during inhome care, before and after admission of the care recipient into long-term residential or nursing care, and after the death of the care recipient. This research had been expected to show that a social support intervention would be of greatest relevance to those carers for whom the demands of caring had impacted adversely on their social networks, but were still providing care for the PwD 
at home. This study used the 'time spent caring' marker of 20 hours or more per week to increase the chance that participants were immersed in the caring role. Further analysis of the demographic, psychological and social characteristics of carers who did and did not take up the offer of befriending may inform the inclusion or exclusion criteria for any future research on befriending interventions or referral criteria for befriending services.

An important consideration for provision of befriending services and funding of befriending schemes is the 'minimum effective dose' of befriending. When drawing up the protocol, the researchers proposed providing befriending weekly for 6 months. For the 60 carers who were matched with befrienders, 42 (71\%) were

befriended for at least 6 months before the end of the befriending scheme (37 before 15-month follow-up). Many carers found weekly commitment difficult in the context of their caring role. A large proportion opted for fortnightly contact, but there was no frequency that suited all participants. Once relationships were established, they endured, with 39 matches lasting over 1 year, and 30 matched carers continuing to meet their befriender beyond the end of the befriending scheme. Of these, 22 became informal friendships and moved away from 'managed' befriending schemes. That is, $37 \%$ befriending relationships became friendships (22 out of 60 matched carers) over the course of the intervention. The remaining eight remained 'formal' befriending relationships, transferred to being supported within other ongoing befriending schemes. The percentage of matches lasting for at least 6 months was slightly below expectation, whereas the percentage lasting for 1 year was within the expected range. As a comparison, the UK-wide survey of 234 general befriending services indicated that $89 \%$ of befriending relationships lasted for over 6 months. ${ }^{80}$ For befriending services for older people, $96 \%$ of befriending relationships lasted for 6 months and $87 \%$ lasted for over 1 year, whereas for people with mental ill-health the corresponding figures were $90 \%$ and $54 \%$. For matches lasting for at least 6 months, the mean duration of match (to the end of the relationship or the end of the befriending schemes, whichever was sooner) was 677 days (just under 1 year and 10 months), ranging from 6 months and 13 days to 3 years and 6 months for one of the earliest matches. The duration is in keeping with other schemes. For example, in the Norfolk befriending audit, users received services for between 1 and 4 years. $^{89}$

\section{Is the cost of intervention data generalisable to locally commissioned schemes?}

The mean cost of the intervention was 11138 per carer at 15 months. Costs varied by scheme, with the largest and longest running scheme having lower costs per carer than the smaller schemes. There are economies of scale for both fixed and running costs, but once a scheme grows beyond the size at which a BF can support the befrienders and carers within it, additional staff costs will be necessary.

The BECCA befriending schemes were set up specifically for the research trial. The local voluntary organisations involved in setting up the county-wide BECCA befriending services commented on the difference between the scope of these services and the more localised scope of the services that they would usually run. Factors that would increase the expense of the intervention include the ratio of carers to befrienders, the travel distances involved and criteria for matching.

In terms of carer to befriender ratios, 49 befriending volunteers were matched with carers, giving a ratio of 1.2 to 1 . Nationally, the average number of users to volunteers is 170 to 52 (3.3 to 1) for befriending services to older people, with an average of 44 users and 32 volunteers (1.4 to 1 ) for people with mental health difficulties. ${ }^{80}$ In a Norfolk-wide audit of befriending schemes for people who are aged 65 and over, ${ }^{89}$ the average number of users and volunteers was 210 and 42, respectively ( 5 to 1 ). In a befriending scheme specifically for carers of people with dementia, ten volunteers support 50 family carers (Mid-Essex Alzheimer's Society befriending programme, personal communication). In this context, the BECCA schemes required more trained volunteers per scheme user than any of the previously reported schemes, and would therefore be more costly per carer. This, in part, was due to a policy decision to require all volunteers to establish one match before volunteering for a second match, so that they could assess for themselves the level of emotional demand that they experienced in their befriending role.

Voluntary sector-generated befriending services would more often cover a town and its immediate rural hinterland in order to minimise volunteer travel costs and times. Some BECCA volunteers living in rural areas sometimes had to travel for up to an hour each way to undertake their befriending task. In some instances this led to 
decisions to minimise volunteer travel by mixing face-to-face meetings with telephone befriending or to meet fortnightly rather than weekly, but for 2 hours rather than 1 hour. This will also have meant that initial face-to-face assessment and introductory visits by BFs would have entailed more travel than non-BECCA befriending schemes might have entailed. For these reasons, costs for the BECCA befriending service may have been higher than in a more usual locally implemented befriending service.

\section{Is it safe to involve volunteers?}

Overall, few risk issues arose. Active steps were taken to follow guidelines on good practice in supporting volunteers working in settings with potentially vulnerable people. ${ }^{90,91}$ A code of confidentiality was maintained, risk assessments carried out by BFs, and health and safety guidelines were developed in partnership with the voluntary organisations helping to provide the befriending services. Written information and training were provided to ensure that volunteers were fully informed about these issues and about how they needed to be applied in practice.

There were a few occasions where issues affecting the safety of befrienders as well as the safety of carers, people cared for or other family members had to be explicitly considered and responded to by the BF. These usually followed instances where the carer sought to step outside the boundaries of the befriending relationship in some way. These were picked up at an early stage by the befriender, who brought them to the attention of the BF. It was found that the early development of a riskassessment procedure as well as befriender training in risk management proved useful in deciding how to respond to such incidents, and responses ranged from $\mathrm{BF}$ reminders to the carer involved about their agreement to respect boundaries to changes in the terms of the befriender arrangement. These, on two occasions, included a change of befriender and type of contact from face-to-face visits to telephone befriending. In all such cases, good working relationships were successfully maintained.

\section{User involvement}

The local consultation groups were formed to support and develop the befriending scheme intervention. However, their remit soon expanded to include consultation on aspects of research design and project literature. The authors would strongly endorse the involvement of carers and their representatives from the early stages of project development, including opportunity to comment on project information sheets and in planning recruitment strategies. Consultation groups can also suggest local links and small area initiatives. Such microknowledge is useful in all areas, but especially so in rural areas, where the difficulties with disseminating information to hidden communities has already been highlighted.

\section{Volunteer support}

Many of the volunteers were above retirement age and there were instances where befriending arrangements needed also to take account of volunteer health. Some had episodes of ill-health which in some cases prevented them from driving to visit carers or meant that they had to withdraw from volunteering completely. Both volunteers and carers were supported by the BF through such episodes to maintain the continuity of the befriending relationship according to the wishes of the participants. Recent studies such as that of older volunteers in Newcastle ${ }^{92}$ have illustrated how older people have valued their own engagement as befrienders of frailer elders, in which they were able to connect meaningfully with previous roles in which they had been able to make a contribution.

\section{Factors to consider in carer support research}

\section{Recruitment}

Recruitment to the project was one of the main challenges for BECCA, and led to both the extension of the recruitment period and the consequent changes in follow-up schedule. There were considerable difficulties in recruiting only through primary care, and the recognition of carers in primary care is an ongoing area of concern. ${ }^{93}$ A move towards multiple strategies, as recommended by Adams and colleagues ${ }^{94}$ and DiBartolo and McCrone, ${ }^{95}$ improved overall recruitment, but barriers remained, including non-identification with the term 'carer', nonfacilitative gatekeepers, burden of written information and a disperse client group. ${ }^{96}$

Reflecting on the recruitment activity, from the identification of potential participants through to randomisation, it appears that the recruitment strategy that produced the highest number of expressions of interest was not necessarily the most productive strategy for identifying eligible participants. Twenty-seven out of 54 GP practices (20 out of 35 in Norfolk; seven out of 19 in Suffolk) sent out a total of 484 standard invitation letters and approved participant information 
sheets. There were 107 responses to the research team, representing a response rate of $22 \%$ in primary care. Of the 107 respondees, 86 were randomised; that is, $18 \%$ of invitees and $80 \%$ of respondees were randomised. From the figures available from some of the voluntary- and charitable-sector organisations (especially in Havering and Suffolk), 303 invitations resulted in 45 responses (response rate of $15 \%$ ) and 25 randomisations; that is, $8 \%$ invitees and $55 \%$ respondees were randomised. Figures from the voluntary- and charitable-sector mailings do not represent all of the organisations involved, but seem to indicate that although most expressions of interest for the trial arose from recruitment activity within the voluntary sector, activity within primary care produced a higher proportion of eligible carers from those expressing interest.

\section{Improving uptake}

The issue of intervention uptake arises in much of the research on carer intervention. A possible strategy for increasing uptake could be to use a patient preference design, or to use eligibility criteria that narrow the participant population to those most likely to take up the intervention offered. Both strategies would reduce the generalisability to the total carer population, but increase specificity. In the BECCA trial, the researchers sought the opinion of the user consultation group on the reasons for low uptake. The term 'befriending' was seen as offputting, in that it could imply that a carer was unable to make friends and needed to have one provided. Other schemes have used terms such as 'friendly visiting' or 'peer support'. Another point made was the time taken by carers to choose to take up a service. Lack of initial uptake does not mean that the service is not wanted, simply that it is not wanted at that time. In the BECCA trial, a proportion of carers did indeed take up the service some time after it was initially offered; on one occasion a carer came back to the facilitator after 2 years. The befriending scheme was still running, but it was after the completion of the research interviews for that individual.

\section{Measures and data collection}

Costs reported include PwD and carer medication, primary and secondary care use, day-care services, home-care and other service use such as meals on wheels, specialist consultant, nurse or other healthcare professional visits to the home, respite stays, aids and adaptations, and time spent caring for the PwD by carer and friends and family. However, questions on PwD visits from other professionals (counsellor, chiropodist or other), continence and complementary therapy, carer use of support services such as telephone helplines and support groups, visits to professionals (counsellor, chiropodist or other) and childcare costs were excluded. The costs associated with lost employment to care for a PwD were also excluded, for two reasons: first, approximately $66 \%$ of carers were retired and therefore had zero cost of lost employment and, secondly, caring time was valued at a shadow price equal to the average gross wage rate. Therefore, forgoing employment to care for a PwD does not represent a loss of productivity to society, merely a transfer of direct cost from the household (lost wages) to indirect benefit (value of care given). Thus, there is no net change in productivity from a societal perspective, although this would have impacts on the analysis from a household perspective.

The value of carer time was calculated on the basis of the simple question: "how many hours in a 24-hour day are you "on duty" to care for your relative?' Many carers responded ' 24 hours per day'. This is undoubtedly the case for many, but for others this was interpreted as being available on the telephone at any time. This is not the same as actually being present for 24 hours, and thus the value of the time may be overestimated.

To obtain a societal cost within the BECCA trial, the aim was to measure resource use in the key sectors affected, namely statutory services (health and social care), voluntary sector and the household. Data were collected for service use by both the carer and the PwD, as difficulties arise in identifying the boundaries of costs between family carers and care recipients, and the aim was to construct a comprehensive longitudinal model of costs, rather than taking repeated cross-sectional snapshots of services at the time of each follow-up. Carer and PwD resource-use data were collected through carer interview, and therefore the data are subject to the vagaries of the individual carer's recall. Data were not collected from agencies' records, given the large number of agencies potentially involved, sensitivity to data protection issues and the limitations of using primary care records to measure secondary and tertiary care use. ${ }^{97}$ The economic data were collected alongside clinical data and therefore a balance had to be found between comprehensive data collection and the need to minimise interview burden on carers. Resource-use diaries were not used in this trial as it was thought that face-to-face interviewers would be more engaging for participants in a longitudinal trial. Diaries form 
part of the methodology for the Canadian Outcomes Study in Dementia (COSID). Analysis of the economic data for the COSID trial was hampered by the non-return of the monthly diaries, with $22 \%$ of participants failing to return at least six out of 12 diaries over the course of the year. $^{98}$

\section{Measures}

The main quality of life measure for the trial was the EQ-5D. Given the limited information on reliability and validity of the EQ5D with the carer population, and the measure being limited to health-related quality of life, broader measures of quality of life should be considered in any future research. The HTA review panel recommended use of the Carer Generated Index of Quality of Life (CGI-QoL) as a user-defined outcome in addition to a measure of health-related quality of life. The CGI-QoL was still under development at the start of 2002. Its use was piloted within the BECCA project and found to be very timeconsuming, leading to interviewee burden. It was therefore dropped from the interview schedule. Health-related quality of life for the $\mathrm{PwD}$ also relied on the EQ-5D, using proxy ratings by the carer. Although the EQ-5D has better measurement qualities than some other healthrelated quality of life measures when carers are used as proxies, ${ }^{99}$ proxy ratings are known to differ from patients' ratings. ${ }^{99,100}$ Given the suggestion that cost-effectiveness analyses should take account of the outcomes for both the carer and $\mathrm{PwD}$, future carer intervention research should include direct measurement of the clinical characteristics of the PwD, including behavioural and psychological symptoms.

\section{Impact of interviewers}

In carer intervention research, good relations between the interviewers and carers were vital to ensure completion of interviews at each timepoint, and retention in the study over time. In the BECCA trial, many participating carers expressed an appreciation of having the space to talk with someone about their caring experiences. While there are advantages to carers feeling positive about their interview involvement, this also leads to the potential narrowing of the difference between intervention and control conditions in a low-level social support trial.

\section{Blinding}

Although interviewers did not ask directly about befriending, it was not possible for interviewers to remain blind to group when carers specifically commented on their befriending receipt.

\section{Recommendations for future research}

This research is strongly suggestive that further research into access to a befriender facilitator is redundant. However, the weak evidence of efficacy in the analysis of befrienders receiving at least 6 months' intervention may suggest that further research into befriending as a form of carer support is warranted. Based on the per-protocol analysis, the effect size was 0.31 . A future study with $90 \%$ power at $5 \%$ significance would need around 220 participants per group. In addition, the befriending interventions could be used as a control for more formal psychotherapeutic interventions for carers.

Before undertaking further intervention research on befriending, it would be of value to establish the characteristics of carers most likely to take up befriending and the befriender-carer characteristics of successful matches. Information relevant to these areas could be derived from further analysis of the BECCA data.

Carer intervention research is complicated by the wide range of services offered to and used by carers over the course of the dementia. The service receipt of carers is often not fully taken into account, nor is the interplay between statutory and voluntary support services and support from families. Greater knowledge of the interaction between formal and informal care is needed. ${ }^{101}$ The BECCA database could be exploited to explore the interplay of statutory and voluntary sectors and the family, and indeed a Small Grant has been provided by the Economic and Social Research Council (ESRC) to do so. A further complication in carer intervention research is assessing well-being in the context of receipt of befriending and placement of the care recipient in long-term residential or nursing care. The BECCA trial completed follow-up irrespective of location of the PwD, as carers were keen to see support continue beyond their life as a hands-on carer. Such ongoing support should be considered in other carer interventions.

Future cost-effectiveness evaluations of carer support should include outcomes for both the carer and care recipient, and further work is required on economic methods for carer intervention research, including:

- explorations of the relationship between health-related quality of life measures and other outcome measures 
- identification of methods for minimising work for respondents and interviewers of resourceuse data collection in economic studies

- methods for measuring and valuing carer time and other informal care inputs for economic analysis

- additional work to confirm or refute the costeffectiveness of befriending from a societal point of view.

\section{Conclusions}

Access to a befriender facilitator is neither an effective nor a cost-effective intervention in the support of carers of people with dementia, although there is a suggestion of cost-effectiveness for the care dyad (carer and care recipient). In common with many services for carers of $\mathrm{PwD}$, uptake of befriending services was not high. However, the small number of carers who engaged with befrienders for 6 months or more reported a reduction in scores on HADS depression that approached statistical significance compared with controls. Although this study provides only weak evidence of any beneficial effect, further research into befriending interventions for carers is warranted. 


\section{Acknowledgements}

$\mathrm{T}$ he Befriending and Costs of Caring (BECCA) project (ISRCTN 08130075) was funded by the Health Technology Assessment (HTA) Programme (project 99/34/07) granted to Charlesworth (University College London), Mugford, Poland, Harvey, Price, Reynolds and Shepstone (University of East Anglia). Befriender expenses were funded by Norfolk and Suffolk Social Services, the King's Lynn and West Norfolk Branch of the Alzheimer's Society and an AdHoc grant from the Department of Health to North East London Mental Health Trust.

The views expressed in this report do not necessarily reflect those of the funders.

The Project Management Group met throughout the project, and included the Grantholders Shirley Reynolds (Professor in Clinical Psychology, UEA) David Price (University of Aberdeen) and Ian Harvey (in addition to the authors contributing to this report).

The befriender facilitators in the three host schemes are thanked for their support of carers and volunteers. The BFs were: Susan Vaughan (Norwich and Norfolk Voluntary Services), Carol Higgins, Wendy Herber and Thelma Wingfield (Age Concern Suffolk), and Jacqui Burke, Lyn Taylor and Elizabeth Palfreman (Age Concern Havering).

Research staff on the project included Sylvia Morley, Liz Hooper, Kim Shutt, Sandra Picken and Nicky Knights at UEA; Hilary Clarke and Amy Bartlett in North East London Mental Health Trust (London Borough of Havering) and Xanthippe Tzimoula at UCL, with additional support from Jamie Murdoch (SAND), Nick Healey (UEA) and Sarah Pennington (UEA).

The staff and volunteers from the contributing voluntary organisations (Appendix 1) are thanked, especially those who contributed to the consultation groups and in befriender training and support, as are all the participating family carers.
The Steering and Advisory Group is also thanked for their support throughout the project, and included Emeritus Professor Tom Arie (Chair), whose suggestion inspired the project, and Ionne Hammond (formerly of the Alzheimer's Society, Eastern Region).

Administrative support was provided by Lesley Barrett, Lynne Wright, Claire Powell and Helen Sayer at different stages of the project.

\section{Contribution of authors}

Georgina Charlesworth (Lecturer in Clinical and Health Psychology of Old Age) had overall responsibility for all aspects of the trial including drafting of the final report. Miranda Mugford (Professor in Health Economics) had overall responsibility for economic evaluation and its reporting. Lee Shepstone (Lecturer in Medical Statistics) carried out the efficacy analysis. Edward Wilson (Health Foundation Research Training Fellow) carried out and reported the economic analyses. Mariamma Thalanany (Research Associate) drew up the resource-use data collection instrument, identified unit costs and designed the costing of the befriending intervention. Fiona Poland (Senior Lecturer in Therapy Research) held overall responsibility for the befriending intervention.

\section{Papers published in other peer-reviewed journals relating to this research}

Charlesworth G, Tzimoula X, Higgs P, Poland F. Social networks, befriending and support for family carers of people with dementia. Quality in Ageing: Policy, Practice and Research 2007;8:37-44.

Charlesworth GM, Tzimoula XM, Newman SP. Carers Assessment of Difficulties Index (CADI): psychometric properties for use with carers of people with dementia. Aging Ment Health 2007; 11:218-25.

Hooper E, Charlesworth G, Poland F, Vaughan S. Recruiting carers and befrienders - experiences from the Befriending and Cost of Caring (BECCA) study. Signpost 2004;9:7-10. 



\section{References}

1. Department of Health. Carers (Recognition and Services) Act 1995. London: HMSO; 1995.

2. Department of Health. Caring about carers: a national strategy for carers. London: Department of Health; 1999.

3. Department of Health. National Service Framework for Mental Health. London: Department of Health; 1999.

4. Department of Health. National Service Framework for Older People. London: Department of Health; 2001.

5. Office for National Statistics. Carers in Britain. 2002. URL: www.statistics.gov.uk/pdfdir/ cib0602.pdf. Accessed 13 October 2006.

6. Schulz R, O'Brien AT, Bookwala J, Fleissner K. Psychiatric and physical morbidity effects of dementia caregiving: prevalence, correlates, and causes. Gerontologist 1995;35:771-91.

7. Ory MG, Hoffman RR, Yee JL, Tennstedt S, Schulz R. Prevalence and impact of caregiving: a detailed comparison between dementia and nondementia caregivers. Gerontologist 1999; 39:177-85.

8. Schulz R, Beach SR. Caregiving as a risk factor for mortality - the caregiver health effects study. JAMA 1999;282:2215-19.

9. Bowling A. Social support and social networks their relationship to the successful and unsuccessful survival of elderly people in the community - an analysis of concepts and a review of the evidence. Fam Pract 1991;8:68-83.

10. Bowling A, Grundy E. The association between social networks and mortality in later life. Rev Clin Gerontol 1998;8:353-61.

11. Lofgren AC, Bucht G, Eriksson S, Winblad B. A comparative study of the social conditions of spouses of long term patients cared for either in nursing home or home care. Scand J Caring Sci 1992;6:45-52.

12. Croog SH, Burleson JA, Sudilovsky A, Baume RM. Spouse caregivers of Alzheimer patients: problem responses to caregiver burden. Aging Ment Health 2006;10:87-100.

13. Sharlach A, Del Santo T, Greenlee J, Whittier S, Coon D, Kietzman K, et al. Family caregivers in California: needs, interventions and programs. San Francisco, CA: University of California; 2001.
14. Rook KS. Social support versus companionship: effects on life stress, loneliness, and evaluations by others. J Pers Soc Psychol 1987;52:1132-47.

15. Hall-Elston C, Mullins LC. Social relationships, emotional closeness, and loneliness among older meal program participants. Soc Behav Pers 1999; 27:503-18.

16. The role of the voluntary and community sector in service delivery: a cross cutting review. London: The Stationery Office; 2002. URL: http://www.hmtreasury.gov.uk/media/8/4/CCRVolSec02.pdf

17. Taylor M. The best of both worlds: partnership between government and voluntary organisations. York: Joseph Rowntree Foundation; 1997.

18. Ware P, Matosevic T, Forder J, Hardy B, Kendall J, Knapp K, et al. Movement and change: independent sector domiciliary care providers between 1995 and 1999. Health Soc Care Community 2001;9:334-40.

19. Ware T, Matosevic T, Hardy B, Knapp K, Kendall J, Forder J. Commissioning care services for older people in England: the view from care managers, users and carers. Ageing Soc 2003;23:411-28.

20. Aneshensel CS, Pearlin LI, Mullan JT, Zarit SH, Whitlatch CJ. Profiles in caregiving, the unexpected career. San Diego, CA: Academic Press; 1995.

21. Schulz R, O'Brien A, Czaja S, Ory M, Norris R, Martire LM, et al. Dementia caregiver intervention research: in search of clinical significance. Gerontologist 2002;42:589-602.

22. Charlesworth G, Newman S. Lessons from psychosocial interventions aimed at caregivers of people with dementia. In Rockwood G, editor. Trial designs and outcomes in dementia therapeutic research. London: Taylor \& Francis; 2005. pp. 235-49.

23. Brodaty H, Green A, Koschera A. Meta-analysis of psychosocial interventions for caregivers of people with dementia. J Am Geriatr Soc 2003;51:657-64.

24. Marriott A, Donaldson C, Tarrier N, Burns A. Effectiveness of cognitive-behavioural family intervention in reducing the burden of care in carers of patients with Alzheimer's disease. $\mathrm{BrJ}$ Psychiatry 2000;176:557-62.

25. Barker C, Pistrang N. Psychotherapy and social support. Clin Psychol Rev 2002;22:361-79.

26. Faust D, Zlotnick C. Another dodo bird verdict? Revisiting the comparative effectiveness of professional and paraprofessional therapists. Clin Psychol Psychother 1995;2:157. 
27. Andersson L. Loneliness research and interventions: a review of the literature. Aging Ment Health 1998;2:264-74.

28. Cattan M, White M, Bond J, Learmouth A. Preventing social isolation and loneliness among older people: a systematic review of health promotion interventions. Ageing Soc 2005; 25:41-67.

29. Hogan BE, Linden W, Najarian B. Social support interventions: do they work? Clin Psychol Rev 2002; 22:381-440.

30. Taggart AV, Short SD, Barclay L. She has made me feel human again; an evaluation of a volunteer home-based visiting project for mothers. Health Soc Care Community 2000;8:1-8.

31. Andrews GJ, Gavin N, Begley S, Brodie D. Assessing friendships, combating loneliness: users' views on a 'befriending scheme' scheme. Aging Soc 2003;23:349-62.

32. Brown SL, Ness RM, Vinkour AD, Smith DM. Providing social support may be more beneficial than receiving it: results from a prospective study of mortality. Psychol Sci 2003;14:320-7.

33. Sensky T, Turkington D, Kingdon D, Scott JL, Scott J, Siddle R, et al. A randomized controlled trial of cognitive-behavioral therapy for persistent symptoms in schizophrenia resistant to medication. Arch Gen Psychiatry 2000;57:165-73.

34. Milne D, Wharton S, James I, Turkington D. Befriending versus CBT for schizophrenia: a convergent and divergent fidelity check. Behavioural and Cognitive Psychotherapy 2006; 34:25-30.

35. Harris T, Brown GW, Robinson R. Befriending as an intervention for chronic depression among women in an inner city I: Randomised controlled trial. Br J Psychiatry 1999;174:219-24.

36. Calsyn RJ, Munson M, Peaco D, Kupferberg J, Jackson J. A comparison of the effectiveness of various approaches to visiting various community elders. J Gerontol Soc Work 1984;7:31-7.

37. MacIntyre I, Corradetti P, Roberts J, Browne G, Watt S, Lane A. Pilot study of a visitor volunteer programme for community elderly people receiving home health care. Health Soc Care Community 1999;7:225-8.

38. Pillemer K, Suitor JJ. Peer support for Alzheimer's caregivers: is it enough to make a difference? Research on Aging 2002;24:171-92.

39. Patel A, Knapp M, Evans A, Perez I, Kalra L. Training care givers of stroke patients: economic evaluation. BMJ 2004;328:1102-4A.

40. Brodaty H, Peters KE. Cost effectiveness of a training program for dementia carers. Int Psychogeriatr 1991;3:11-22.
41. Drummond MF, Mohide EA, Tew M, Streiner DL, Pringle DM, Gilbert JR. Economic evaluation of a support program for caregivers of demented elderly. Int J Technol Assess Health Care 1991; 7:209-19.

42. Knapp M, Marks I, Wolstenholme J, Beecham J, Astin J, Audini B, et al. Home-based versus hospital-based care for serious mental illness controlled cost-effectiveness study over four years. Br J Psychiatry 1998;172:506-12.

43. Donaldson C, Gregson B. Prolonging life at home - what is the cost? Community Med 1989;11:200-9.

44. Payton FC, Brennan PF, Silvers JB. Cost justification of a community health information network: the ComputerLink for AD caregivers. In Proceedings of the 19th Annual Symposium on Computer Applications in Medical Care; 1995. pp. 566-70.

45. Brouwer WBF, van Exel NJA, Koopmanschap MA, Rutten FFH. The valuation of informal care in economic appraisal - a consideration of individual choice and societal costs of time. Int J Technol Assess Health Care 1999;15:147-60.

46. McDaid D. Estimating the costs of informal care for people with Alzheimer's disease: methodological and practical challenges. Int $J$ Geriatr Psychiatry 2001;16:400-5.

47. Wimo A, Jonsson B, Karlsson G, Winblad B. Health economics of dementia. Chichester: John Wiley \& Sons; 1998.

48. Koopmanschap MA, Rutten FFH, Vanineveld BM, Vanroijen L. The friction cost method for measuring indirect costs of disease. J Health Econ 1995;14:171-89.

49. Lipsey MW, Wilson DB. The efficacy of psychological, educational, and behavioral treatment. Confirmation from meta-analysis. $\mathrm{Am}$ Psychol 1993;48:1181-209.

50. Elashoff JD. nQuery Advisor version 5.0 user's guide. Los Angeles, CA; 2002.

51. Grant G, Goodenough T, Harvey I. A randomised controlled trial and economic evaluation of a referrals facilitator between primary care and the voluntary sector. BMJ 2000;320:419-23.

52. Milne A, Hatzidimitriadou E, Chryssamthoupoulou C, Owen T. Caring in later life. Reviewing the role of older carers. Executive Summary. University of Kent; 2001.

53. Carers UK. Rural carers. Policy Briefing. London: Carers UK; 2003.

54. Rybarczyk B, Lopez M. Research methods with older adults. In Kendall PC, Butcher JN, editors. Handbook of research methods in clinical psychology. 2nd ed. New York: Wiley; 1999. pp. 662-80. 
55. Zigmond AS, Snaith RP. The Hospital Anxiety and Depression Scale. Acta Psychiatr Scand 1983; 67:361-70.

56. Stroebe W, Stroebe M, Abakoumkin G, Schut H. The role of loneliness and social support in adjustment to loss: a test of attachment versus stress theory. J Pers Soc Psychol 1996;70:1241-9.

57. Watson D, Clark LA, Tellegen A. Development and validation of brief measures of positive and negative affect: the PANAS scales.J Pers Soc Psychol 1988;54:1063-70.

58. Nolan MR, Grant GJ. Regular respite: an evaluation of a hospital rota bed scheme for elderly people. London: Age Concern; 1992.

59. Charlesworth G, Tzimoula X, Newman S. Carers Assessment of Difficulties Index (CADI): psychometric properties for use with carers of people with dementia. Aging Ment Health 2007; 11:218-25.

60. Williamson GM, Schulz R. Caring for a family member with cancer - past communal behavior and affective reactions. J Appl Soc Psychol 1995; 25:93-116.

61. Wenger GC. Support networks and dementia. Int J Geriatr Psychiatry 1994;9:181-94.

62. Scharf T, Smith AE. Older people in urban neighbourhoods: addressing the risk of social exclusion in later life. In Phillipson C, Allan G, Morgan D, editors. Social networks and social exclusion: sociological and policy perspectives. Aldershot: Ashgate; 2004.

63. Zimet GD, Dahlem NW, Zimet SG, Farley GK. The Multidimensional Scale of Perceived Social Support. J Pers Assess 1988;52:30-41.

64. Stanley MA, Beck JG, Zebb BJ. Psychometric properties of the MSPSS in older adults. Aging Ment Health 1998;2:186-93.

65. Carver CS. You want to measure coping but your protocol's too long: consider the brief COPE. Int J Behav Med 1997;4:92-100.

66. Brugha T, Bebbington P, Tennant C, Hurry J. The list of threatening experiences - a subset of 12 life event categories with considerable longterm contextual threat. Psychol Med 1985; 15:189-94.

67. Brooks R. EuroQol: the current state of play. Health Policy 1996;37:53-72.

68. Dixon S, Deverill M, Gannon M, Brazier J, Haggard M. Improving the validity of economic evaluations alongside controlled trials. J Health Serv Res Pol 1999;4:161-3.

69. Beecham J. The Client Service Receipt Inventory. Discussion Paper 1492. Canterbury: University of Kent at Canterbury, Personal Social Services Research Unit; 1995.
70. Blesa R. Galantamine: therapeutic effects beyond cognition. Dement Geriatr Cogn Disord 2000; 11:28-34.

71. Davis KL, Marin DB, Kane R, Patrick D, Peskind ER, Raskind MA, et al. The Caregiver Activity Survey (CAS): development and validation of a new measure for caregivers of persons with Alzheimer's disease. Int J Geriatr Psychiatry 1997;12:978-88.

72. Marin DB, Dugue M, Schmeidler J, Santoro J, Neugroschl J, Zaklad G, et al. The Caregiver Activity Survey (CAS): longitudinal validation of an instrument that measures time spent caregiving for individuals with Alzheimer's disease. Int J Geriatr Psychiatry 2000;15:680-6.

73. Rubin D. Multiple imputation for nonresponse in surveys. New Jersey: Wiley \& Sons; 1987.

74. Matthews J. An introduction to randomized controlled trials. London: Arnold/Hodder Headline; 2000.

75. Dolan P. Modelling valuations for EuroQol health states. Med Care 1997;35:1095-108.

76. Drummond MF, Sculpher MJ, Torrance GW, O'Brien BJ, Stoddart GL. Methods for the economic evaluation of healthcare programmes. 3rd ed. Oxford: Oxford University Press; 2005.

77. Rawlins MD. 5 NICE years. Lancet 2005;365:907-8.

78. National Centre for Volunteering. Safe and alert: good practice advice on volunteers working with vulnerable clients. London: National Centre for Volunteering; 2000.

79. Scottish Befriending Development Forum. Code of Practice: working together to promote good practice in befriending. Falkirk: Scottish Befriending Development Forum; 1997.

80. Dean J, Goodlad R. Supporting community participation: the role and impact of befriending. Pavilion Publishing/Joseph Rowntree Foundation; 1998.

81. Cuijpers P. Depressive disorders in caregivers of dementia patients: a systematic review. Aging Ment Health 2005;9:325-30.

82. Richards K, Moniz-Cook E, Duggan P, Carr I, Wang M. Defining 'early dementia' and monitoring intervention: what measures are useful in family caregiving? Aging Ment Health 2003; $7: 7-14$.

83. Brodaty H, Thomson C, Thompson C, Fine M. Why caregivers of people with dementia and memory loss don't use services. Int J Geriatr Psychiatry 2005;20:537-46.

84. Bass DM, Noelker LS. The influence of family caregivers on elders' use of in-home services. J Health Soc Behav 1987;28:184-96.

85. Miller B, McFall S. The effect of caregivers' burden on change in frail older person's use of formal helpers. J Health Soc Behav 1991;32:165-79. 
86. Monahan DJ, Green VL, Coleman P. Caregiver support groups: factors affecting use of services. Soc Work 1992;37:254-60.

87. Curry C, Cossich T, Matthews JP, Beresford J, McLachlan SA. Uptake of psychosocial referrals in an outpatient cancer setting: improving service accessibility via the referral process. Support Cancer Care 2002; 10:549-55.

88. Cowley M, Orbell S. Towards a psychology of service use in informal care: social and psychological variables associated with service need and uptake amongst carers of learning disabled adults. Psychol Health 1999;14:217-39.

89. Moseley A. Befriending schemes in Norfolk; how should these be developed? Discussion Paper. Norwich: Norfolk Social Services; 2000.

90. Green T, Stuart M. The good practice guide, National Centre for Volunteering. London: National Centre for Volunteering; 1998.

91. Hawkins S, Restall M. Volunteers across the NHS: improving the patient experience and creating a patientled service. London: Volunteering England; 2006.

92. Baines S, Lie M, Wheelock J. Volunteering, self-help and citizenship in later life. Newcastle: University of Newcastle; 2006.

93. Princess Royal Trust. Primary carers - identifying and providing support to carers in primary care. Executive Summary. Princess Royal Trust; 2003.

94. Adams J, Silverman M, Musa D, Peele P. Recruiting older adults for clinical trials. Control Clin Trials 1997;18:14-26.

95. DiBartolo MC, McCrone S. Recruitment of rural dwelling older adults: barriers, challenges, strategies. Aging Ment Health 2003;7:75-82.

96. Hooper E, Charlesworth G, Poland F, Vaughan S. Recruiting carers and befrienders: experiences from the Befriending and Cost of Caring (BECCA) study. Signpost 2004;9:7-10.

97. Byford S, Leese M, Knapp M, Seivewright H, Cameron S, Jones V, et al. Comparison of alternative methods of collection of service use data for the economic evaluation of health care interventions. Health Econ 2007;16:531-6.
98. Herrmann N, Lanctot KL, Sambrook R, Lesnikova N, Hebert R, McCracken P, Robillard A, Nguyen $\mathrm{E}$ and The COSID Investigators. The contribution of neuropsychiatric symptoms to the cost of dementia care. Int J Geriatr Psychiatry 2006;21:972-76.

99. Naglie G, Tomlinson G, Tansey C, Irvine J, Ritvo P, Black SE, et al. Utility-based quality of life measures in Alzheimer's disease. Qual Life Res 2006;15:631-43.

100. Coucill W, Bryan S, Bentham P, Buckley A, Laight A. EQ-5D in patients with dementia: an investigation of inter-rater agreement. Med Care 2001;39:760-71.

101. Nordberg G, von Strauss E, Kareholt I, Johansson L, Wimo A. The amount of informal and formal care among non-demented and demented elderly persons - results from a Swedish population-based study. Int J Geriatr Psychiatry 2005;20:862-71.

102. Netten A, Curtis L. Unit costs of health and social care 2002. Canterbury: Personal Social Services Research Unit, University of Kent; 2002.

103. Department of Health. National schedule of performance costs 2005. URL: http://www.dh. gov.uk/en/Publicationsandstatistics/Publications/ PublicationsPolicyAndGuidance/DH_4133221. Accessed 10 December 2007.

104. Netten A, Curtis L. Unit costs of health and social care 2005. Canterbury: Personal Social Services Research Unit, University of Kent; 2005.

105. National Audit Office. NHS Direct in England. Report 2002. URL: http://www.nao.org.uk/ publications/nao_reports/01-02/0102505.pdf. Accessed 10 December 2007.

106. The AA. Motoring costs 2005. URL: http://www. theaa.com/motoring_advice/running_costs/ petrol2005.pdf. Accessed 10 December 2007.

107. Office for National Statistics. 2005 Annual survey of hours and earnings. Analysis by all employees, Table 1.5a. URL: http://www.statistics.gov.uk/ downloads/theme_labour/ASHE_2005/ 2005 all employees.pdf. Accessed 10 December 2007. 


\section{Appendix I}

\section{Organisations involved in the trial}

ACCESS, Age Concern Suffolk

ACCESS, Younger People with Dementia, Age

Concern Suffolk

Age Concern, Havering, London

Age Concern, Norfolk

Alzheimer's Society

Beccles Volunteer Bureau, Beccles, Suffolk

Bury Volunteer Group, Bury St Edmunds, Suffolk

Community Mental Health Nursing Services, Norwich

Experience Corps, Cambridge

Hadleigh Volunteer Centre, Suffolk

Halesworth Volunteer Group, Suffolk

Health Centre, Ipswich, Suffolk

Ipswich Volunteer Centre, Suffolk

Ixworth GP Surgery, Ixworth, Suffolk

Julian Hospital, Norwich

Lowestoft Volunteer Group, Suffolk

Norfolk Social Services

Norwich \& Norfolk Voluntary Services (NVS)

Norwich \& District Carers Forum, Norwich

Nursing \& Patient Services, Ipswich Hospital NHS

Trust, Suffolk

Pabulum Project, Norwich

Rethink Disability, Stowmarket, Suffolk
Rookery Medical Centre, Newmarket, Suffolk

Suffolk Social Services

Stowmarket Volunteer Centre, Stowmarket, Suffolk

Suffolk Acre, Ipswich, Suffolk

Suffolk Association Voluntary Organisation (SAVO)

Suffolk Carers, Suffolk

Waveney Primary Care Trust, Suffolk

The SAND group of practices (Thorpewood Surgery; Manor Farm Close, Drayton; Bacon Road Medical Centre; Orchard St 1; Botesdale H/C, Diss; Bungay) is thanked for their assistance in recruitment, as are the following: Acle, Coastal Villages Practices (Mensby, Ormesby, Caister, Martham), King Street, Great Yarmouth; Central Surgery, Great Yarmouth; Aldborough; Holt Medical Practice; Old Palace Medical Practice; Castle Partnership; Trinity St (\& Bowthorpe); Oak St Medical Practice; Manor Dr, Litcham;

Watlington Medical Centre; Carole Brown H/C, Dersingham; Gayton Road; Grimston Medical Centre, Kings Lynn; Woodbridge Road, Ipswich; Chesterfield Drive, Ipswich; Dr Jones \& Partners, Bury. 



\section{Appendix 2}

\section{Unit costs and sources}

\begin{tabular}{|c|c|c|c|}
\hline Item & Unit & Cost & Source/notes \\
\hline \multicolumn{4}{|l|}{ Hospital visits } \\
\hline NHS inpatient & per night & $£ 309.77$ & 2002 cost of $£ 273$ inflated to 2005 (PSSRU, 2002) 102 \\
\hline NHS A\&E attendance & per visit & $£ 106.00$ & $\begin{array}{l}\text { NHS reference costs } 2005,{ }^{103} \text { NHS trust and PCT } \\
\text { combined schedule, TOPS FA, code } 180\end{array}$ \\
\hline NHS outpatient attendance & per visit & $£ 93.04$ & 2002 cost of $£ 82$ inflated to 2005 (PSSRU, 2002) 102 \\
\hline NHS day-case attendance & per visit & $£ 93.04$ & Assumed same as outpatient cost \\
\hline NHS other attendance & per visit & $£ 93.04$ & Assumed same as outpatient cost \\
\hline \multicolumn{4}{|l|}{ Primary care } \\
\hline GP surgery visit & per visit & $€ 24.00$ & $\begin{array}{l}\text { Per surgery consultation lasting } 10 \text { minutes (PSSRU, } \\
2005, \mathrm{P} \mid 33)^{104}\end{array}$ \\
\hline GP home visit & per visit & $£ 69.00$ & $\begin{array}{l}\text { Per home visit lasting } 13.2 \text { minutes }+12 \text { minutes travel } \\
\text { (PSSRU 2005, PI33) }\end{array}$ \\
\hline GP telephone contact & per call & $£ 25.00$ & $\begin{array}{l}\text { Per telephone conversation lasting } 10.8 \text { minutes (PSSRU, } \\
2005, \mathrm{PI} 33)^{104}\end{array}$ \\
\hline Nurse surgery visit & per visit & $£ 10.00$ & $\begin{array}{l}\text { Per consultation, including qualification costs (PSSRU, } \\
2005, \mathrm{PI} 30)^{104}\end{array}$ \\
\hline Nurse home visit & per visit & $£ 23.00$ & $\begin{array}{l}\text { Per district nurse home visit, including qualification costs } \\
\text { (PSSRU, 2005, PI25) }\end{array}$ \\
\hline Nurse telephone contact & per call & $€ 18.02$ & $\begin{array}{l}\text { National Audit Office report on NHS Direct in England, } \\
\text { 2002, inflated to } 2005^{105}\end{array}$ \\
\hline Other surgery visit & per visit & $£ 10.00$ & Assumed same as nurse surgery visit \\
\hline Other home visit & per visit & $£ 23.00$ & Assumed same as nurse surgery visit \\
\hline Other telephone contact & per call & $£ \mid 8.02$ & Assumed same as nurse surgery visit \\
\hline \multicolumn{4}{|l|}{ Travel costs } \\
\hline Private car & per mile & $£ 0.34$ & AA motoring costs $(2005)^{106}$ \\
\hline Community transport & per mile & $£ \mid .75$ & Trial data, average patient transport service journey \\
\hline \multicolumn{4}{|l|}{ Visits to other professionals } \\
\hline NHS counsellor, home visit & per visit & $£ \mid 67.81$ & $\begin{array}{l}\text { NHS psychologist domiciliary visit (NHS reference costs, } \\
2005)^{103}\end{array}$ \\
\hline NHS counsellor, clinic visit & per visit & $£ 39.00$ & $\begin{array}{l}\text { Per hour counselling service in primary care (PSSRU, } \\
\left.2005, \mathrm{PI}^{100}\right)^{104}\end{array}$ \\
\hline NHS chiropodist, home visit & per visit & $£ 20.00$ & $\begin{array}{l}\text { Per home visit, community chiropodist (PSSRU, 2005, } \\
\text { PI20) }\end{array}$ \\
\hline NHS chiropodist, clinic visit & per visit & 611.00 & $\begin{array}{l}\text { Per clinic visit, community chiropodist (PSSRU, 2005, } \\
\text { PI20) }\end{array}$ \\
\hline NHS other, home visit & per visit & $£ 20.00$ & Assumed same as chiropodist \\
\hline NHS other, clinic visit & per visit & $f 11.00$ & Assumed same as chiropodist \\
\hline \multicolumn{4}{|l|}{ Day care/day hospital } \\
\hline Local authority day care & per day & $£ 38.00$ & $\begin{array}{l}\text { Per day, local authority social services day care for } \\
\text { people with mental health problems (PSSRU, 2005, } \\
\text { P58) }\end{array}$ \\
\hline
\end{tabular}




\begin{tabular}{|c|c|c|c|}
\hline Item & Unit & Cost & Source/notes \\
\hline Voluntary-sector day care & per day & $£ 37.00$ & $\begin{array}{l}\text { Per day, voluntary/not-for-profit organisation providing } \\
\text { day care for people with mental health problems } \\
\text { (PSSRU, 2005, P59) }\end{array}$ \\
\hline Day hospital & per day & $£ 57.00$ & $\begin{array}{l}\text { Per day, NHS trust day care for people with mental } \\
\text { health problems (PSSRU, 2005, P57) }\end{array}$ \\
\hline \multicolumn{4}{|l|}{ Home care } \\
\hline Sitting service & per session & $€ \mid 1.50$ & Mean cost of five agencies in Torbay \\
\hline Home care & $\begin{array}{l}\text { per weekday } \\
\text { hour }\end{array}$ & $£ \mid 3.00$ & $\begin{array}{l}\text { Local authority home care worker (PSSRU, 2005, } \\
\text { PI4I) }\end{array}$ \\
\hline Other & per session & $f 12.25$ & Assumed mean of sitting service and home care service \\
\hline \multicolumn{4}{|l|}{ Other services } \\
\hline Meals on wheels & per meal & $£ 2.27$ & $\begin{array}{l}\text { Mean cost of ten councils (Haringey, Trafford, } \\
\text { Manchester, Powys, Isle of Man, Northamptonshire, } \\
\text { Medway, North Tyneside, Birmingham, Tameside) }\end{array}$ \\
\hline Other & per unit & $£ 13.00$ & $\begin{array}{l}\text { I hour of housework, local authority care worker } \\
(\text { PSSRU, 2005, PI4I) })^{104}\end{array}$ \\
\hline \multicolumn{4}{|c|}{ Occasional visits to the home/community services } \\
\hline NHS district nurse, home visit & per visit & $£ 23.00$ & District nurse home visit (PSSRU, 2005, PI25) 104 \\
\hline NHS district nurse, clinic visit & per visit & $£ 46.00$ & District nurse per hour in clinic (PSSRU, 2005, PI25) \\
\hline $\begin{array}{l}\text { NHS district nurse, telephone } \\
\text { contact }\end{array}$ & per call & $£ 46.00$ & Assumed same as clinic cost \\
\hline $\begin{array}{l}\text { NHS occupational therapist, } \\
\text { home visit }\end{array}$ & per visit & $£ 54.00$ & $\begin{array}{l}\text { Per home visit, NHS community occupational therapist } \\
\text { (PSSRU, 2005, PI I8) } 104\end{array}$ \\
\hline $\begin{array}{l}\text { NHS occupational therapist, } \\
\text { clinic visit }\end{array}$ & per visit & $£ 20.00$ & $\begin{array}{l}\text { Per clinic visit, NHS community occupational therapist } \\
\text { (PSSRU, 2005, PII8) }\end{array}$ \\
\hline $\begin{array}{l}\text { NHS occupational therapist, } \\
\text { telephone contact }\end{array}$ & per call & $£ 20.00$ & Assumed same as clinic cost \\
\hline NHS psychiatrist, home visit & per visit & $£ 87.00$ & Assumed same as clinic cost \\
\hline NHS psychiatrist, clinic visit & per visit & $£ 87.00$ & $\begin{array}{l}\text { Consultant: psychiatric cost per hour, including } \\
\text { qualification costs (PSSRU, 2005, PI86) }\end{array}$ \\
\hline NHS psychiatrist, telephone contact & per call & $£ 87.00$ & Assumed same as clinic cost \\
\hline NHS psychologist, home visit & per visit & $f \mid 67.81$ & $\begin{array}{l}\text { Domiciliary visit, clinical/consultant psychologist (NHS } \\
\text { reference, costs, 2005) }\end{array}$ \\
\hline NHS psychologist, clinic visit & per visit & $£ 44.00$ & $\begin{array}{l}\text { Per professional chargeable hour, clinic psychologist } \\
(\text { PSSRU, 2005, PI2I) }\end{array}$ \\
\hline NHS psychologist, telephone contact & per call & $£ 44.00$ & Assumed same as clinic cost \\
\hline NHS CPN, home visit & per visit & $£ 31.00$ & $\begin{array}{l}\text { Per home visit, including qualification costs (PSSRU, } \\
2005, P \mid 26)^{104}\end{array}$ \\
\hline NHS CPN, clinic visit & per visit & $£ 64.00$ & $\begin{array}{l}\text { Per hour clinic contact, including qualification costs } \\
\text { (PSSRU, 2005, PI26) }\end{array}$ \\
\hline NHS CPN, telephone contact & per call & $£ 64.00$ & Assumed same as clinic cost \\
\hline Social worker, home visit & per visit & $£ 58.00$ & $\begin{array}{l}\text { Per hour of home visiting (PSSRU, 2005, PI39) } \\
\text { (children social worker; adult home visit cost not } \\
\text { available) }\end{array}$ \\
\hline Social worker, clinic visit & per visit & $£ 35.00$ & Per hour of client-related work (PSSRU, 2005, PI39) ${ }^{104}$ \\
\hline Social worker, telephone contact & per call & $£ 35.00$ & Assumed same as clinic cost \\
\hline NHS physiotherapist, home visit & per visit & $£ 54.00$ & $\begin{array}{l}\text { Per physiotherapist home visit, including qualification } \\
\text { cost (PSSRU, 2005, PII } 7)^{104}\end{array}$ \\
\hline
\end{tabular}




\begin{tabular}{|c|c|c|c|}
\hline Item & Unit & Cost & Source/notes \\
\hline NHS physiotherapist, clinic visit & per visit & $£ 20.00$ & $\begin{array}{l}\text { Per physiotherapist clinic visit, including qualification cost } \\
\text { (PSSRU, 2005, PII } 7)^{104}\end{array}$ \\
\hline $\begin{array}{l}\text { NHS physiotherapist, telephone } \\
\text { contact }\end{array}$ & per call & $£ 20.00$ & Assumed same as clinic cost \\
\hline NHS other, home visit & per visit & $£ 23.00$ & Assumed same as district nurse \\
\hline NHS other, clinic visit & per visit & $£ 46.00$ & Assumed same as district nurse \\
\hline NHS other, telephone contact & per call & $£ 46.00$ & Assumed same as district nurse \\
\hline \multicolumn{4}{|l|}{ Respite stays and care-home admission } \\
\hline NHS residential care & per day & $£ 62.43$ & $\begin{array}{l}\text { Local authority residential care, based on weekly rate/7 } \\
(\text { PSSRU, 2005, P49) }\end{array}$ \\
\hline NHS respite care & per day & $€ 62.43$ & Assumed same as residential care \\
\hline NHS nursing care & per day & $€ 75.14$ & $\begin{array}{l}\text { Private nursing home for older people, based on weekly } \\
\text { rate/7 (PSSRU, 2005, P3I) }\end{array}$ \\
\hline NHS EMI care & per day & $E \mid 75.14$ & $\begin{array}{l}\text { Psychiatric reprovision package, nursing home } \\
\text { placement, weekly rate/7 (PSSRU, 2005, P64) }\end{array}$ \\
\hline Voluntary residential care & per day & $£ 55.00$ & $\begin{array}{l}\text { Voluntary agency residential care, based on weekly } \\
\text { rate/7 (PSSRU, 2005, P5I) }\end{array}$ \\
\hline Voluntary respite care & per day & $£ 62.43$ & Assumed same as NHS residential care \\
\hline Voluntary nursing care & per day & $€ 75.14$ & Assumed same as NHS nursing care \\
\hline Voluntary EMI care & per day & $E \mid 75.14$ & Assumed same as NHS EMI care \\
\hline Dual registered & per week & $£ 437.00$ & $\begin{array}{l}\text { Assumed same as local authority residential care, weekly } \\
\text { rate }\end{array}$ \\
\hline Other & per week & $£ 437.00$ & $\begin{array}{l}\text { Assumed same as local authority residential care, weekly } \\
\text { rate }\end{array}$ \\
\hline $\begin{array}{l}\text { Complementary therapy } \\
\text { Complementary therapy }\end{array}$ & per session & $£ 35.00$ & $\begin{array}{l}\text { Notional average cost of range of interventions costing } \\
\text { between } £ 20 \text { and } £ 65 \text { per session, collected from } \\
\text { Internet price lists from range of clinics }\end{array}$ \\
\hline \multicolumn{4}{|l|}{ Carer's assessment } \\
\hline Carer's assessment & $\begin{array}{l}\text { per } \\
\text { assessment }\end{array}$ & $€ 74.25$ & $\begin{array}{l}\text { Community mental health team per hour of patient } \\
\text { contact, including travel costs (PSSRU, 2005, PI50) }\end{array}$ \\
\hline \multicolumn{4}{|l|}{ Carer social support } \\
\hline $\begin{array}{l}\text { Indirect costs - value of caring time } \\
\text { Gross average wage rate }\end{array}$ & per hour & $E|3.1|$ & $\begin{array}{l}\text { Gross hourly rate for women and men, UK, } 2005 \\
\text { (ONS) }{ }^{107}\end{array}$ \\
\hline
\end{tabular}





\section{Appendix 3}

\section{Resource-use quantities at 15 months (complete case analysis)}

\begin{tabular}{|c|c|c|c|c|c|c|c|c|}
\hline & \multirow[b]{2}{*}{ Units } & \multicolumn{3}{|c|}{ Intervention } & \multicolumn{3}{|c|}{ Control } & \multirow{2}{*}{$\begin{array}{l}\text { Difference } \\
\text { in mean }\end{array}$} \\
\hline & & Valid $n$ & Mean & SD & Valid $n$ & Mean & SD & \\
\hline \multicolumn{9}{|l|}{ PwD hospital visits } \\
\hline Inpatient nights & nights & 93 & 6.89 & 16.25 & 102 & $|1.5|$ & 24.80 & -4.63 \\
\hline A\&E visit & visits & 94 & 0.30 & 0.96 & 103 & 0.31 & 1.24 & -0.01 \\
\hline Outpatient visit & visits & 94 & 1.78 & 2.73 & 103 & 1.57 & 2.40 & 0.21 \\
\hline Day case & visits & 94 & 0.13 & 0.58 & 103 & 0.23 & 1.09 & -0.10 \\
\hline \multicolumn{9}{|l|}{ PwD GP surgery visits } \\
\hline Surgery visits & visits & 94 & 4.32 & 6.46 & 102 & 4.91 & 7.56 & -0.59 \\
\hline Home visits & visits & 94 & 1.82 & 3.53 & 102 & 3.52 & 12.91 & -1.69 \\
\hline Telephone calls & calls & 94 & 1.54 & 4.18 & 102 & 1.58 & 7.60 & -0.04 \\
\hline PwD day care/day hospital & visits & 94 & 54.97 & 86.27 & 104 & 51.43 & 68.55 & 3.54 \\
\hline PwD home care & hours & 87 & 185.80 & 549.98 & 100 & 99.72 & $|77.9|$ & 86.08 \\
\hline \multicolumn{9}{|l|}{ PwD other services } \\
\hline Meals & meals & 90 & 5.25 & 26.22 & 97 & 7.62 & 49.58 & -2.37 \\
\hline Other service NHS/voluntary & hours & 90 & 1.08 & 5.44 & 97 & 0.27 & 2.64 & 0.81 \\
\hline Other service private & weeks & 90 & $|3.6|$ & 26.46 & 97 & 19.72 & 39.61 & -6.11 \\
\hline \multicolumn{9}{|l|}{ PwD occasional visits to home } \\
\hline Home visits & visits & 93 & 5.87 & 7.39 & 104 & 8.52 & $|8.4|$ & -2.65 \\
\hline Clinic visits & visits & 94 & 1.50 & 4.19 & 104 & 2.01 & 5.22 & -0.51 \\
\hline Telephone calls & call & 94 & 1.10 & 5.09 & 104 & 0.22 & 1.15 & 0.87 \\
\hline \multicolumn{9}{|l|}{ PwD respite stays } \\
\hline Residential care & nights & 94 & 6.54 & 16.11 & 104 & 6.24 & 17.14 & 0.31 \\
\hline Respite care & nights & 94 & 2.31 & 8.51 & 104 & 0.37 & 2.78 & 1.94 \\
\hline Nursing home & nights & 94 & 1.00 & 6.58 & 104 & 1.87 & 9.84 & -0.86 \\
\hline EMI & nights & 94 & 1.28 & 5.17 & 104 & 2.33 & 21.09 & -1.05 \\
\hline $\begin{array}{l}\text { Hours spent caring for PwD } \\
\text { by carer }\end{array}$ & hours & 94 & 7529.64 & 3448.35 & 105 & 7768.59 & 3587.45 & -238.95 \\
\hline $\begin{array}{l}\text { Hours spent caring for PwD } \\
\text { by family/friends }\end{array}$ & hours & 81 & 282.70 & 720.84 & 87 & 269.55 & 364.79 & 13.14 \\
\hline Carer assessment & number & 94 & 0.26 & 0.53 & 100 & 0.23 & 0.47 & 0.03 \\
\hline \multicolumn{9}{|l|}{ Carer GP surgery visits } \\
\hline Surgery visits & visits & 99 & 6.70 & 7.22 & 106 & 6.61 & 5.88 & 0.08 \\
\hline Home visits & visits & 99 & 0.19 & 0.84 & 106 & 0.49 & 2.35 & -0.30 \\
\hline Telephone calls & calls & 99 & 0.39 & 1.32 & 106 & 0.65 & 1.85 & -0.25 \\
\hline \multicolumn{9}{|l|}{ Carer hospital visits } \\
\hline Inpatient nights & nights & 99 & 0.49 & 1.53 & 105 & 1.20 & 3.62 & $-0.7 \mid$ \\
\hline A\&E visit & visits & 99 & 0.12 & 0.58 & 105 & 0.29 & 1.12 & -0.17 \\
\hline Outpatient visit & visits & 98 & 2.21 & 3.38 & 105 & 2.16 & 4.12 & 0.05 \\
\hline Day case & visits & 99 & 0.81 & 6.32 & 105 & 0.12 & 0.43 & 0.69 \\
\hline Other & visits & 99 & 0.13 & 0.89 & 105 & 0.05 & 0.25 & 0.08 \\
\hline \multicolumn{9}{|l|}{ Carer community services } \\
\hline Home visits & visits & 99 & 1.13 & 4.87 & 106 & 0.68 & 3.89 & 0.45 \\
\hline Clinic visits & visits & 99 & 0.22 & 1.17 & 106 & 0.41 & 2.28 & -0.18 \\
\hline Carer complementary therapy & sessions & 98 & 3.11 & 12.60 & 106 & 2.60 & 8.05 & 0.51 \\
\hline Carer social support & sessions & 98 & 30.65 & 51.07 & 103 & 31.21 & 52.66 & -0.56 \\
\hline Carer social worker & visits & 115 & 0.35 & 2.56 & 118 & 0.14 & 0.42 & 0.21 \\
\hline Carer other services & units & 98 & 6.79 & 16.78 & 104 & 4.79 & 13.60 & 2.01 \\
\hline PwD in care & weeks & 88 & 5.47 & 13.95 & 98 & 2.58 & 10.21 & 2.89 \\
\hline
\end{tabular}





\section{Appendix 4}

\section{Detailed breakdown of per-carer/person with dementia costs at 15 months}




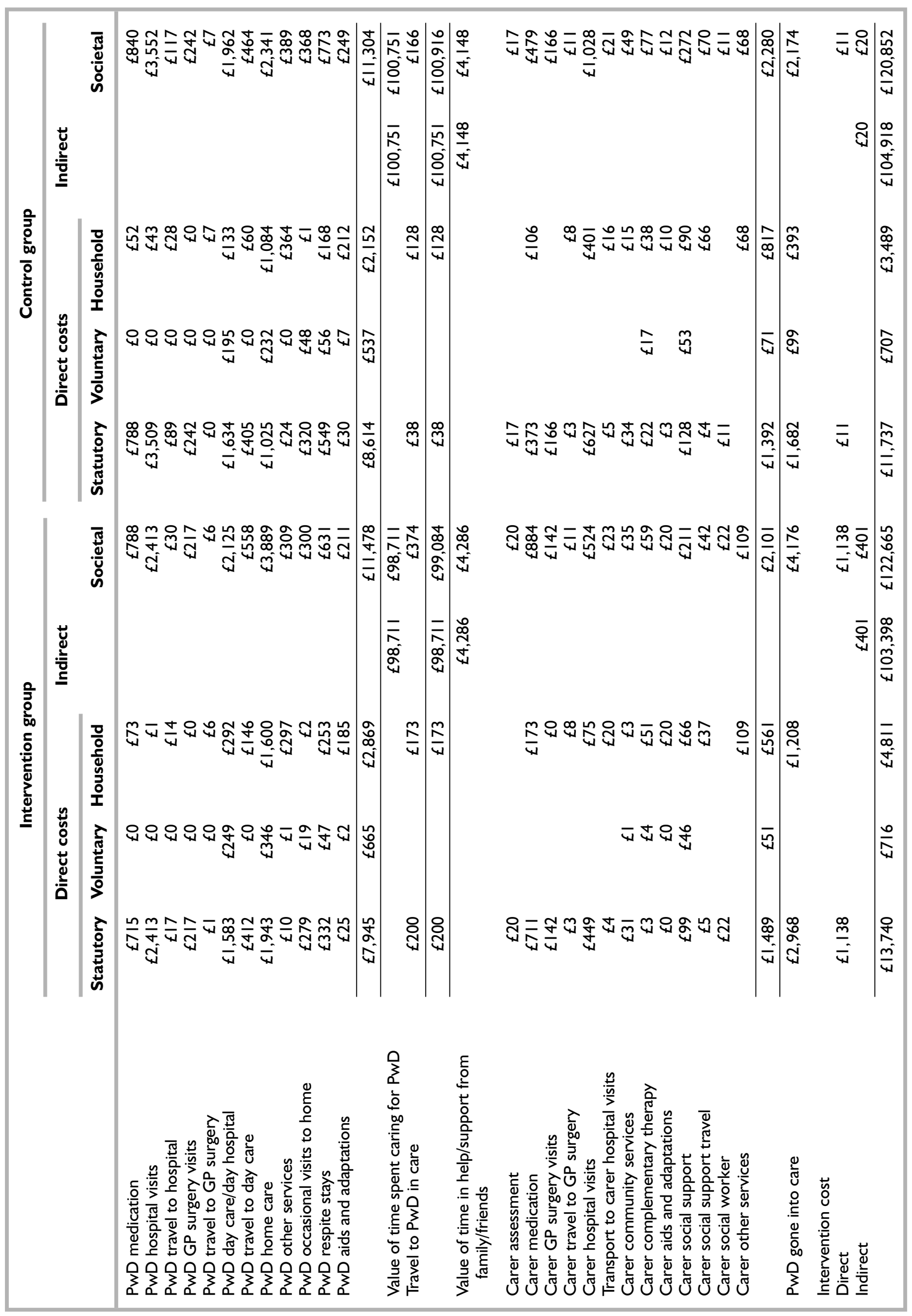




\section{Health Technology Assessment reports published to date}

\section{Volume I, 1997}

No. 1

Home parenteral nutrition: a systematic review.

By Richards DM, Deeks JJ, Sheldon TA, Shaffer JL.

No. 2

Diagnosis, management and screening of early localised prostate cancer.

A review by Selley S, Donovan J, Faulkner A, Coast J, Gillatt D.

No. 3

The diagnosis, management, treatment and costs of prostate cancer in England and Wales.

A review by Chamberlain J, Melia J, Moss S, Brown J.

No. 4

Screening for fragile $\mathrm{X}$ syndrome.

A review by Murray J, Cuckle $\mathrm{H}$, Taylor G, Hewison J.

No. 5

A review of near patient testing in primary care.

By Hobbs FDR, Delaney BC, Fitzmaurice DA, Wilson S, Hyde CJ, Thorpe GH, et al.

No. 6

Systematic review of outpatient services for chronic pain control.

By McQuay HJ, Moore RA, Eccleston C, Morley S, de C Williams AC.

No. 7

Neonatal screening for inborn errors of metabolism: cost, yield and outcome.

A review by Pollitt RJ, Green A,

McCabe CJ, Booth A, Cooper NJ,

Leonard JV, et al.

No. 8

Preschool vision screening.

A review by Snowdon SK, Stewart-Brown SL.

No. 9

Implications of socio-cultural contexts for the ethics of clinical trials.

A review by Ashcroft RE, Chadwick

DW, Clark SRL, Edwards RHT, Frith L, Hutton JL.

No. 10

A critical review of the role of neonatal hearing screening in the detection of congenital hearing impairment.

By Davis A, Bamford J, Wilson I,

Ramkalawan T, Forshaw M, Wright S.
No. 11

Newborn screening for inborn errors of metabolism: a systematic review.

By Seymour CA, Thomason MJ,

Chalmers RA, Addison GM, Bain MD, Cockburn F, et al.

No. 12

Routine preoperative testing: a systematic review of the evidence. By Munro J, Booth A, Nicholl J.

No. 13

Systematic review of the effectiveness of laxatives in the elderly.

By Petticrew M, Watt I, Sheldon T.

No. 14

When and how to assess fast-changing technologies: a comparative study of medical applications of four generic technologies.

A review by Mowatt G, Bower DJ, Brebner JA, Cairns JA, Grant AM, McKee L.

\section{Volume 2, 1998}

No. 1

Antenatal screening for Down's syndrome.

A review by Wald NJ, Kennard A, Hackshaw A, McGuire A.

No. 2

Screening for ovarian cancer:

a systematic review.

By Bell R, Petticrew M, Luengo S, Sheldon TA.

No. 3

Consensus development methods, and their use in clinical guideline development.

A review by Murphy MK, Black NA, Lamping DL, McKee CM, Sanderson CFB, Askham J, et al.

No. 4

A cost-utility analysis of interferon beta for multiple sclerosis.

By Parkin D, McNamee P, Jacoby A, Miller P, Thomas S, Bates D.

No. 5

Effectiveness and efficiency of methods of dialysis therapy for end-stage renal

disease: systematic reviews.

By MacLeod A, Grant A

Donaldson C, Khan I, Campbell M, Daly C, et al.
No. 6

Effectiveness of hip prostheses in primary total hip replacement: a critical review of evidence and an economic model.

By Faulkner A, Kennedy LG,

Baxter K, Donovan J, Wilkinson M, Bevan G.

\section{No. 7}

Antimicrobial prophylaxis in colorectal surgery: a systematic review of randomised controlled trials. By Song F, Glenny AM.

No. 8

Bone marrow and peripheral blood stem cell transplantation for malignancy.

A review by Johnson PWM, Simnett SJ, Sweetenham JW, Morgan GJ, Stewart LA.

No. 9

Screening for speech and language

delay: a systematic review of the literature.

By Law J, Boyle J, Harris F, Harkness A, Nye C.

No. 10

Resource allocation for chronic stable angina: a systematic review of effectiveness, costs and cost-effectiveness of alternative interventions.

By Sculpher MJ, Petticrew M, Kelland JL, Elliott RA, Holdright DR, Buxton MJ.

No. 11

Detection, adherence and control of hypertension for the prevention of stroke: a systematic review.

By Ebrahim S.

No. 12

Postoperative analgesia and vomiting, with special reference to day-case surgery: a systematic review.

By McQuay HJ, Moore RA.

No. 13

Choosing between randomised and nonrandomised studies: a systematic review.

By Britton A, McKee M, Black N, McPherson K, Sanderson C, Bain C.

No. 14

Evaluating patient-based outcome measures for use in clinical trials.

A review by Fitzpatrick R, Davey C, Buxton MJ, Jones DR. 
No. 15

Ethical issues in the design and conduct of randomised controlled trials.

A review by Edwards SJL, Lilford RJ, Braunholtz DA, Jackson JC, Hewison J, Thornton J.

\section{No. 16}

Qualitative research methods in health technology assessment: a review of the literature.

By Murphy E, Dingwall R, Greatbatch D, Parker S, Watson P.

No. 17

The costs and benefits of paramedic skills in pre-hospital trauma care.

By Nicholl J, Hughes S, Dixon S, Turner J, Yates D.

\section{No. 18}

Systematic review of endoscopic ultrasound in gastro-oesophageal cancer.

By Harris KM, Kelly S, Berry E, Hutton J, Roderick P, Cullingworth J, et al.

No. 19

Systematic reviews of trials and other studies.

By Sutton AJ, Abrams KR, Jones DR, Sheldon TA, Song F

No. 20

Primary total hip replacement surgery: a systematic review of outcomes and modelling of cost-effectiveness associated with different prostheses.

A review by Fitzpatrick R, Shortall E, Sculpher M, Murray D, Morris R, Lodge $\mathrm{M}$, et al.

\section{Volume 3, 1999}

No. 1

Informed decision making: an annotated bibliography and systematic review.

By Bekker H, Thornton JG,

Airey CM, Connelly JB, Hewison J, Robinson MB, et al.

No. 2

Handling uncertainty when performing economic evaluation of healthcare interventions.

A review by Briggs AH, Gray AM.

No. 3

The role of expectancies in the placebo effect and their use in the delivery of health care: a systematic review.

By Crow R, Gage H, Hampson S, Hart J, Kimber A, Thomas H.

No. 4

A randomised controlled trial of different approaches to universal antenatal HIV testing: uptake and acceptability. Annex: Antenatal HIV testing - assessment of a routine voluntary approach.

By Simpson WM, Johnstone FD, Boyd FM, Goldberg DJ, Hart GJ, Gormley $\mathrm{SM}$, et al.
No. 5

Methods for evaluating area-wide and organisation-based interventions in health and health care: a systematic review.

By Ukoumunne OC, Gulliford MC, Chinn S, Sterne JAC, Burney PGJ.

No. 6

Assessing the costs of healthcare technologies in clinical trials.

A review by Johnston $\mathrm{K}$, Buxton $\mathrm{MJ}$, Jones DR, Fitzpatrick R.

No. 7

Cooperatives and their primary care emergency centres: organisation and impact.

By Hallam L, Henthorne K.

No. 8

Screening for cystic fibrosis.

A review by Murray J, Cuckle $\mathrm{H}$, Taylor G, Littlewood J, Hewison J.

No. 9

A review of the use of health status measures in economic evaluation.

By Brazier J, Deverill M, Green C, Harper R, Booth A.

No. 10

Methods for the analysis of quality-oflife and survival data in health technology assessment.

A review by Billingham LJ, Abrams KR, Jones DR.

No. 11

Antenatal and neonatal

haemoglobinopathy screening in the

UK: review and economic analysis.

By Zeuner D, Ades AE, Karnon J,

Brown J, Dezateux C, Anionwu EN.

\section{No. 12}

Assessing the quality of reports of randomised trials: implications for the conduct of meta-analyses.

A review by Moher D, Cook DJ, Jadad AR, Tugwell P, Moher M, Jones A, et al.

No. 13

'Early warning systems' for identifying new healthcare technologies.

By Robert G, Stevens A, Gabbay J.

No. 14

A systematic review of the role of human papillomavirus testing within a cervical screening programme.

By Cuzick J, Sasieni P, Davies P, Adams J, Normand C, Frater A, et al.

\section{No. 15}

Near patient testing in diabetes clinics: appraising the costs and outcomes.

By Grieve R, Beech R, Vincent J, Mazurkiewicz J

\section{No. 16}

Positron emission tomography: establishing priorities for health technology assessment.

A review by Robert G, Milne R.
No. 17 (Pt 1)

The debridement of chronic wounds: a systematic review.

By Bradley M, Cullum N, Sheldon T.

\section{No. 17 (Pt 2)}

Systematic reviews of wound care management: (2) Dressings and topical agents used in the healing of chronic wounds.

By Bradley M, Cullum N, Nelson EA, Petticrew M, Sheldon T, Torgerson D.

\section{No. 18}

A systematic literature review of spiral and electron beam computed

tomography: with particular reference to clinical applications in hepatic lesions, pulmonary embolus and coronary artery disease.

By Berry E, Kelly S, Hutton J, Harris KM, Roderick P, Boyce JC, et al.

\section{No. 19}

What role for statins? A review and economic model.

By Ebrahim S, Davey Smith G

McCabe C, Payne N, Pickin M, Sheldon TA, et al.

\section{No. 20}

Factors that limit the quality, number and progress of randomised controlled trials.

A review by Prescott RJ, Counsell CE, Gillespie WJ, Grant AM, Russell IT, Kiauka S, et al.

No. 21

Antimicrobial prophylaxis in total hip replacement: a systematic review.

By Glenny AM, Song F.

No. 22

Health promoting schools and health promotion in schools: two systematic reviews.

By Lister-Sharp D, Chapman S, Stewart-Brown S, Sowden A.

No. 23

Economic evaluation of a primary carebased education programme for patients with osteoarthritis of the knee.

A review by Lord I, Victor $C$, Littlejohns P, Ross FM, Axford JS.

\section{Volume 4, 2000}

No. 1

The estimation of marginal time preference in a UK-wide sample (TEMPUS) project.

A review by Cairns JA, van der Pol MM.

No. 2

Geriatric rehabilitation following fractures in older people: a systematic review.

By Cameron I, Crotty M, Currie C, Finnegan T, Gillespie L, Gillespie W, et al. 
No. 3

Screening for sickle cell disease and thalassaemia: a systematic review with supplementary research.

By Davies SC, Cronin E, Gill M, Greengross P, Hickman M, Normand C.

No. 4

Community provision of hearing aids and related audiology services.

A review by Reeves DJ, Alborz A, Hickson FS, Bamford JM.

No. 5

False-negative results in screening programmes: systematic review of impact and implications.

By Petticrew MP, Sowden AJ, Lister-Sharp D, Wright K.

No. 6

Costs and benefits of community postnatal support workers: a randomised controlled trial.

By Morrell CJ, Spiby H, Stewart P, Walters S, Morgan A.

No. 7

Implantable contraceptives (subdermal implants and hormonally impregnated intrauterine systems) versus other forms of reversible contraceptives: two systematic reviews to assess relative effectiveness, acceptability, tolerability and cost-effectiveness.

By French RS, Cowan FM, Mansour DJA, Morris S, Procter T, Hughes D, et al.

No. 8

An introduction to statistical methods for health technology assessment

A review by White SJ, Ashby D, Brown PJ

No. 9

Disease-modifying drugs for multiple sclerosis: a rapid and systematic review.

By Clegg A, Bryant J, Milne R.

\section{No. 10}

Publication and related biases.

A review by Song F, Eastwood AJ, Gilbody S, Duley L, Sutton AJ.

No. 11

Cost and outcome implications of the organisation of vascular services.

By Michaels J, Brazier J, Palfreyman S, Shackley P, Slack R.

No. 12

Monitoring blood glucose control in diabetes mellitus: a systematic review.

By Coster S, Gulliford MC, Seed PT, Powrie JK, Swaminathan R.

No. 13

The effectiveness of domiciliary health visiting: a systematic review of international studies

and a selective review of the British literature.

By Elkan R, Kendrick D, Hewitt M, Robinson JJA, Tolley K, Blair M, et al.
No. 14

The determinants of screening uptake and interventions for increasing uptake: a systematic review.

By Jepson R, Clegg A, Forbes C, Lewis R, Sowden A, Kleijnen J.

\section{No. 15}

The effectiveness and cost-effectiveness of prophylactic removal of wisdom teeth.

A rapid review by Song F, O'Meara S, Wilson P, Golder S, Kleijnen J.

\section{No. 16}

Ultrasound screening in pregnancy: a systematic review of the clinical effectiveness, cost-effectiveness and women's views.

By Bricker L, Garcia J, Henderson J, Mugford M, Neilson J, Roberts T, et al.

\section{No. 17}

A rapid and systematic review of the effectiveness and cost-effectiveness of the taxanes used in the treatment of advanced breast and ovarian cancer.

By Lister-Sharp D, McDonagh MS, Khan KS, Kleijnen J.

\section{No. 18}

Liquid-based cytology in cervical screening: a rapid and systematic review.

By Payne N, Chilcott J, McGoogan E.

No. 19

Randomised controlled trial of nondirective counselling, cognitive-behaviour therapy and usual general practitioner care in the management of depression as well as mixed anxiety and depression in primary care.

By King M, Sibbald B, Ward E, Bower P, Lloyd M, Gabbay M, et al.

\section{No. 20}

Routine referral for radiography of patients presenting with low back pain: is patients' outcome influenced by GPs' referral for plain radiography?

By Kerry S, Hilton S, Patel S, Dundas D, Rink E, Lord J.

\section{No. 21}

Systematic reviews of wound care management: (3) antimicrobial agents for chronic wounds; (4) diabetic foot ulceration.

By O'Meara S, Cullum N, Majid M, Sheldon T.

\section{No. 22}

Using routine data to complement and enhance the results of randomised controlled trials.

By Lewsey JD, Leyland AH,

Murray GD, Boddy FA.

No. 23

Coronary artery stents in the treatment of ischaemic heart disease: a rapid and systematic review.

By Meads C, Cummins C, Jolly K, Stevens A, Burls A, Hyde C.
No. 24

Outcome measures for adult critical

care: a systematic review.

By Hayes JA, Black NA,

Jenkinson C, Young JD, Rowan KM, Daly K, et al.

\section{No. 25}

A systematic review to evaluate the effectiveness of interventions to promote the initiation of breastfeeding.

By Fairbank L, O'Meara S, Renfrew MJ, Woolridge M, Sowden AJ, Lister-Sharp D.

No. 26

Implantable cardioverter defibrillators: arrhythmias. A rapid and systematic review.

By Parkes J, Bryant J, Milne R.

No. 27

Treatments for fatigue in multiple sclerosis: a rapid and systematic review.

By Brañas P, Jordan R, Fry-Smith A, Burls A, Hyde C.

No. 28

Early asthma prophylaxis, natural history, skeletal development and economy (EASE): a pilot randomised controlled trial.

By Baxter-Jones ADG, Helms PJ, Russell G, Grant A, Ross S, Cairns JA, et al.

No. 29

Screening for hypercholesterolaemia versus case finding for familial hypercholesterolaemia: a systematic review and cost-effectiveness analysis.

By Marks D, Wonderling D,

Thorogood M, Lambert H, Humphries SE, Neil HAW.

No. 30

A rapid and systematic review of the clinical effectiveness and cost-

effectiveness of glycoprotein IIb/IIIa antagonists in the medical management of unstable angina.

By McDonagh MS, Bachmann LM, Golder S, Kleijnen J, ter Riet G.

No. 31

A randomised controlled trial of prehospital intravenous fluid replacement therapy in serious trauma. By Turner J, Nicholl J, Webber L, Cox H, Dixon S, Yates D.

No. 32

Intrathecal pumps for giving opioids in chronic pain: a systematic review.

By Williams JE, Louw G, Towlerton G.

No. 33

Combination therapy (interferon alfa and ribavirin) in the treatment of chronic hepatitis C: a rapid and systematic review.

By Shepherd J, Waugh N, Hewitson P. 
No. 34

A systematic review of comparisons of effect sizes derived from randomised and non-randomised studies.

By MacLehose RR, Reeves BC, Harvey IM, Sheldon TA, Russell IT, Black AMS.

No. 35

Intravascular ultrasound-guided interventions in coronary artery disease: a systematic literature review, with decision-analytic modelling, of outcomes and cost-effectiveness.

By Berry E, Kelly S, Hutton J, Lindsay HSJ, Blaxill JM, Evans JA, et al.

No. 36

A randomised controlled trial to evaluate the effectiveness and costeffectiveness of counselling patients with chronic depression.

By Simpson S, Corney R, Fitzgerald P, Beecham J.

No. 37

Systematic review of treatments for atopic eczema.

By Hoare C, Li Wan Po A, Williams H.

No. 38

Bayesian methods in health technology assessment: a review.

By Spiegelhalter DJ, Myles JP, Jones DR, Abrams KR.

No. 39

The management of dyspepsia: a systematic review.

By Delaney B, Moayyedi P, Deeks J, Innes M, Soo S, Barton $\mathrm{P}$, et al.

No. 40

A systematic review of treatments for severe psoriasis.

By Griffiths CEM, Clark CM, Chalmers RJG, Li Wan Po A, Williams HC.

\section{Volume 5, 200I}

No. 1

Clinical and cost-effectiveness of donepezil, rivastigmine and galantamine for Alzheimer's disease: a rapid and systematic review.

By Clegg A, Bryant J, Nicholson T, McIntyre L, De Broe S, Gerard K, et al.

No. 2

The clinical effectiveness and costeffectiveness of riluzole for motor neurone disease: a rapid and systematic review.

By Stewart A, Sandercock J, Bryan S, Hyde C, Barton PM, Fry-Smith A, et al.

No. 3

Equity and the economic evaluation of healthcare.

By Sassi F, Archard L, Le Grand J.

No. 4

Quality-of-life measures in chronic

diseases of childhood

By Eiser C, Morse R.
No. 5

Eliciting public preferences for

healthcare: a systematic review of techniques.

By Ryan M, Scott DA, Reeves C, Bate A, van Teijlingen ER, Russell EM, et al.

No. 6

General health status measures for people with cognitive impairment: learning disability and acquired brain injury.

By Riemsma RP, Forbes CA, Glanville JM, Eastwood AJ, Kleijnen J.

No. 7

An assessment of screening strategies for fragile $\mathrm{X}$ syndrome in the UK.

By Pembrey ME, Barnicoat AJ, Carmichael B, Bobrow M, Turner G.

No. 8

Issues in methodological research: perspectives from researchers and commissioners.

By Lilford RJ, Richardson A, Stevens A, Fitzpatrick R, Edwards S, Rock F, et al.

No. 9

Systematic reviews of wound care management: (5) beds; (6) compression;

(7) laser therapy, therapeutic

ultrasound, electrotherapy and

electromagnetic therapy.

By Cullum N, Nelson EA, Flemming

K, Sheldon T.

No. 10

Effects of educational and psychosocial interventions for adolescents with diabetes mellitus: a systematic review.

By Hampson SE, Skinner TC, Hart J, Storey L, Gage H, Foxcroft D, et al.

\section{No. 11}

Effectiveness of autologous chondrocyte transplantation for hyaline cartilage defects in knees: a rapid and systematic review.

By Jobanputra P, Parry D, Fry-Smith A, Burls A.

\section{No. 12}

Statistical assessment of the learning curves of health technologies.

By Ramsay CR, Grant AM,

Wallace SA, Garthwaite PH, Monk AF, Russell IT.

\section{No. 13}

The effectiveness and cost-effectiveness of temozolomide for the treatment of recurrent malignant glioma: a rapid and systematic review.

By Dinnes J, Cave C, Huang S, Major K, Milne R.

\section{No. 14}

A rapid and systematic review of the clinical effectiveness and costeffectiveness of debriding agents in treating surgical wounds healing by secondary intention.

By Lewis R, Whiting P, ter Riet G, O’Meara S, Glanville J.
No. 15

Home treatment for mental health

problems: a systematic review.

By Burns T, Knapp M,

Catty J, Healey A, Henderson J, Watt $\mathrm{H}$, et al.

\section{No. 16}

How to develop cost-conscious guidelines.

By Eccles M, Mason J.

No. 17

The role of specialist nurses in multiple sclerosis: a rapid and systematic review.

By De Broe S, Christopher F, Waugh N.

No. 18

A rapid and systematic review of the clinical effectiveness and costeffectiveness of orlistat in the management of obesity.

By O'Meara S, Riemsma R, Shirran L, Mather L, ter Riet G.

\section{No. 19}

The clinical effectiveness and costeffectiveness of pioglitazone for type 2 diabetes mellitus: a rapid and systematic review.

By Chilcott J, Wight J, Lloyd Jones M, Tappenden P.

\section{No. 20}

Extended scope of nursing practice: a multicentre randomised controlled trial of appropriately trained nurses and preregistration house officers in preoperative assessment in elective general surgery.

By Kinley H, Czoski-Murray C, George S, McCabe C, Primrose J, Reilly C, et al.

No. 21

Systematic reviews of the effectiveness of day care for people with severe mental disorders: (1) Acute day hospital versus admission; (2) Vocational rehabilitation; (3) Day hospital versus outpatient care.

By Marshall M, Crowther R, AlmarazSerrano A, Creed F, Sledge W, Kluiter $\mathrm{H}$, et al.

No. 22

The measurement and monitoring of surgical adverse events.

By Bruce J, Russell EM, Mollison J, Krukowski ZH.

\section{No. 23}

Action research: a systematic review and guidance for assessment.

By Waterman H, Tillen D, Dickson R, de Koning $\mathbf{K}$.

No. 24

A rapid and systematic review of the clinical effectiveness and costeffectiveness of gemcitabine for the treatment of pancreatic cancer.

By Ward S, Morris E, Bansback N, Calvert N, Crellin A, Forman D, et al. 


\section{No. 25}

A rapid and systematic review of the evidence for the clinical effectiveness and cost-effectiveness of irinotecan, oxaliplatin and raltitrexed for the treatment of advanced colorectal cancer.

By Lloyd Jones M, Hummel S, Bansback N, Orr B, Seymour M.

\section{No. 26}

Comparison of the effectiveness of inhaler devices in asthma and chronic obstructive airways disease: a systematic review of the literature.

By Brocklebank D, Ram F, Wright J, Barry P, Cates C, Davies L, et al.

\section{No. 27}

The cost-effectiveness of magnetic resonance imaging for investigation of the knee joint.

By Bryan S, Weatherburn G, Bungay

H, Hatrick C, Salas C, Parry D, et al.

\section{No. 28}

A rapid and systematic review of the clinical effectiveness and costeffectiveness of topotecan for ovarian cancer.

By Forbes C, Shirran L, Bagnall A-M, Duffy S, ter Riet G.

\section{No. 29}

Superseded by a report published in a later volume.

\section{No. 30}

The role of radiography in primary care patients with low back pain of at least 6 weeks duration: a randomised (unblinded) controlled trial.

By Kendrick D, Fielding K, Bentley E, Miller P, Kerslake R, Pringle M.

\section{No. 31}

Design and use of questionnaires: a review of best practice applicable to surveys of health service staff and patients.

By McColl E, Jacoby A, Thomas L, Soutter J, Bamford C, Steen N, et al.

\section{No. 32}

A rapid and systematic review of the clinical effectiveness and cost-

effectiveness of paclitaxel, docetaxel, gemcitabine and vinorelbine in nonsmall-cell lung cancer.

By Clegg A, Scott DA, Sidhu M, Hewitson P, Waugh N.

No. 33

Subgroup analyses in randomised controlled trials: quantifying the risks of false-positives and false-negatives.

By Brookes ST, Whitley E, Peters TJ, Mulheran PA, Egger M, Davey Smith G.

\section{No. 34}

Depot antipsychotic medication in the treatment of patients with schizophrenia: (1) Meta-review; (2) Patient and nurse attitudes.

By David AS, Adams C.

\section{No. 35}

A systematic review of controlled trials of the effectiveness and costeffectiveness of brief psychological treatments for depression.

By Churchill R, Hunot V, Corney R, Knapp M, McGuire H, Tylee A, et al.

No. 36

Cost analysis of child health surveillance.

By Sanderson D, Wright D, Acton C, Duree D.

\section{Volume 6, 2002}

\section{No. 1}

A study of the methods used to select review criteria for clinical audit.

By Hearnshaw H, Harker R, Cheater F, Baker R, Grimshaw G.

No. 2

Fludarabine as second-line therapy for B cell chronic lymphocytic leukaemia: a technology assessment.

By Hyde C, Wake B, Bryan S, Barton P, Fry-Smith A, Davenport C, et al.

No. 3

Rituximab as third-line treatment for refractory or recurrent Stage III or IV follicular non-Hodgkin's lymphoma: a systematic review and economic evaluation.

By Wake B, Hyde C, Bryan S, Barton P, Song F, Fry-Smith A, et al.

No. 4

A systematic review of discharge arrangements for older people.

By Parker SG, Peet SM, McPherson A, Cannaby AM, Baker R, Wilson A, et al.

No. 5

The clinical effectiveness and costeffectiveness of inhaler devices used in the routine management of chronic asthma in older children: a systematic review and economic evaluation.

By Peters J, Stevenson M, Beverley C, Lim J, Smith S.

No. 6

The clinical effectiveness and costeffectiveness of sibutramine in the management of obesity: a technology assessment.

By O'Meara S, Riemsma R, Shirran L, Mather L, ter Riet G.

No. 7

The cost-effectiveness of magnetic resonance angiography for carotid artery stenosis and peripheral vascular disease: a systematic review.

By Berry E, Kelly S, Westwood ME, Davies LM, Gough MJ, Bamford JM, et al.

No. 8

Promoting physical activity in South Asian Muslim women through 'exercise on prescription'.

By Carroll B, Ali N, Azam N.
No. 9

Zanamivir for the treatment of influenza in adults: a systematic review and economic evaluation.

By Burls A, Clark W, Stewart T, Preston C, Bryan S, Jefferson T, et al.

\section{No. 10}

A review of the natural history and epidemiology of multiple sclerosis: implications for resource allocation and health economic models.

By Richards RG, Sampson FC, Beard SM, Tappenden P.

No. 11

Screening for gestational diabetes: a systematic review and economic evaluation.

By Scott DA, Loveman E, McIntyre L, Waugh N.

No. 12

The clinical effectiveness and costeffectiveness of surgery for people with morbid obesity: a systematic review and economic evaluation.

By Clegg AJ, Colquitt J, Sidhu MK, Royle P, Loveman E, Walker A.

\section{No. 13}

The clinical effectiveness of trastuzumab for breast cancer: a systematic review.

By Lewis R, Bagnall A-M, Forbes C, Shirran E, Duffy S, Kleijnen J, et al.

\section{No. 14}

The clinical effectiveness and costeffectiveness of vinorelbine for breast cancer: a systematic review and economic evaluation.

By Lewis R, Bagnall A-M, King S, Woolacott N, Forbes C, Shirran L, et al.

\section{No. 15}

A systematic review of the effectiveness and cost-effectiveness of metal-on-metal hip resurfacing arthroplasty for treatment of hip disease.

By Vale L, Wyness L, McCormack K, McKenzie L, Brazzelli M, Stearns SC.

\section{No. 16}

The clinical effectiveness and costeffectiveness of bupropion and nicotine replacement therapy for smoking cessation: a systematic review and economic evaluation.

By Woolacott NF, Jones L, Forbes CA, Mather LC, Sowden AJ, Song FJ, et al.

\section{No. 17}

A systematic review of effectiveness and economic evaluation of new drug treatments for juvenile idiopathic arthritis: etanercept.

By Cummins C, Connock M, Fry-Smith A, Burls A.

No. 18

Clinical effectiveness and costeffectiveness of growth hormone in children: a systematic review and economic evaluation.

By Bryant J, Cave C, Mihaylova B, Chase D, McIntyre L, Gerard K, et al. 
No. 19

Clinical effectiveness and cost-

effectiveness of growth hormone in adults in relation to impact on quality of life: a systematic review and economic evaluation.

By Bryant J, Loveman E, Chase D, Mihaylova B, Cave C, Gerard K, et al.

\section{No. 20}

Clinical medication review by a pharmacist of patients on repeat prescriptions in general practice: a randomised controlled trial.

By Zermansky AG, Petty DR, Raynor DK, Lowe CJ, Freementle N, Vail A.

No. 21

The effectiveness of infliximab and etanercept for the treatment of rheumatoid arthritis: a systematic review and economic evaluation.

By Jobanputra P, Barton P, Bryan S, Burls A.

No. 22

A systematic review and economic evaluation of computerised cognitive behaviour therapy for depression and anxiety.

By Kaltenthaler E, Shackley P, Stevens K, Beverley C, Parry G, Chilcott J.

No. 23

A systematic review and economic evaluation of pegylated liposomal doxorubicin hydrochloride for ovarian cancer.

By Forbes C, Wilby J, Richardson G, Sculpher M, Mather L, Reimsma R.

No. 24

A systematic review of the effectiveness of interventions based on a stages-ofchange approach to promote individual behaviour change.

By Riemsma RP, Pattenden J, Bridle C, Sowden AJ, Mather L, Watt IS, et al.

No. 25

A systematic review update of the clinical effectiveness and costeffectiveness of glycoprotein IIb/IIIa antagonists.

By Robinson M, Ginnelly L, Sculpher M, Jones L, Riemsma R, Palmer S, et al.

No. 26

A systematic review of the effectiveness, cost-effectiveness and barriers to implementation of thrombolytic and neuroprotective therapy for acute ischaemic stroke in the NHS.

By Sandercock P, Berge E, Dennis M, Forbes J, Hand P, Kwan J, et al.

No. 27

A randomised controlled crossover trial of nurse practitioner versus doctor-led outpatient care in a bronchiectasis clinic.

By Caine N, Sharples LD,

Hollingworth W, French J, Keogan M,
No. 28

Clinical effectiveness and cost consequences of selective serotonin reuptake inhibitors in the treatment of sex offenders.

By Adi Y, Ashcroft D, Browne K, Beech A, Fry-Smith A, Hyde C.

\section{No. 29}

Treatment of established osteoporosis: a systematic review and cost-utility analysis.

By Kanis JA, Brazier JE, Stevenson M, Calvert NW, Lloyd Jones M.

No. 30

Which anaesthetic agents are costeffective in day surgery? Literature review, national survey of practice and randomised controlled trial.

By Elliott RA Payne K, Moore JK,

Davies LM, Harper NJN, St Leger AS, et al.

\section{No. 31}

Screening for hepatitis $\mathrm{C}$ among injecting drug users and in genitourinary medicine clinics: systematic reviews of effectiveness, modelling study and national survey of current practice.

By Stein K, Dalziel K, Walker A, McIntyre L, Jenkins B, Horne J, et al.

\section{No. 32}

The measurement of satisfaction with healthcare: implications for practice from a systematic review of the literature.

By Crow R, Gage H, Hampson S, Hart J, Kimber A, Storey L, et al.

No. 33

The effectiveness and cost-effectiveness of imatinib in chronic myeloid leukaemia: a systematic review.

By Garside R, Round A, Dalziel K, Stein K, Royle R.

\section{No. 34}

A comparative study of hypertonic saline, daily and alternate-day rhDNase in children with cystic fibrosis.

By Suri R, Wallis C, Bush A,

Thompson S, Normand C, Flather M, et al.

No. 35

A systematic review of the costs and effectiveness of different models of paediatric home care.

By Parker G, Bhakta P, Lovett CA, Paisley S, Olsen R, Turner D, et al.

\section{Volume 7, 2003}

No. 1

How important are comprehensive literature searches and the assessment of trial quality in systematic reviews? Empirical study.

By Egger M, Jüni P, Bartlett C, Holenstein F, Sterne J.

\section{No. 2}

Systematic review of the effectiveness and cost-effectiveness, and economic evaluation, of home versus hospital or satellite unit haemodialysis for people with end-stage renal failure.

By Mowatt G, Vale L, Perez J, Wyness L, Fraser C, MacLeod A, et al.

No. 3

Systematic review and economic evaluation of the effectiveness of infliximab for the treatment of Crohn's disease.

By Clark W, Raftery J, Barton P, Song F, Fry-Smith A, Burls A.

No. 4

A review of the clinical effectiveness and cost-effectiveness of routine anti-D prophylaxis for pregnant women who are rhesus negative.

By Chilcott J, Lloyd Jones M, Wight J, Forman K, Wray J, Beverley C, et al.

No. 5

Systematic review and evaluation of the use of tumour markers in paediatric oncology: Ewing's sarcoma and neuroblastoma.

By Riley RD, Burchill SA, Abrams KR, Heney D, Lambert PC, Jones DR, et al.

No. 6

The cost-effectiveness of screening for Helicobacter pylori to reduce mortality and morbidity from gastric cancer and peptic ulcer disease: a discrete-event simulation model.

By Roderick P, Davies R, Raftery J, Crabbe D, Pearce R, Bhandari P, et al.

No. 7

The clinical effectiveness and costeffectiveness of routine dental checks: a systematic review and economic evaluation.

By Davenport C, Elley K, Salas C, Taylor-Weetman CL, Fry-Smith A, Bryan S, et al.

\section{No. 8}

A multicentre randomised controlled trial assessing the costs and benefits of using structured information and analysis of women's preferences in the management of menorrhagia.

By Kennedy ADM, Sculpher MJ, Coulter A, Dwyer N, Rees M, Horsley S, et al.

No. 9

Clinical effectiveness and cost-utility of photodynamic therapy for wet age-related macular degeneration: a systematic review and economic evaluation.

By Meads C, Salas C, Roberts T, Moore D, Fry-Smith A, Hyde C.

\section{No. 10}

Evaluation of molecular tests for prenatal diagnosis of chromosome abnormalities.

By Grimshaw GM, Szczepura A,

Hultén M, MacDonald F, Nevin NC, Sutton F, et al. 
No. 11

First and second trimester antenatal screening for Down's syndrome: the results of the Serum, Urine and Ultrasound Screening Study (SURUSS).

By Wald NJ, Rodeck C, Hackshaw AK, Walters J, Chitty L, Mackinson AM.

No. 12

The effectiveness and cost-effectiveness of ultrasound locating devices for central venous access: a systematic review and economic evaluation.

By Calvert N, Hind D, McWilliams RG, Thomas SM, Beverley C, Davidson A

No. 13

A systematic review of atypical antipsychotics in schizophrenia.

By Bagnall A-M, Jones L, Lewis R, Ginnelly L, Glanville J, Torgerson D, et al.

No. 14

Prostate Testing for Cancer and Treatment (ProtecT) feasibility study.

By Donovan J, Hamdy F, Neal D, Peters T, Oliver S, Brindle L, et al.

No. 15

Early thrombolysis for the treatment of acute myocardial infarction: systematic review and economic evaluation.

By Boland A, Dundar Y, Bagust A, Haycox A, Hill R, Mujica Mota R, et al.

\section{No. 16}

Screening for fragile $\mathrm{X}$ syndrome: a literature review and modelling.

By Song FJ, Barton P, Sleightholme V, Yao GL, Fry-Smith A

No. 17

Systematic review of endoscopic sinus surgery for nasal polyps.

By Dalziel K, Stein K, Round A, Garside R, Royle P

\section{No. 18}

Towards efficient guidelines: how to monitor guideline use in primary care.

By Hutchinson A, McIntosh A, Cox S, Gilbert C.

\section{No. 19}

Effectiveness and cost-effectiveness of acute hospital-based spinal cord injuries services: systematic review.

By Bagnall A-M, Jones L,

Richardson G, Duffy S,

Riemsma R.

\section{No. 20}

Prioritisation of health technology assessment. The PATHS model: methods and case studies.

By Townsend J, Buxton M, Harper G.
No. 21

Systematic review of the clinical effectiveness and cost-effectiveness of tension-free vaginal tape for treatment of urinary stress incontinence.

By Cody J, Wyness L, Wallace S, Glazener C, Kilonzo M, Stearns S, et al.

\section{No. 22}

The clinical and cost-effectiveness of patient education models for diabetes: a systematic review and economic evaluation.

By Loveman E, Cave C, Green C, Royle P, Dunn N, Waugh N.

\section{No. 23}

The role of modelling in prioritising and planning clinical trials.

By Chilcott J, Brennan A, Booth A, Karnon J, Tappenden P.

No. 24

Cost-benefit evaluation of routine influenza immunisation in people $65-74$ years of age.

By Allsup S, Gosney M, Haycox A, Regan M.

No. 25

The clinical and cost-effectiveness of pulsatile machine perfusion versus cold storage of kidneys for transplantation retrieved from heart-beating and nonheart-beating donors.

By Wight J, Chilcott J, Holmes M, Brewer N

\section{No. 26}

Can randomised trials rely on existing electronic data? A feasibility study to explore the value of routine data in health technology assessment.

By Williams JG, Cheung WY,

Cohen DR, Hutchings HA, Longo MF, Russell IT.

No. 27

Evaluating non-randomised intervention studies.

By Deeks JJ, Dinnes J, D’Amico R, Sowden AJ, Sakarovitch C, Song F, et al.

No. 28

A randomised controlled trial to assess the impact of a package comprising a patient-orientated, evidence-based selfhelp guidebook and patient-centred consultations on disease management and satisfaction in inflammatory bowel disease.

By Kennedy A, Nelson E, Reeves D, Richardson G, Roberts C, Robinson A, et al.

No. 29

The effectiveness of diagnostic tests for the assessment of shoulder pain due to soft tissue disorders: a systematic review.

By Dinnes J, Loveman E, McIntyre L, Waugh N.
No. 30

The value of digital imaging in diabetic retinopathy.

By Sharp PF, Olson J, Strachan F, Hipwell J, Ludbrook A, O'Donnell M, et al.

No. 31

Lowering blood pressure to prevent myocardial infarction and stroke: a new preventive strategy.

By Law M, Wald N, Morris J.

No. 32

Clinical and cost-effectiveness of capecitabine and tegafur with uracil for the treatment of metastatic colorectal cancer: systematic review and economic evaluation.

By Ward S, Kaltenthaler E, Cowan J, Brewer N.

No. 33

Clinical and cost-effectiveness of new and emerging technologies for early localised prostate cancer: a systematic review.

By Hummel S, Paisley S, Morgan A, Currie E, Brewer N.

No. 34

Literature searching for clinical and cost-effectiveness studies used in health technology assessment reports carried out for the National Institute for Clinical Excellence appraisal system

By Royle P, Waugh N.

No. 35

Systematic review and economic decision modelling for the prevention and treatment of influenza

$\mathrm{A}$ and $\mathrm{B}$.

By Turner D, Wailoo A, Nicholson K, Cooper N, Sutton A, Abrams K.

No. 36

A randomised controlled trial to evaluate the clinical and costeffectiveness of Hickman line insertions in adult cancer patients by nurses.

By Boland A, Haycox A, Bagust A, Fitzsimmons L.

No. 37

Redesigning postnatal care: a randomised controlled trial of protocol-based midwifery-led care focused on individual women's physical and psychological health needs.

By MacArthur C, Winter HR,

Bick DE, Lilford RJ, Lancashire RJ, Knowles $\mathrm{H}$, et al.

No. 38

Estimating implied rates of discount in healthcare decision-making.

By West RR, McNabb R,

Thompson AGH, Sheldon TA, Grimley Evans J. 
No. 39

Systematic review of isolation policies in the hospital management of methicillinresistant Staphylococcus aureus: a review of the literature with epidemiological and economic modelling.

By Cooper BS, Stone SP, Kibbler CC, Cookson BD, Roberts JA, Medley GF, et al.

No. 40

Treatments for spasticity and pain in multiple sclerosis: a systematic review.

By Beard S, Hunn A, Wight J.

No. 41

The inclusion of reports of randomised trials published in languages other than English in systematic reviews.

By Moher D, Pham B, Lawson ML, Klassen TP.

No. 42

The impact of screening on future health-promoting behaviours and health beliefs: a systematic review.

By Bankhead CR, Brett J, Bukach C, Webster P, Stewart-Brown S, Munafo M, et al.

\section{Volume 8, 2004}

No. 1

What is the best imaging strategy for acute stroke?

By Wardlaw JM, Keir SL, Seymour J, Lewis S, Sandercock PAG, Dennis MS, et al.

No. 2

Systematic review and modelling of the investigation of acute and chronic chest pain presenting in primary care.

By Mant J, McManus RJ, Oakes RAL, Delaney BC, Barton PM, Deeks JJ, et al.

No. 3

The effectiveness and cost-effectiveness of microwave and thermal balloon endometrial ablation for heavy menstrual bleeding: a systematic review and economic modelling.

By Garside R, Stein K, Wyatt K, Round A, Price A.

No. 4

A systematic review of the role of bisphosphonates in metastatic disease.

By Ross JR, Saunders Y, Edmonds PM, Patel S, Wonderling D, Normand C, et al.

No. 5

Systematic review of the clinical effectiveness and cost-effectiveness of capecitabine (Xeloda ${ }^{\circledR}$ ) for locally advanced and/or metastatic breast cancer.

By Jones L, Hawkins N, Westwood M, Wright K, Richardson G, Riemsma R.

No. 6

Effectiveness and efficiency of guideline dissemination and implementation strategies.

By Grimshaw JM, Thomas RE, MacLennan G, Fraser C, Ramsay CR, Vale L, et al.
No. 7

Clinical effectiveness and costs of the Sugarbaker procedure for the treatment of pseudomyxoma peritonei.

By Bryant J, Clegg AJ, Sidhu MK, Brodin H, Royle P, Davidson P.

No. 8

Psychological treatment for insomnia in the regulation of long-term hypnotic drug use.

By Morgan K, Dixon S, Mathers N, Thompson J, Tomeny M.

No. 9

Improving the evaluation of therapeutic interventions in multiple sclerosis: development of a patient-based measure of outcome.

By Hobart JC, Riazi A, Lamping DL, Fitzpatrick R, Thompson AJ.

\section{No. 10}

A systematic review and economic evaluation of magnetic resonance cholangiopancreatography compared with diagnostic endoscopic retrograde cholangiopancreatography.

By Kaltenthaler E, Bravo Vergel Y, Chilcott J, Thomas S, Blakeborough T, Walters SJ, et al.

\section{No. 11}

The use of modelling to evaluate new drugs for patients with a chronic condition: the case of antibodies against tumour necrosis factor in rheumatoid arthritis.

By Barton P, Jobanputra P, Wilson J, Bryan S, Burls A.

No. 12

Clinical effectiveness and costeffectiveness of neonatal screening for inborn errors of metabolism using tandem mass spectrometry: a systematic review.

By Pandor A, Eastham J, Beverley C, Chilcott J, Paisley S.

\section{No. 13}

Clinical effectiveness and costeffectiveness of pioglitazone and rosiglitazone in the treatment of type 2 diabetes: a systematic review and economic evaluation.

By Czoski-Murray C, Warren E, Chilcott J, Beverley C, Psyllaki MA, Cowan J.

\section{No. 14}

Routine examination of the newborn: the EMREN study. Evaluation of an extension of the midwife role including a randomised controlled trial of appropriately trained midwives and paediatric senior house officers.

By Townsend J, Wolke D, Hayes J, Davé S, Rogers C, Bloomfield L, et al.
No. 15

Involving consumers in research and development agenda setting for the NHS: developing an evidence-based approach.

By Oliver S, Clarke-Jones L, Rees R, Milne R, Buchanan P, Gabbay J, et al.

No. 16

A multi-centre randomised controlled trial of minimally invasive direct coronary bypass grafting versus percutaneous transluminal coronary angioplasty with stenting for proximal stenosis of the left anterior descending coronary artery.

By Reeves BC, Angelini GD, Bryan AJ, Taylor FC, Cripps T, Spyt TJ, et al.

No. 17

Does early magnetic resonance imaging influence management or improve outcome in patients referred to secondary care with low back pain? A pragmatic randomised controlled trial.

By Gilbert FJ, Grant AM, Gillan MGC, Vale L, Scott NW, Campbell MK, et al.

No. 18

The clinical and cost-effectiveness of anakinra for the treatment of rheumatoid arthritis in adults: a systematic review and economic analysis.

By Clark W, Jobanputra P, Barton P, Burls A.

No. 19

A rapid and systematic review and economic evaluation of the clinical and cost-effectiveness of newer drugs for treatment of mania associated with bipolar affective disorder.

By Bridle C, Palmer S, Bagnall A-M, Darba J, Duffy S, Sculpher M, et al.

No. 20

Liquid-based cytology in cervical screening: an updated rapid and systematic review and economic analysis.

By Karnon J, Peters J, Platt J, Chilcott J, McGoogan E, Brewer N.

No. 21

Systematic review of the long-term effects and economic consequences of treatments for obesity and implications for health improvement.

By Avenell A, Broom J, Brown TJ, Poobalan A, Aucott L, Stearns SC, et al.

No. 22

Autoantibody testing in children with newly diagnosed type 1 diabetes mellitus.

By Dretzke J, Cummins C, Sandercock J, Fry-Smith A, Barrett T, Burls A. 
No. 23

Clinical effectiveness and cost-

effectiveness of prehospital intravenous fluids in trauma patients.

By Dretzke J, Sandercock J, Bayliss S, Burls A.

\section{No. 24}

Newer hypnotic drugs for the shortterm management of insomnia: a systematic review and economic evaluation.

By Dündar Y, Boland A, Strobl J, Dodd S, Haycox A, Bagust A, et al.

\section{No. 25}

Development and validation of methods for assessing the quality of diagnostic accuracy studies.

By Whiting P, Rutjes AWS, Dinnes J, Reitsma JB, Bossuyt PMM, Kleijnen J.

No. 26

EVALUATE hysterectomy trial: a multicentre randomised trial comparing abdominal, vaginal and laparoscopic methods of hysterectomy.

By Garry R, Fountain J, Brown J, Manca A, Mason S, Sculpher M, et al.

No. 27

Methods for expected value of information analysis in complex health economic models: developments on the health economics of interferon- $\beta$ and glatiramer acetate for multiple sclerosis.

By Tappenden P, Chilcott JB, Eggington S, Oakley J, McCabe C.

No. 28

Effectiveness and cost-effectiveness of imatinib for first-line treatment of chronic myeloid leukaemia in chronic phase: a systematic review and economic analysis.

By Dalziel K, Round A, Stein K, Garside R, Price A.

\section{No. 29}

VenUS I: a randomised controlled trial of two types of bandage for treating venous leg ulcers.

By Iglesias C, Nelson EA, Cullum NA, Torgerson DJ on behalf of the VenUS Team.

\section{No. 30}

Systematic review of the effectiveness and cost-effectiveness, and economic evaluation, of myocardial perfusion scintigraphy for the diagnosis and management of angina and myocardial infarction.

By Mowatt G, Vale L, Brazzelli M, Hernandez R, Murray A, Scott N, et al.

No. 31

A pilot study on the use of decision theory and value of information analysis as part of the NHS Health Technology Assessment programme.

By Claxton K, Ginnelly L, Sculpher M, Philips Z, Palmer S.
No. 32

The Social Support and Family Health Study: a randomised controlled trial and economic evaluation of two alternative forms of postnatal support for mothers living in disadvantaged inner-city areas.

By Wiggins M, Oakley A, Roberts I,

Turner H, Rajan L, Austerberry H, et al.

No. 33

Psychosocial aspects of genetic screening of pregnant women and newborns: a systematic review.

By Green JM, Hewison J, Bekker HL, Bryant, Cuckle HS.

No. 34

Evaluation of abnormal uterine

bleeding: comparison of three outpatient procedures within cohorts defined by age and menopausal status.

By Critchley HOD, Warner P,

Lee AJ, Brechin S, Guise J, Graham B.

\section{No. 35}

Coronary artery stents: a rapid systematic review and economic evaluation.

By Hill R, Bagust A, Bakhai A, Dickson R, Dündar Y, Haycox A, et al.

\section{No. 36}

Review of guidelines for good practice in decision-analytic modelling in health technology assessment.

By Philips Z, Ginnelly L, Sculpher M, Claxton K, Golder S, Riemsma R, et al.

No. 37

Rituximab (MabThera ${ }^{\circledR}$ ) for aggressive non-Hodgkin's lymphoma: systematic review and economic evaluation.

By Knight C, Hind D, Brewer N, Abbott V.

No. 38

Clinical effectiveness and costeffectiveness of clopidogrel and modified-release dipyridamole in the secondary prevention of occlusive vascular events: a systematic review and economic evaluation.

By Jones L, Griffin S, Palmer S, Main C, Orton V, Sculpher M, et al.

\section{No. 39}

Pegylated interferon $\alpha-2 \mathrm{a}$ and -2b in combination with ribavirin in the treatment of chronic hepatitis C: a systematic review and economic evaluation.

By Shepherd J, Brodin H, Cave C, Waugh N, Price A, Gabbay J.

\section{No. 40}

Clopidogrel used in combination with aspirin compared with aspirin alone in the treatment of non-ST-segmentelevation acute coronary syndromes: a systematic review and economic evaluation.

By Main C, Palmer S, Griffin S, Jones L, Orton V, Sculpher M, et al.
No. 41

Provision, uptake and cost of cardiac rehabilitation programmes: improving services to under-represented groups.

By Beswick AD, Rees K, Griebsch I, Taylor FC, Burke M, West RR, et al.

\section{No. 42}

Involving South Asian patients in clinical trials.

By Hussain-Gambles M, Leese B, Atkin K, Brown J, Mason S, Tovey P.

No. 43

Clinical and cost-effectiveness of continuous subcutaneous insulin infusion for diabetes.

By Colquitt JL, Green C, Sidhu MK, Hartwell D, Waugh N.

No. 44

Identification and assessment of ongoing trials in health technology assessment reviews.

By Song FJ, Fry-Smith A, Davenport C, Bayliss S, Adi Y, Wilson JS, et al.

No. 45

Systematic review and economic evaluation of a long-acting insulin analogue, insulin glargine

By Warren E, Weatherley-Jones E, Chilcott J, Beverley C.

\section{No. 46}

Supplementation of a home-based exercise programme with a class-based programme for people with osteoarthritis of the knees: a randomised controlled trial and health economic analysis.

By McCarthy CJ, Mills PM,

Pullen R, Richardson G, Hawkins N, Roberts CR, et al.

\section{No. 47}

Clinical and cost-effectiveness of oncedaily versus more frequent use of same potency topical corticosteroids for atopic eczema: a systematic review and economic evaluation.

By Green C, Colquitt JL, Kirby J, Davidson P, Payne E.

No. 48

Acupuncture of chronic headache disorders in primary care: randomised controlled trial and economic analysis.

By Vickers AJ, Rees RW, Zollman CE, McCarney R, Smith CM, Ellis N, et al.

\section{No. 49}

Generalisability in economic evaluation studies in healthcare: a review and case studies.

By Sculpher MJ, Pang FS, Manca A, Drummond MF, Golder S, Urdahl H, et al.

No. 50

Virtual outreach: a randomised controlled trial and economic evaluation of joint teleconferenced medical consultations.

By Wallace P, Barber J, Clayton W, Currell R, Fleming K, Garner P, et al. 


\section{Volume 9, 2005}

No. 1

Randomised controlled multiple treatment comparison to provide a cost-effectiveness rationale for the selection of antimicrobial therapy in acne.

By Ozolins M, Eady EA, Avery A, Cunliffe WJ, O’Neill C, Simpson NB, et al.

No. 2

Do the findings of case series studies vary significantly according to methodological characteristics?

By Dalziel K, Round A, Stein K, Garside R, Castelnuovo E, Payne L.

No. 3

Improving the referral process for familial breast cancer genetic counselling: findings of three randomised controlled trials of two interventions.

By Wilson BJ, Torrance N, Mollison J, Wordsworth S, Gray JR, Haites NE, et al.

No. 4

Randomised evaluation of alternative electrosurgical modalities to treat bladder outflow obstruction in men with benign prostatic hyperplasia.

By Fowler C, McAllister W, Plail R, Karim O, Yang $Q$.

No. 5

A pragmatic randomised controlled trial of the cost-effectiveness of palliative therapies for patients with inoperable oesophageal cancer.

By Shenfine J, McNamee P, Steen N, Bond J, Griffin SM.

No. 6

Impact of computer-aided detection prompts on the sensitivity and specificity of screening mammography.

By Taylor P, Champness J, GivenWilson R, Johnston K, Potts H.

No. 7

Issues in data monitoring and interim analysis of trials.

By Grant AM, Altman DG, Babiker $\mathrm{AB}$, Campbell MK, Clemens FJ, Darbyshire JH, et al.

No. 8

Lay public's understanding of equipoise and randomisation in randomised controlled trials.

By Robinson EJ, Kerr CEP, Stevens AJ, Lilford RJ, Braunholtz DA, Edwards SJ, et al.

No. 9

Clinical and cost-effectiveness of electroconvulsive therapy for depressive illness, schizophrenia, catatonia and mania: systematic reviews and economic modelling studies.

By Greenhalgh J, Knight C, Hind D, Beverley C, Walters S.

\section{No. 10}

Measurement of health-related quality of life for people with dementia: development of a new instrument (DEMQOL) and an evaluation of current methodology.

By Smith SC, Lamping DL,

Banerjee S, Harwood R, Foley B, Smith P, et al.

\section{No. 11}

Clinical effectiveness and costeffectiveness of drotrecogin alfa (activated) $\left(\right.$ Xigris $\left.^{\circledR}\right)$ for the treatment of severe sepsis in adults: a systematic review and economic evaluation.

By Green C, Dinnes J, Takeda A, Shepherd J, Hartwell D, Cave C, et al.

\section{No. 12}

A methodological review of how heterogeneity has been examined in systematic reviews of diagnostic test accuracy.

By Dinnes J, Deeks J, Kirby J, Roderick P.

\section{No. 13}

Cervical screening programmes: can automation help? Evidence from systematic reviews, an economic analysis and a simulation modelling exercise applied to the UK.

By Willis BH, Barton P, Pearmain P, Bryan S, Hyde C.

\section{No. 14}

Laparoscopic surgery for inguinal hernia repair: systematic review of effectiveness and economic evaluation.

By McCormack K, Wake B, Perez J, Fraser C, Cook J, McIntosh E, et al.

\section{No. 15}

Clinical effectiveness, tolerability and cost-effectiveness of newer drugs for epilepsy in adults: a systematic review and economic evaluation.

By Wilby J, Kainth A, Hawkins N, Epstein D, McIntosh H, McDaid C, et al.

\section{No. 16}

A randomised controlled trial to compare the cost-effectiveness of tricyclic antidepressants, selective serotonin reuptake inhibitors and lofepramine.

By Peveler R, Kendrick T, Buxton M, Longworth L, Baldwin D, Moore M, et al.

\section{No. 17}

Clinical effectiveness and costeffectiveness of immediate angioplasty for acute myocardial infarction: systematic review and economic evaluation.

By Hartwell D, Colquitt J, Loveman $\mathrm{E}$, Clegg AJ, Brodin $\mathrm{H}$, Waugh N, et al.
No. 18

A randomised controlled comparison of alternative strategies in stroke care.

By Kalra L, Evans A, Perez I,

Knapp M, Swift C, Donaldson N.

No. 19

The investigation and analysis of critical incidents and adverse events in healthcare.

By Woloshynowych M, Rogers S,

Taylor-Adams S, Vincent C.

\section{No. 20}

Potential use of routine databases in health technology assessment.

By Raftery J, Roderick P, Stevens A.

No. 21

Clinical and cost-effectiveness of newer immunosuppressive regimens in renal transplantation: a systematic review and modelling study.

By Woodroffe R, Yao GL, Meads C, Bayliss S, Ready A, Raftery J, et al.

No. 22

A systematic review and economic evaluation of alendronate, etidronate, risedronate, raloxifene and teriparatide for the prevention and treatment of postmenopausal osteoporosis.

By Stevenson M, Lloyd Jones M, De Nigris E, Brewer N, Davis S, Oakley J.

No. 23

A systematic review to examine the impact of psycho-educational interventions on health outcomes and costs in adults and children with difficult asthma.

By Smith JR, Mugford M, Holland R, Candy B, Noble MJ, Harrison BDW, et al.

No. 24

An evaluation of the costs, effectiveness and quality of renal replacement therapy provision in renal satellite units in England and Wales.

By Roderick P, Nicholson T, Armitage A, Mehta R, Mullee M, Gerard K, et al.

No. 25

Imatinib for the treatment of patients with unresectable and/or metastatic gastrointestinal stromal tumours: systematic review and economic evaluation.

By Wilson J, Connock M, Song F, Yao G, Fry-Smith A, Raftery J, et al.

No. 26

Indirect comparisons of competing interventions.

By Glenny AM, Altman DG, Song F, Sakarovitch C, Deeks JJ, D'Amico R, et al.

No. 27

Cost-effectiveness of alternative strategies for the initial medical management of non-ST elevation acute coronary syndrome: systematic review and decision-analytical modelling.

By Robinson M, Palmer S, Sculpher M, Philips Z, Ginnelly L, Bowens A, et al. 
No. 28

Outcomes of electrically stimulated gracilis neosphincter surgery.

By Tillin T, Chambers M, Feldman R.

No. 29

The effectiveness and cost-effectiveness of pimecrolimus and tacrolimus for atopic eczema: a systematic review and economic evaluation.

By Garside R, Stein K, Castelnuovo E, Pitt M, Ashcroft D, Dimmock P, et al.

No. 30

Systematic review on urine albumin testing for early detection of diabetic complications.

By Newman DJ, Mattock MB, Dawnay ABS, Kerry S, McGuire A, Yaqoob M, et al.

No. 31

Randomised controlled trial of the costeffectiveness of water-based therapy for lower limb osteoarthritis.

By Cochrane T, Davey RC, Matthes Edwards SM.

No. 32

Longer term clinical and economic benefits of offering acupuncture care to patients with chronic low back pain.

By Thomas KJ, MacPherson $\mathrm{H}$, Ratcliffe J, Thorpe L, Brazier J, Campbell M, et al.

No. 33

Cost-effectiveness and safety of epidural steroids in the management of sciatica.

By Price C, Arden N, Coglan L, Rogers P.

No. 34

The British Rheumatoid Outcome Study Group (BROSG) randomised controlled trial to compare the effectiveness and cost-effectiveness of aggressive versus symptomatic therapy in established rheumatoid arthritis.

By Symmons D, Tricker K, Roberts C, Davies L, Dawes P, Scott DL.

\section{No. 35}

Conceptual framework and systematic review of the effects of participants' and professionals' preferences in randomised controlled trials.

By King M, Nazareth I, Lampe F, Bower P, Chandler M, Morou M, et al.

No. 36

The clinical and cost-effectiveness of implantable cardioverter defibrillators: a systematic review.

By Bryant J, Brodin H, Loveman E, Payne E, Clegg A.

No. 37

A trial of problem-solving by community mental health nurses for anxiety, depression and life difficulties among general practice patients. The CPN-GP study.

By Kendrick T, Simons L, Mynors-Wallis L, Gray A, Lathlean J, Pickering $\mathrm{R}$, et al.
No. 38

The causes and effects of sociodemographic exclusions from clinical trials.

By Bartlett C, Doyal L, Ebrahim S, Davey P, Bachmann M, Egger M, et al.

No. 39

Is hydrotherapy cost-effective? A randomised controlled trial of combined hydrotherapy programmes compared with physiotherapy land techniques in children with juvenile idiopathic arthritis.

By Epps H, Ginnelly L, Utley M, Southwood T, Gallivan S, Sculpher M, et al.

\section{No. 40}

A randomised controlled trial and costeffectiveness study of systematic screening (targeted and total population screening) versus routine practice for the detection of atrial fibrillation in people aged 65 and over. The SAFE study.

By Hobbs FDR, Fitzmaurice DA, Mant J, Murray E, Jowett S, Bryan S, et al.

\section{No. 41}

Displaced intracapsular hip fractures in fit, older people: a randomised comparison of reduction and fixation, bipolar hemiarthroplasty and total hip arthroplasty.

By Keating JF, Grant A, Masson M, Scott NW, Forbes JF.

\section{No. 42}

Long-term outcome of cognitive behaviour therapy clinical trials in central Scotland.

By Durham RC, Chambers JA, Power KG, Sharp DM, Macdonald RR, Major KA, et al.

\section{No. 43}

The effectiveness and cost-effectiveness of dual-chamber pacemakers compared with single-chamber pacemakers for bradycardia due to atrioventricular block or sick sinus syndrome: systematic review and economic evaluation.

By Castelnuovo E, Stein K, Pitt M, Garside R, Payne E.

\section{No. 44}

Newborn screening for congenital heart defects: a systematic review and cost-effectiveness analysis.

By Knowles R, Griebsch I, Dezateux C, Brown J, Bull C, Wren C.

\section{No. 45}

The clinical and cost-effectiveness of left ventricular assist devices for end-stage heart failure: a systematic review and economic evaluation.

By Clegg AJ, Scott DA, Loveman E, Colquitt J, Hutchinson J, Royle P, et al.
No. 46

The effectiveness of the Heidelberg

Retina Tomograph and laser diagnostic glaucoma scanning system (GDx) in detecting and monitoring glaucoma

By Kwartz AJ, Henson DB,

Harper RA, Spencer AF,

McLeod D.

No. 47

Clinical and cost-effectiveness of autologous chondrocyte implantation for cartilage defects in knee joints: systematic review and economic evaluation.

By Clar C, Cummins E, McIntyre L, Thomas S, Lamb J, Bain L, et al.

\section{No. 48}

Systematic review of effectiveness of different treatments for childhood retinoblastoma.

By McDaid C, Hartley S, Bagnall A-M, Ritchie G, Light K, Riemsma R.

No. 49

Towards evidence-based guidelines for the prevention of venous thromboembolism: systematic reviews of mechanical methods, oral anticoagulation, dextran and regional anaesthesia as thromboprophylaxis.

By Roderick P, Ferris G, Wilson K, Halls H, Jackson D, Collins R, et al.

No. 50

The effectiveness and cost-effectiveness of parent training/education programmes for the treatment of conduct disorder, including oppositional defiant disorder, in children.

By Dretzke J, Frew E, Davenport C, Barlow J, Stewart-Brown S, Sandercock J, et al.

\section{Volume 10, 2006}

No. 1

The clinical and cost-effectiveness of donepezil, rivastigmine, galantamine and memantine for Alzheimer's disease.

By Loveman E, Green C, Kirby J, Takeda A, Picot J, Payne E, et al.

\section{No. 2}

FOOD: a multicentre randomised tria evaluating feeding policies in patients admitted to hospital with a recent stroke.

By Dennis M, Lewis S, Cranswick G, Forbes J.

No. 3

The clinical effectiveness and costeffectiveness of computed tomography screening for lung cancer: systematic reviews.

By Black C, Bagust A, Boland A, Walker S, McLeod C, De Verteuil R, et al. 
No. 4

A systematic review of the effectiveness and cost-effectiveness of neuroimaging assessments used to visualise the seizure focus in people with refractory epilepsy being considered for surgery.

By Whiting P, Gupta R, Burch J, Mujica Mota RE, Wright K, Marson A, et al.

\section{No. 5}

Comparison of conference abstracts and presentations with full-text articles in the health technology assessments of rapidly evolving technologies.

By Dundar Y, Dodd S, Dickson R, Walley T, Haycox A, Williamson PR.

\section{No. 6}

Systematic review and evaluation of methods of assessing urinary incontinence.

By Martin JL, Williams KS, Abrams KR, Turner DA, Sutton AJ, Chapple C, et al.

\section{No. 7}

The clinical effectiveness and costeffectiveness of newer drugs for children with epilepsy. A systematic review.

By Connock M, Frew E, Evans B-W, Bryan S, Cummins C, Fry-Smith A, et al.

\section{No. 8}

Surveillance of Barrett's oesophagus: exploring the uncertainty through systematic review, expert workshop and economic modelling.

By Garside R, Pitt M, Somerville M, Stein K, Price A, Gilbert N.

\section{No. 9}

Topotecan, pegylated liposomal doxorubicin hydrochloride and paclitaxel for second-line or subsequent treatment of advanced ovarian cancer: a systematic review and economic evaluation.

By Main C, Bojke L, Griffin S, Norman G, Barbieri M, Mather L, et al.

No. 10

Evaluation of molecular techniques in prediction and diagnosis of cytomegalovirus disease in immunocompromised patients.

By Szczepura A, Westmoreland D, Vinogradova Y, Fox J, Clark M.

No. 11

Screening for thrombophilia in high-risk situations: systematic review and costeffectiveness analysis. The Thrombosis: Risk and Economic Assessment of Thrombophilia Screening (TREATS) study.

By Wu O, Robertson L, Twaddle S,

Lowe GDO, Clark P, Greaves M, et al.

\section{No. 12}

A series of systematic reviews to inform a decision analysis for sampling and treating infected diabetic foot

ulcers.

By Nelson EA, O'Meara S, Craig D, Iglesias C, Golder S, Dalton J, et al.

\section{No. 13}

Randomised clinical trial, observational study and assessment of cost-

effectiveness of the treatment of varicose veins (REACTIV trial).

By Michaels JA, Campbell WB,

Brazier JE, MacIntyre JB, Palfreyman SJ, Ratcliffe J, et al.

\section{No. 14}

The cost-effectiveness of screening for oral cancer in primary care.

By Speight PM, Palmer S, Moles DR, Downer MC, Smith DH, Henriksson M et al.

\section{No. 15}

Measurement of the clinical and costeffectiveness of non-invasive diagnostic testing strategies for deep vein thrombosis.

By Goodacre S, Sampson F, Stevenson M, Wailoo A, Sutton A, Thomas S, et al.

\section{No. 16}

Systematic review of the effectiveness and cost-effectiveness of HealOzone ${ }^{\circledR}$ for the treatment of occlusal pit/fissure caries and root caries.

By Brazzelli M, McKenzie L, Fielding S, Fraser C, Clarkson J, Kilonzo M, et al.

\section{No. 17}

Randomised controlled trials of conventional antipsychotic versus new atypical drugs, and new atypical drugs versus clozapine, in people with schizophrenia responding poorly to, or intolerant of, current drug treatment.

By Lewis SW, Davies L, Jones PB, Barnes TRE, Murray RM, Kerwin R, et al.

\section{No. 18}

Diagnostic tests and algorithms used in the investigation of haematuria: systematic reviews and economic evaluation.

By Rodgers M, Nixon J, Hempel S, Aho T, Kelly J, Neal D, et al.

\section{No. 19}

Cognitive behavioural therapy in addition to antispasmodic therapy for irritable bowel syndrome in primary care: randomised controlled trial.

By Kennedy TM, Chalder T, McCrone P, Darnley S, Knapp M, Jones RH, et al.
No. 20

A systematic review of the clinical effectiveness and cost-effectiveness of enzyme replacement therapies for

Fabry's disease and mucopolysaccharidosis type 1 .

By Connock M, Juarez-Garcia A, Frew E, Mans A, Dretzke J, Fry-Smith A, et al.

No. 21

Health benefits of antiviral therapy for mild chronic hepatitis C: randomised controlled trial and economic evaluation.

By Wright M, Grieve R, Roberts J, Main J, Thomas HC on behalf of the UK Mild Hepatitis C Trial Investigators.

\section{No. 22}

Pressure relieving support surfaces: a randomised evaluation.

By Nixon J, Nelson EA, Cranny G, Iglesias CP, Hawkins K, Cullum NA, et al.

No. 23

A systematic review and economic model of the effectiveness and costeffectiveness of methylphenidate, dexamfetamine and atomoxetine for the treatment of attention deficit hyperactivity disorder in children and adolescents.

By King S, Griffin S, Hodges Z, Weatherly H, Asseburg C, Richardson G, et al.

No. 24

The clinical effectiveness and costeffectiveness of enzyme replacement therapy for Gaucher's disease:

a systematic review.

By Connock M, Burls A, Frew E, Fry-Smith A, Juarez-Garcia A, McCabe C, et al.

No. 25

Effectiveness and cost-effectiveness of salicylic acid and cryotherapy for cutaneous warts. An economic decision model.

By Thomas KS, Keogh-Brown MR, Chalmers JR, Fordham RJ, Holland RC, Armstrong SJ, et al.

No. 26

A systematic literature review of the effectiveness of non-pharmacological interventions to prevent wandering in dementia and evaluation of the ethical implications and acceptability of their use.

By Robinson L, Hutchings D, Corner L, Beyer F, Dickinson H, Vanoli A, et al.

\section{No. 27}

A review of the evidence on the effects and costs of implantable cardioverter defibrillator therapy in different patient groups, and modelling of costeffectiveness and cost-utility for these groups in a UK context.

By Buxton M, Caine N, Chase D, Connelly D, Grace A, Jackson C, et al. 
No. 28

Adefovir dipivoxil and pegylated interferon alfa-2a for the treatment of chronic hepatitis B: a systematic review and economic evaluation.

By Shepherd J, Jones J, Takeda A, Davidson P, Price A.

No. 29

An evaluation of the clinical and costeffectiveness of pulmonary artery catheters in patient management in intensive care: a systematic review and a randomised controlled trial.

By Harvey S, Stevens K, Harrison D, Young D, Brampton W, McCabe C, et al.

\section{No. 30}

Accurate, practical and cost-effective assessment of carotid stenosis in the UK.

By Wardlaw JM, Chappell FM, Stevenson M, De Nigris E, Thomas S, Gillard J, et al.

No. 31

Etanercept and infliximab for the treatment of psoriatic arthritis: a systematic review and economic evaluation.

By Woolacott N, Bravo Vergel Y, Hawkins N, Kainth A, Khadjesari Z, Misso K, et al.

No. 32

The cost-effectiveness of testing for hepatitis $\mathrm{C}$ in former injecting drug users.

By Castelnuovo E, Thompson-Coon J, Pitt M, Cramp M, Siebert U, Price A, et al.

No. 33

Computerised cognitive behaviour therapy for depression and anxiety update: a systematic review and economic evaluation.

By Kaltenthaler E, Brazier J, De Nigris E, Tumur I, Ferriter M, Beverley C, et al.

No. 34

Cost-effectiveness of using prognostic information to select women with breast cancer for adjuvant systemic therapy.

By Williams C, Brunskill S, Altman D, Briggs A, Campbell H, Clarke M, et al.

No. 35

Psychological therapies including dialectical behaviour therapy for borderline personality disorder: a systematic review and preliminary economic evaluation.

By Brazier J, Tumur I, Holmes M, Ferriter M, Parry G, Dent-Brown K, et al.

No. 36

Clinical effectiveness and costeffectiveness of tests for the diagnosis and investigation of urinary tract infection in children: a systematic review and economic model.

By Whiting P, Westwood M, Bojke L, Palmer S, Richardson G, Cooper J, et al.
No. 37

Cognitive behavioural therapy in chronic fatigue syndrome: a randomised controlled trial of an outpatient group programme.

By O'Dowd H, Gladwell P, Rogers CA, Hollinghurst S, Gregory A.

No. 38

A comparison of the cost-effectiveness of five strategies for the prevention of nonsteroidal anti-inflammatory drug-induced gastrointestinal toxicity: a systematic review with economic modelling.

By Brown TJ, Hooper L, Elliott RA, Payne K, Webb R, Roberts C, et al.

\section{No. 39}

The effectiveness and cost-effectiveness of computed tomography screening for coronary artery disease: systematic review.

By Waugh N, Black C, Walker S, McIntyre L, Cummins E, Hillis G.

No. 40

What are the clinical outcome and costeffectiveness of endoscopy undertaken by nurses when compared with doctors? A Multi-Institution Nurse Endoscopy Trial (MINuET).

By Williams J, Russell I, Durai D, Cheung W-Y, Farrin A, Bloor K, et al.

\section{No. 41}

The clinical and cost-effectiveness of oxaliplatin and capecitabine for the adjuvant treatment of colon cancer: systematic review and economic evaluation.

By Pandor A, Eggington S, Paisley S, Tappenden P, Sutcliffe P.

\section{No. 42}

A systematic review of the effectiveness of adalimumab, etanercept and infliximab for the treatment of rheumatoid arthritis in adults and an economic evaluation of their costeffectiveness.

By Chen Y-F, Jobanputra P, Barton P, Jowett S, Bryan S, Clark W, et al.

No. 43

Telemedicine in dermatology: a randomised controlled trial.

By Bowns IR, Collins K, Walters SJ, McDonagh AJG.

\section{No. 44}

Cost-effectiveness of cell salvage and alternative methods of minimising perioperative allogeneic blood transfusion: a systematic review and economic model.

By Davies L, Brown TJ, Haynes S, Payne K, Elliott RA, McCollum C.

\section{No. 45}

Clinical effectiveness and costeffectiveness of laparoscopic surgery for colorectal cancer: systematic reviews and economic evaluation.

By Murray A, Lourenco T, de Verteuil R, Hernandez R, Fraser C, McKinley A, et al.
No. 46

Etanercept and efalizumab for the treatment of psoriasis: a systematic review.

By Woolacott N, Hawkins N, Mason A, Kainth A, Khadjesari Z, Bravo Vergel Y, et al.

No. 47

Systematic reviews of clinical decision tools for acute abdominal pain.

By Liu JLY, Wyatt JC, Deeks JJ, Clamp S, Keen J, Verde P, et al.

\section{No. 48}

Evaluation of the ventricular assist device programme in the UK.

By Sharples L, Buxton M, Caine N, Cafferty F, Demiris N, Dyer M, et al.

\section{No. 49}

A systematic review and economic model of the clinical and costeffectiveness of immunosuppressive therapy for renal transplantation in children.

By Yao G, Albon E, Adi Y, Milford D, Bayliss S, Ready A, et al.

No. 50

Amniocentesis results: investigation of anxiety. The ARIA trial.

By Hewison J, Nixon J, Fountain J, Cocks K, Jones C, Mason G, et al.

\section{Volume I I, 2007}

No. 1

Pemetrexed disodium for the treatment of malignant pleural mesothelioma: a systematic review and economic evaluation.

By Dundar Y, Bagust A, Dickson R, Dodd S, Green J, Haycox A, et al.

No. 2

A systematic review and economic model of the clinical effectiveness and cost-effectiveness of docetaxel in combination with prednisone or prednisolone for the treatment of hormone-refractory metastatic prostate cancer.

By Collins R, Fenwick E, Trowman R, Perard R, Norman G, Light K, et al.

No. 3

A systematic review of rapid diagnostic tests for the detection of tuberculosis infection.

By Dinnes J, Deeks J, Kunst H, Gibson A, Cummins E, Waugh N, et al.

No. 4

The clinical effectiveness and costeffectiveness of strontium ranelate for the prevention of osteoporotic fragility fractures in postmenopausal women.

By Stevenson M, Davis S, Lloyd-Jones M, Beverley C. 
No. 5

A systematic review of quantitative and qualitative research on the role and effectiveness of written information available to patients about individual medicines.

By Raynor DK, Blenkinsopp A, Knapp P, Grime J, Nicolson DJ, Pollock K, et al.

No. 6

Oral naltrexone as a treatment for relapse prevention in formerly opioid-dependent drug users: a systematic review and economic evaluation.

By Adi Y, Juarez-Garcia A, Wang D, Jowett S, Frew E, Day E, et al.

No. 7

Glucocorticoid-induced osteoporosis: a systematic review and cost-utility analysis.

By Kanis JA, Stevenson M, McCloskey EV, Davis S, Lloyd-Jones M.

\section{No. 8}

Epidemiological, social, diagnostic and economic evaluation of population screening for genital chlamydial infection.

By Low N, McCarthy A, Macleod J, Salisbury C, Campbell R, Roberts TE, et al.

\section{No. 9}

Methadone and buprenorphine for the management of opioid dependence: a systematic review and economic evaluation.

By Connock M, Juarez-Garcia A, Jowett S, Frew E, Liu Z, Taylor RJ, et al.

\section{No. 10}

Exercise Evaluation Randomised Trial (EXERT): a randomised trial comparing GP referral for leisure centre-based exercise, community-based walking and advice only.

By Isaacs AJ, Critchley JA, See Tai S, Buckingham K, Westley D, Harridge SDR, et al.

\section{No. 11}

Interferon alfa (pegylated and non-pegylated) and ribavirin for the treatment of mild chronic hepatitis C: a systematic review and economic evaluation.

By Shepherd J, Jones J, Hartwell D, Davidson P, Price A, Waugh N.

\section{No. 12}

Systematic review and economic evaluation of bevacizumab and cetuximab for the treatment of metastatic colorectal cancer.

By Tappenden P, Jones R, Paisley S, Carroll C.

\section{No. 13}

A systematic review and economic evaluation of epoetin alfa, epoetin beta and darbepoetin alfa in anaemia associated with cancer, especially that attributable to cancer treatment.

By Wilson J, Yao GL, Raftery J,

Bohlius J, Brunskill S, Sandercock J, et al.

\section{No. 14}

A systematic review and economic evaluation of statins for the prevention of coronary events.

By Ward S, Lloyd Jones M, Pandor A, Holmes M, Ara R, Ryan A, et al.

\section{No. 15}

A systematic review of the effectiveness and cost-effectiveness of different models of community-based respite care for frail older people and their carers.

By Mason A, Weatherly H, Spilsbury K, Arksey H, Golder S, Adamson J, et al.

\section{No. 16}

Additional therapy for young children with spastic cerebral palsy:

a randomised controlled trial.

By Weindling AM, Cunningham CC, Glenn SM, Edwards RT, Reeves DJ.

\section{No. 17}

Screening for type 2 diabetes: literature review and economic modelling.

By Waugh N, Scotland G,

McNamee P, Gillett M, Brennan A, Goyder E, et al.

\section{No. 18}

The effectiveness and cost-effectiveness of cinacalcet for secondary hyperparathyroidism in end-stage renal disease patients on dialysis: a systematic review and economic evaluation.

By Garside R, Pitt M, Anderson R, Mealing S, Roome C, Snaith A, et al.

\section{No. 19}

The clinical effectiveness and cost-effectiveness of gemcitabine for metastatic breast cancer: a systematic review and economic evaluation.

By Takeda AL, Jones J, Loveman E, Tan SC, Clegg AJ.

\section{No. 20}

A systematic review of duplex ultrasound, magnetic resonance angiography and computed tomography angiography for the diagnosis and assessment of symptomatic, lower limb peripheral arterial disease.

By Collins R, Cranny G, Burch J, Aguiar-Ibáñez R, Craig D, Wright K, et al.
No. 21

The clinical effectiveness and costeffectiveness of treatments for children with idiopathic steroid-resistant nephrotic syndrome: a systematic review.

By Colquitt JL, Kirby J, Green C, Cooper K, Trompeter RS.

No. 22

A systematic review of the routine monitoring of growth in children of primary school age to identify growth-related conditions.

By Fayter D, Nixon J, Hartley S, Rithalia A, Butler G, Rudolf M, et al.

No. 23

Systematic review of the effectiveness of preventing and treating Staphylococcus aureus carriage in reducing peritoneal catheter-related infections.

By McCormack K, Rabindranath K, Kilonzo M, Vale L, Fraser C, McIntyre L, et al.

\section{No. 24}

The clinical effectiveness and cost of repetitive transcranial magnetic stimulation versus electroconvulsive therapy in severe depression: a multicentre pragmatic randomised controlled trial and economic analysis.

By McLoughlin DM, Mogg A, Eranti S, Pluck G, Purvis R, Edwards D, et al.

\section{No. 25}

A randomised controlled trial and economic evaluation of direct versus indirect and individual versus group modes of speech and language therapy for children with primary language impairment.

By Boyle J, McCartney E, Forbes J, O'Hare A.

No. 26

Hormonal therapies for early breast cancer: systematic review and economic evaluation.

By Hind D, Ward S, De Nigris E, Simpson E, Carroll C, Wyld L.

No. 27

Cardioprotection against the toxic effects of anthracyclines given to children with cancer: a systematic review.

By Bryant J, Picot J, Levitt G, Sullivan I, Baxter L, Clegg A.

No. 28

Adalimumab, etanercept and infliximab for the treatment of ankylosing spondylitis: a systematic review and economic evaluation.

By McLeod C, Bagust A, Boland A, Dagenais P, Dickson R, Dundar Y, et al. 
No. 29

Prenatal screening and treatment strategies to prevent group B streptococcal and other bacterial infections in early infancy: costeffectiveness and expected value of information analyses.

By Colbourn T, Asseburg C, Bojke L, Philips Z, Claxton K, Ades AE, et al.

No. 30

Clinical effectiveness and costeffectiveness of bone morphogenetic proteins in the non-healing of fractures and spinal fusion: a systematic review.

By Garrison KR, Donell S, Ryder J, Shemilt I, Mugford M, Harvey I, et al.

\section{No. 31}

A randomised controlled trial of postoperative radiotherapy following breast-conserving surgery in a minimum-risk older population. The PRIME trial.

By Prescott RJ, Kunkler IH, Williams LJ, King CC, Jack W, van der Pol M, et al.

\section{No. 32}

Current practice, accuracy, effectiveness and cost-effectiveness of the school entry hearing screen.

By Bamford J, Fortnum H, Bristow K, Smith J, Vamvakas G, Davies L, et al.

\section{No. 33}

The clinical effectiveness and cost-effectiveness of inhaled insulin in diabetes mellitus: a systematic review and economic evaluation.

By Black C, Cummins E, Royle P, Philip S, Waugh N.

No. 34

Surveillance of cirrhosis for hepatocellular carcinoma: systematic review and economic analysis.

By Thompson Coon J, Rogers G, Hewson P, Wright D, Anderson R, Cramp M, et al.

\section{No. 35}

The Birmingham Rehabilitation Uptake Maximisation Study (BRUM). Homebased compared with hospital-based cardiac rehabilitation in a multi-ethnic population: cost-effectiveness and patient adherence.

By Jolly K, Taylor R, Lip GYH, Greenfield S, Raftery J, Mant J, et al.

\section{No. 36}

A systematic review of the clinical, public health and cost-effectiveness of rapid diagnostic tests for the detection and identification of bacterial intestinal pathogens in faeces and food.

By Abubakar I, Irvine L, Aldus CF, Wyatt GM, Fordham R, Schelenz S, et al.

\section{No. 37}

A randomised controlled trial

examining the longer-term outcomes of standard versus new antiepileptic drugs. The SANAD trial.

By Marson AG, Appleton R, Baker GA, Chadwick DW, Doughty J, Eaton B, et al.

\section{No. 38}

Clinical effectiveness and cost-

effectiveness of different models

of managing long-term oral

anticoagulation therapy: a systematic

review and economic modelling.

By Connock M, Stevens C, Fry-Smith A, Jowett S, Fitzmaurice D, Moore D, et al.

\section{No. 39}

A systematic review and economic model of the clinical effectiveness and cost-effectiveness of interventions for preventing relapse in people with bipolar disorder.

By Soares-Weiser K, Bravo Vergel Y, Beynon S, Dunn G, Barbieri M, Duffy S, et al.

\section{No. 40}

Taxanes for the adjuvant treatment of early breast cancer: systematic review and economic evaluation.

By Ward S, Simpson E, Davis S, Hind D, Rees A, Wilkinson A.

\section{No. 41}

The clinical effectiveness and costeffectiveness of screening for open angle glaucoma: a systematic review and economic evaluation.

By Burr JM, Mowatt G, Hernández R, Siddiqui MAR, Cook J, Lourenco T, et al.

\section{No. 42}

Acceptability, benefit and costs of early screening for hearing disability: a study of potential screening tests and models.

By Davis A, Smith P, Ferguson M, Stephens D, Gianopoulos I.

\section{No. 43}

Contamination in trials of educational interventions.

By Keogh-Brown MR, Bachmann MO, Shepstone L, Hewitt C, Howe A, Ramsay CR, et al.

\section{No. 44}

Overview of the clinical effectiveness of positron emission tomography imaging in selected cancers

By Facey K, Bradbury I, Laking G, Payne E.

\section{No. 45}

The effectiveness and cost-effectiveness of carmustine implants and temozolomide for the treatment of newly diagnosed high-grade glioma: a systematic review and economic evaluation.

By Garside R, Pitt M, Anderson R, Rogers G, Dyer M, Mealing S, et al.
No. 46

Drug-eluting stents: a systematic review and economic evaluation.

By Hill RA, Boland A, Dickson R, Dündar Y, Haycox A, McLeod C, et al.

No. 47

The clinical effectiveness and costeffectiveness of cardiac resynchronisation (biventricular pacing) for heart failure: systematic review and economic model.

By Fox M, Mealing S, Anderson R, Dean J, Stein K, Price A, et al.

\section{No. 48}

Recruitment to randomised trials: strategies for trial enrolment and participation study. The STEPS study.

By Campbell MK, Snowdon C, Francis D, Elbourne D, McDonald AM, Knight R, et al.

No. 49

Cost-effectiveness of functional cardiac testing in the diagnosis and management of coronary artery disease: a randomised controlled trial.

The CECaT trial.

By Sharples L, Hughes V, Crean A, Dyer M, Buxton M, Goldsmith K, et al.

No. 50

Evaluation of diagnostic tests when there is no gold standard. A review of methods.

By Rutjes AWS, Reitsma JB,

Coomarasamy A, Khan KS,

Bossuyt PMM.

No. 51

Systematic reviews of the clinical effectiveness and cost-effectiveness of proton pump inhibitors in acute upper gastrointestinal bleeding.

By Leontiadis GI, Sreedharan A, Dorward S, Barton P, Delaney B, Howden CW, et al.

No. 52

A review and critique of modelling in prioritising and designing screening programmes.

By Karnon J, Goyder E, Tappenden P, McPhie S, Towers I, Brazier J, et al.

No. 53

An assessment of the impact of the NHS Health Technology Assessment Programme.

By Hanney S, Buxton M, Green C, Coulson D, Raftery J.

\section{Volume 12, 2008}

\section{No. 1}

A systematic review and economic model of switching from nonglycopeptide to glycopeptide antibiotic prophylaxis for surgery.

By Cranny G, Elliott R, Weatherly H, Chambers D, Hawkins N, Myers L, et al. 
No. 2

'Cut down to quit' with nicotine replacement therapies in smoking cessation: a systematic review of effectiveness and economic analysis.

By Wang D, Connock M, Barton P, Fry-Smith A, Aveyard P, Moore D.
No. 3

A systematic review of the effectiveness of strategies for reducing fracture risk in children with juvenile idiopathic arthritis with additional data on longterm risk of fracture and cost of disease management.

By Thornton J, Ashcroft D, O'Neill T, Elliott R, Adams J, Roberts C, et al.
No. 4

Does befriending by trained lay workers improve psychological wellbeing and quality of life for carers of people with dementia, and at what cost? A randomised controlled trial.

By Charlesworth G, Shepstone L, Wilson E, Thalanany M, Mugford M, Poland F. 


\section{Health Technology Assessment Programme}

\section{Members}

\section{Chair,}

Professor Tom Walley,

Director, NHS HTA Programme,

Department of Pharmacology \&

Therapeutics,

University of Liverpool

\section{Director,}

Professor Tom Walley,

Director, NHS HTA Programme,

Department of Pharmacology \&

Therapeutics,

University of Liverpool

\section{Deputy Director,}

Professor Jon Nicholl,

Director, Medical Care Research

Unit, University of Sheffield,

School of Health and Related

Research

\section{Prioritisation Strategy Group}

Professor Bruce Campbell,

Consultant Vascular \& General

Surgeon, Royal Devon \& Exeter Hospital

Professor Robin E Ferner Consultant Physician and Director, West Midlands Centre for Adverse Drug Reactions, City Hospital NHS Trust, Birmingham
Dr Edmund Jessop, Medical

Adviser, National Specialist, Commissioning Advisory Group (NSCAG), Department of Health, London

Professor Jon Nicholl, Director, Medical Care Research Unit,

University of Sheffield,

School of Health and

Related Research
Dr Ron Zimmern, Director, Public Health Genetics Unit, Strangeways Research Laboratories, Cambridge

\section{HTA Commissioning Board}

Members

Programme Director,

Professor Tom Walley,

Director, NHS HTA Programme,

Department of Pharmacology \&

Therapeutics,

University of Liverpool

Chair,

Professor Jon Nicholl,

Director, Medical Care Research

Unit, University of Sheffield,

School of Health and Related

Research

Deputy Chair,

Dr Andrew Farmer,

University Lecturer in General

Practice, Department of

Primary Health Care,

University of Oxford
Professor Deborah Ashby,

Professor of Medical Statistics,

Department of Environmental

and Preventative Medicine,

Queen Mary University of

London

Professor Ann Bowling,

Professor of Health Services

Research, Primary Care and

Population Studies,

University College London

Professor John Cairns,

Professor of Health Economics,

Public Health Policy,

London School of Hygiene

and Tropical Medicine,

London

Professor Nicky Cullum,

Director of Centre for Evidence

Based Nursing, Department of

Health Sciences, University of

Dr Jeffrey Aronson,

Reader in Clinical

Pharmacology, Department of

Clinical Pharmacology,

Radcliffe Infirmary, Oxford

\section{York}

Professor Jon Deeks,

Professor of Health Statistics,

University of Birmingham
Professor Jenny Donovan,

Professor of Social Medicine,

Department of Social Medicine,

University of Bristol

Professor Freddie Hamdy,

Professor of Urology,

University of Sheffield

Professor Allan House,

Professor of Liaison Psychiatry,

University of Leeds

Professor Sallie Lamb, Director, Warwick Clinical Trials Unit, University of Warwick

Professor Stuart Logan, Director of Health \& Social Care Research, The Peninsula Medical School, Universities of Exeter \& Plymouth

Professor Miranda Mugford, Professor of Health Economics, University of East Anglia

Dr Linda Patterson,

Consultant Physician,

Department of Medicine,

Burnley General Hospital
Professor Ian Roberts, Professor of Epidemiology \& Public Health, Intervention Research Unit, London School of Hygiene and Tropical Medicine

Professor Mark Sculpher, Professor of Health Economics, Centre for Health Economics, Institute for Research in the Social Services,

University of York

Professor Kate Thomas, Professor of Complementary and Alternative Medicine, University of Leeds

Professor David John Torgerson, Director of York Trial Unit, Department of Health Sciences, University of York

Professor Hywel Williams,

Professor of

Dermato-Epidemiology,

University of Nottingham 


\section{Diagnostic Technologies \& Screening Panel}

Members

\section{Chair,}

Dr Ron Zimmern, Director of the Public Health Genetics Unit, Strangeways Research Laboratories, Cambridge

Ms Norma Armston, Freelance Consumer Advocate, Bolton

Professor Max Bachmann, Professor of Health Care Interfaces, Department of Health Policy and Practice, University of East Anglia

Professor Rudy Bilous Professor of Clinical Medicine \& Consultant Physician,

The Academic Centre,

South Tees Hospitals NHS Trust

Ms Dea Birkett, Service User Representative, London
Dr Paul Cockcroft, Consultant Medical Microbiologist and Clinical Director of Pathology, Department of Clinical Microbiology, St Mary's Hospital, Portsmouth

Professor Adrian K Dixon, Professor of Radiology, University Department of Radiology, University of Cambridge Clinical School

Dr David Elliman, Consultant in Community Child Health, Islington PCT \& Great Ormond Street Hospital, London

Professor Glyn Elwyn, Research Chair, Centre for Health Sciences Research, Cardiff University, Department of General Practice, Cardiff

Professor Paul Glasziou, Director, Centre for Evidence-Based Practice, University of Oxford
Dr Jennifer J Kurinczuk, Consultant Clinical Epidemiologist, National Perinatal Epidemiology Unit, Oxford

Dr Susanne M Ludgate, Clinical Director, Medicines \& Healthcare Products Regulatory Agency, London

Mr Stephen Pilling, Director, Centre for Outcomes, Research \& Effectiveness, Joint Director, National Collaborating Centre for Mental Health, University College London

Mrs Una Rennard,

Service User Representative,

Oxford

Dr Phil Shackley, Senior Lecturer in Health Economics, Academic Vascular Unit, University of Sheffield
Dr Margaret Somerville, Director of Public Health Learning, Peninsula Medical School, University of Plymouth

Dr Graham Taylor, Scientific Director \& Senior Lecturer, Regional DNA Laboratory, The Leeds Teaching Hospitals

Professor Lindsay Wilson Turnbull, Scientific Director, Centre for MR Investigations \& YCR Professor of Radiology, University of Hul

Professor Martin J Whittle, Clinical Co-director, National Co-ordinating Centre for Women's and Childhealth

Dr Dennis Wright, Consultant Biochemist \& Clinical Director, The North West London Hospitals NHS Trust, Middlesex

\section{Pharmaceuticals Panel}

\section{Chair,}

Professor Robin Ferner,

Consultant Physician and Director, West Midlands Centre for Adverse Drug Reactions, City Hospital NHS Trust, Birmingham

Ms Anne Baileff, Consultant Nurse in First Contact Care, Southampton City Primary Care Trust, University of Southampton
Professor Imti Choonara, Professor in Child Health, Academic Division of Child Health, University of Nottingham

Professor John Geddes, Professor of Epidemiological Psychiatry, University of Oxford

Mrs Barbara Greggains, Non-Executive Director, Greggains Management Ltd

Dr Bill Gutteridge, Medical Adviser, National Specialist Commissioning Advisory Group (NSCAG), London

Mrs Sharon Hart, Consultant Pharmaceutical Adviser, Reading
Dr Jonathan Karnon, Senior Research Fellow, Health Economics and Decision Science, University of Sheffield

Dr Yoon Loke, Senior Lecturer in Clinical Pharmacology, University of East Anglia

Ms Barbara Meredith, Lay Member, Epsom

Dr Andrew Prentice, Senior Lecturer and Consultant Obstetrician \& Gynaecologist, Department of Obstetrics \& Gynaecology, University of Cambridge

Dr Frances Rotblat, CPMP Delegate, Medicines \& Healthcare Products Regulatory Agency, London

\section{Dr Martin Shelly, General Practitioner, Leeds}

Mrs Katrina Simister, Assistant Director New Medicines, National Prescribing Centre, Liverpool

Dr Richard Tiner, Medical Director, Medical Department, Association of the British Pharmaceutical Industry, London 


\section{Therapeutic Procedures Panel}

Members

\section{Chair,}

Professor Bruce Campbell,

Consultant Vascular and General Surgeon, Department of Surgery, Royal Devon \& Exeter Hospital

Dr Mahmood Adil, Deputy Regional Director of Public Health, Department of Health, Manchester

Dr Aileen Clarke, Consultant in Public Health, Public Health Resource Unit, Oxford
Professor Matthew Cooke,

Professor of Emergency

Medicine, Warwick Emergency

Care and Rehabilitation,

University of Warwick

Mr Mark Emberton, Senior

Lecturer in Oncological

Urology, Institute of Urology,

University College Hospital

Professor Paul Gregg,

Professor of Orthopaedic

Surgical Science, Department of

General Practice and Primary

Care, South Tees Hospital NHS

Trust, Middlesbrough

Ms Maryann L Hardy,

Lecturer, Division of

Radiography, University of

Bradford
Dr Simon de Lusignan, Senior Lecturer, Primary Care Informatics, Department of Community Health Sciences, St George's Hospital Medical School, London

Dr Peter Martin, Consultant Neurologist, Addenbrooke's Hospital, Cambridge

Professor Neil McIntosh, Edward Clark Professor of Child Life \& Health, Department of Child Life \& Health, University of Edinburgh

Professor Jim Neilson, Professor of Obstetrics and Gynaecology, Department of Obstetrics and Gynaecology, University of Liverpool
Dr John C Pounsford,

Consultant Physician,

Directorate of Medical Services, North Bristol NHS Trust

Dr Karen Roberts, Nurse Consultant, Queen Elizabeth Hospital, Gateshead

Dr Vimal Sharma, Consultant Psychiatrist/Hon. Senior Lecturer, Mental Health Resource Centre, Cheshire and Wirral Partnership NHS Trust, Wallasey

Professor Scott Weich, Professor of Psychiatry, Division of Health in the Community, University of Warwick

Members

\section{Chair, \\ Dr Edmund Jessop, Medical} Adviser, National Specialist Commissioning Advisory Group (NSCAG), London

Mrs Sheila Clark, Chief Executive, St James's Hospital, Portsmouth

Mr Richard Copeland, Lead Pharmacist: Clinical Economy/Interface, Wansbeck General Hospital, Northumberland
Dr Elizabeth Fellow-Smith, Medical Director, West London Mental Health Trust, Middlesex

Mr Ian Flack, Director PPI Forum Support, Council of Ethnic Minority Voluntary Sector Organisations, Stratford

Dr John Jackson, General Practitioner, Newcastle upon Tyne

Mrs Veronica James, Chief Officer, Horsham District Age Concern, Horsham

Professor Mike Kelly, Director, Centre for Public Health Excellence,

National Institute for Health and Clinical Excellence, London
Professor Yi Mien Koh, Director of Public Health and Medical Director, London NHS (North West London Strategic Health Authority), London

Ms Jeanett Martin, Director of Clinical Leadership \& Quality, Lewisham PCT, London

Dr Chris McCall, General Practitioner, Dorset

Dr David Pencheon, Director, Eastern Region Public Health Observatory, Cambridge

Dr Ken Stein, Senior Clinical Lecturer in Public Health, Director, Peninsula Technology

Assessment Group,

University of Exeter,

Exeter
Dr Carol Tannahill, Director, Glasgow Centre for Population Health, Glasgow

Professor Margaret Thorogood, Professor of Epidemiology, University of Warwick, Coventry

Dr Ewan Wilkinson, Consultant in Public Health, Royal Liverpool University Hospital, Liverpool 


\section{Expert Advisory Network}

\section{Members}

Professor Douglas Altman, Professor of Statistics in Medicine, Centre for Statistics in Medicine, University of Oxford

Professor John Bond, Director, Centre for Health Services Research, University of Newcastle upon Tyne, School of Population \& Health Sciences, Newcastle upon Tyne

Professor Andrew Bradbury, Professor of Vascular Surgery, Solihull Hospital, Birmingham

Mr Shaun Brogan,

Chief Executive, Ridgeway

Primary Care Group, Aylesbury

Mrs Stella Burnside OBE

Chief Executive,

Regulation and Improvement

Authority, Belfast

Ms Tracy Bury,

Project Manager, World

Confederation for Physical

Therapy, London

Professor Iain T Cameron, Professor of Obstetrics and Gynaecology and Head of the School of Medicine, University of Southampton

Dr Christine Clark, Medical Writer \& Consultant Pharmacist, Rossendale

Professor Collette Clifford, Professor of Nursing \& Head of Research, School of Health Sciences, University of Birmingham, Edgbaston, Birmingham

Professor Barry Cookson, Director, Laboratory of Healthcare Associated Infection, Health Protection Agency, London

Dr Carl Counsell, Clinical Senior Lecturer in Neurology, Department of Medicine \& Therapeutics, University of Aberdeen

Professor Howard Cuckle, Professor of Reproductive Epidemiology, Department of Paediatrics, Obstetrics \& Gynaecology, University of Leeds

Dr Katherine Darton, Information Unit, MIND The Mental Health Charity, London
Professor Carol Dezateux, Professor of Paediatric Epidemiology, London

Dr Keith Dodd, Consultant Paediatrician, Derby

Mr John Dunning, Consultant Cardiothoracic Surgeon, Cardiothoracic Surgical Unit, Papworth Hospital NHS Trust, Cambridge

Mr Jonothan Earnshaw, Consultant Vascular Surgeon, Gloucestershire Royal Hospital, Gloucester

Professor Martin Eccles, Professor of Clinical

Effectiveness, Centre for Health Services Research, University of Newcastle upon Tyne

Professor Pam Enderby, Professor of Community Rehabilitation, Institute of General Practice and Primary Care, University of Sheffield

Professor Gene Feder, Professor of Primary Care Research \& Development, Centre for Health Sciences, Barts \& The London Queen Mary's School of Medicine \& Dentistry, London

Mr Leonard R Fenwick,

Chief Executive, Newcastle upon Tyne Hospitals NHS Trust

Mrs Gillian Fletcher,

Antenatal Teacher \& Tutor and President, National Childbirth Trust, Henfield

Professor Jayne Franklyn, Professor of Medicine,

Department of Medicine, University of Birmingham, Queen Elizabeth Hospital,

Edgbaston, Birmingham

Dr Neville Goodman,

Consultant Anaesthetist, Southmead Hospital, Bristol

Professor Robert E Hawkins, CRC Professor and Director of Medical Oncology, Christie CRC Research Centre, Christie Hospital NHS Trust, Manchester

Professor Allen Hutchinson, Director of Public Health \& Deputy Dean of ScHARR, Department of Public Health, University of Sheffield

Professor Peter Jones, Professor of Psychiatry, University of Cambridge, Cambridge
Professor Stan Kave, Cancer Research UK Professor of Medical Oncology, Section of Medicine, Royal Marsden Hospital \& Institute of Cancer Research, Surrey

Dr Duncan Keeley, General Practitioner (Dr Burch \& Ptnrs), The Health Centre, Thame

Dr Donna Lamping, Research Degrees Programme Director \& Reader in Psychology, Health Services Research Unit, London School of Hygiene and Tropical Medicine, London

Mr George Levvy,

Chief Executive, Motor

Neurone Disease Association, Northampton

Professor James Lindesay, Professor of Psychiatry for the Elderly, University of Leicester, Leicester General Hospital

Professor Julian Little, Professor of Human Genome Epidemiology, Department of Epidemiology \& Community Medicine, University of Ottawa

Professor Rajan Madhok, Consultant in Public Health, South Manchester Primary Care Trust, Manchester

Professor Alexander Markham, Director, Molecular Medicine Unit, St James's University Hospital, Leeds

Professor Alistaire McGuire, Professor of Health Economics, London School of Economics

Dr Peter Moore,

Freelance Science Writer, Ashtead

Dr Andrew Mortimore, Public Health Director, Southampton City Primary Care Trust, Southampton

Dr Sue Moss, Associate Director, Cancer Screening Evaluation Unit, Institute of Cancer Research, Sutton

Mrs Julietta Patnick, Director, NHS Cancer Screening Programmes, Sheffield

Professor Robert Peveler, Professor of Liaison Psychiatry, Royal South Hants Hospital, Southampton
Professor Chris Price,

Visiting Professor in Clinica Biochemistry, University of Oxford

Professor William Rosenberg, Professor of Hepatology and Consultant Physician, University of Southampton, Southampton

Professor Peter Sandercock, Professor of Medical Neurology, Department of Clinical Neurosciences, University of Edinburgh

Dr Susan Schonfield, Consultant in Public Health, Hillingdon PCT, Middlesex

Dr Eamonn Sheridan,

Consultant in Clinical Genetics, Genetics Department, St James's University Hospital, Leeds

Professor Sarah Stewart-Brown, Professor of Public Health, University of Warwick, Division of Health in the Community Warwick Medical School, LWMS, Coventry

Professor Ala Szczepura, Professor of Health Service Research, Centre for Health Services Studies, University of Warwick

Dr Ross Taylor, Senior Lecturer, Department of General Practice and Primary Care, University of Aberdeen

Mrs Joan Webster, Consumer member, HTA Expert Advisory Network 



\section{Feedback}

The HTA Programme and the authors would like to know your views about this report.

The Correspondence Page on the HTA website (http://www.hta.ac.uk) is a convenient way to publish your comments. If you prefer, you can send your comments

to the address below, telling us whether you would like us to transfer them to the website.

We look forward to hearing from you.

The National Coordinating Centre for Health Technology Assessment,

Mailpoint 728, Boldrewood,

University of Southampton,

Southampton, SO 16 7PX, UK.

Fax: +44 (0) $2380595639 \quad$ Email: hta@hta.ac.uk

http://www.hta.ac.uk 